\title{
The Effect of Right-Turn-On-Red on Pedestrian and Bicyclist Accidents
}

D. F. Preusser

W. A. Leaf

K. B. DeBartolo

R. D. Blomberg

Dunlap and Associates, Inc.

One Parkland Drive

Darien, Connecticut 06820

Contract No. DOT-HS-6-01411

Contract Amount \$146,727

This document is available to the U.S. public through the National Technical Information Service, Springfield, Virginia 22161 
This document is disseminated under the sponsorship of the U.S. Department of Transportation in the interest of information exchange. The U.S. Government assumes no liability for the contents or use thereof. 
TECHNICAL REPORT STANDARD TITLE PAGE

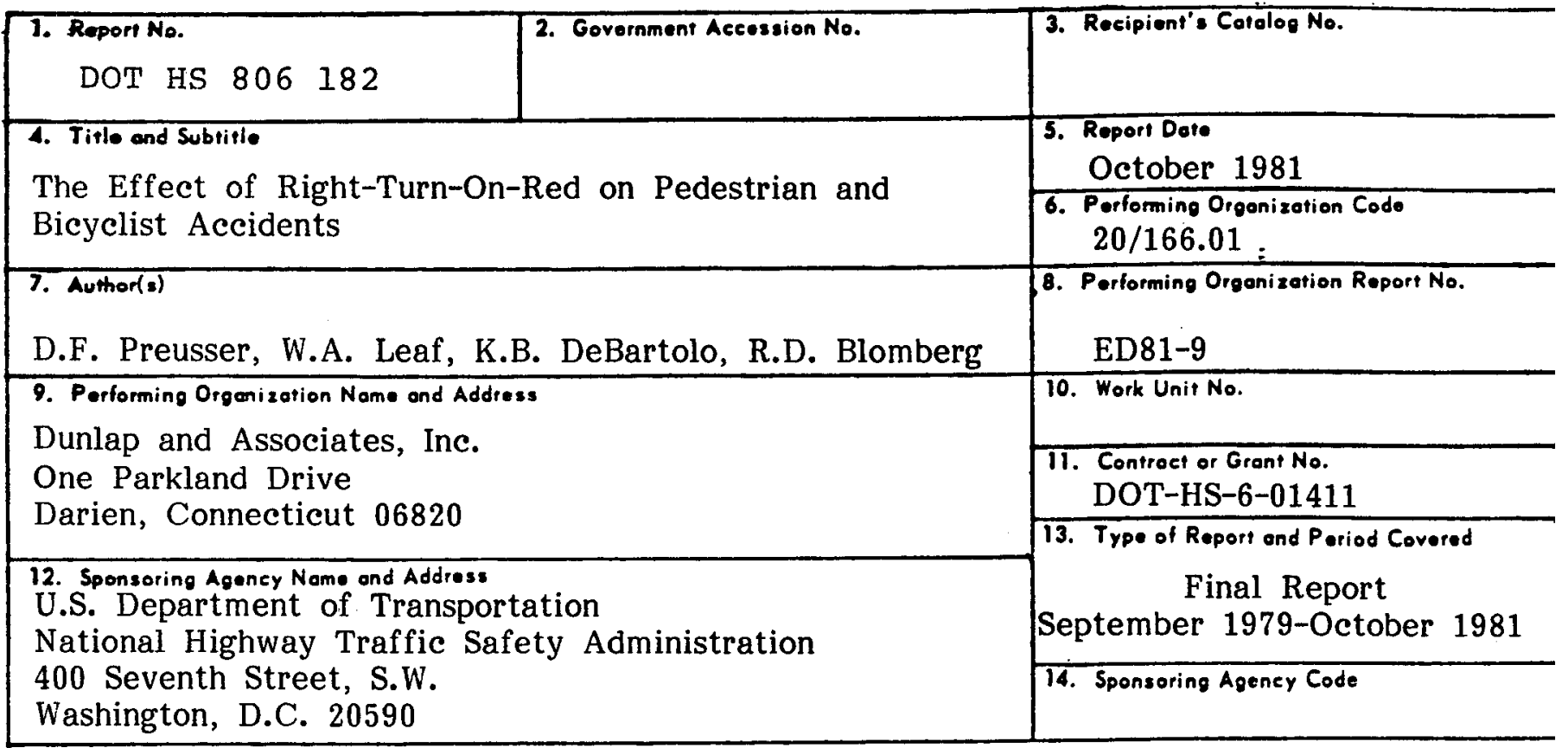

15. Supplomentary Notes

16. Abstract

Right-Turn-On-Red (RTOR) in its "Western" or "permissive" version allows motorists to turn right on a red signal after stopping unless prohibited by a sign. Many states adopted Western RTOR in the mid-1970's. The objectives of this study were to assess the impact of adopting Western RTOR on the frequency of pedestrian and bicycle crashes with motor vehicles, and to determine the characteristics of any pedestrian and bicycle RTOR accidents. Data from the states of New York, Ohio an Wisconsin and the cities of Los Angeles, California and New Orleans, Louisiana were examined. Time series was the major analytic technique for determining pre/post accident rate changes. Content analyses of police reports provided data on accident characteristics.

Measures of Pedestrian and bicycle accidents involving a motorist making a right turn at a signalized location increased significantly at all study sites after the adoption of Western RTOR. Estimates of the magnitude of the increases ranged from $43 \frac{\circ}{\circ}$ to $107 \%$ for pedestrian accidents and $72 \%$ to $123 \%$ for bicyclist accidents. Over half of the accidents in which a vehicle turned right at a signalized location after the adoption of Western RTOR involved a right turn on a red signal. These RTOR accidents constituted between $1 \%$ and $3 \%$ of all pedestrian or bicycle accidents in the studied locations. The majority of these RTOR crashes involved a driver looking left for a gap in traffic and striking a pedestrian or bicyclist coming from the driver's right. Educational countermeasures for bicyclists and pedestrians and traffic engineering approaches, including the further development of warrants for sign prohibitions of RTOR, appear to be worthy of additional research.

\begin{tabular}{l|l} 
17. Koy Words & 18. Distribution Statement
\end{tabular}

Right-turn-on-red, Western Rule RTOR, Regulation Effects, Pedestrian/Bicyclist Accidents, Time Series Analysis, Highway Safety, Rules of the Road, Traffic Control

Document is available to the U.S. Public through the NTIS Springfield, VA 22161

\begin{tabular}{|c|c|c|l|}
\hline $\begin{array}{c}\text { 19. Socurity Clossif. (of this report) } \\
\text { Unclassified }\end{array}$ & $\begin{array}{c}\text { 20. Socurity Clossif. (of thi s page) } \\
\text { Unclassified }\end{array}$ & $\begin{array}{c}\text { 21. No. of Poges } \\
84\end{array}$ & 22. Price \\
\hline
\end{tabular}


metaic COnYeasion factors

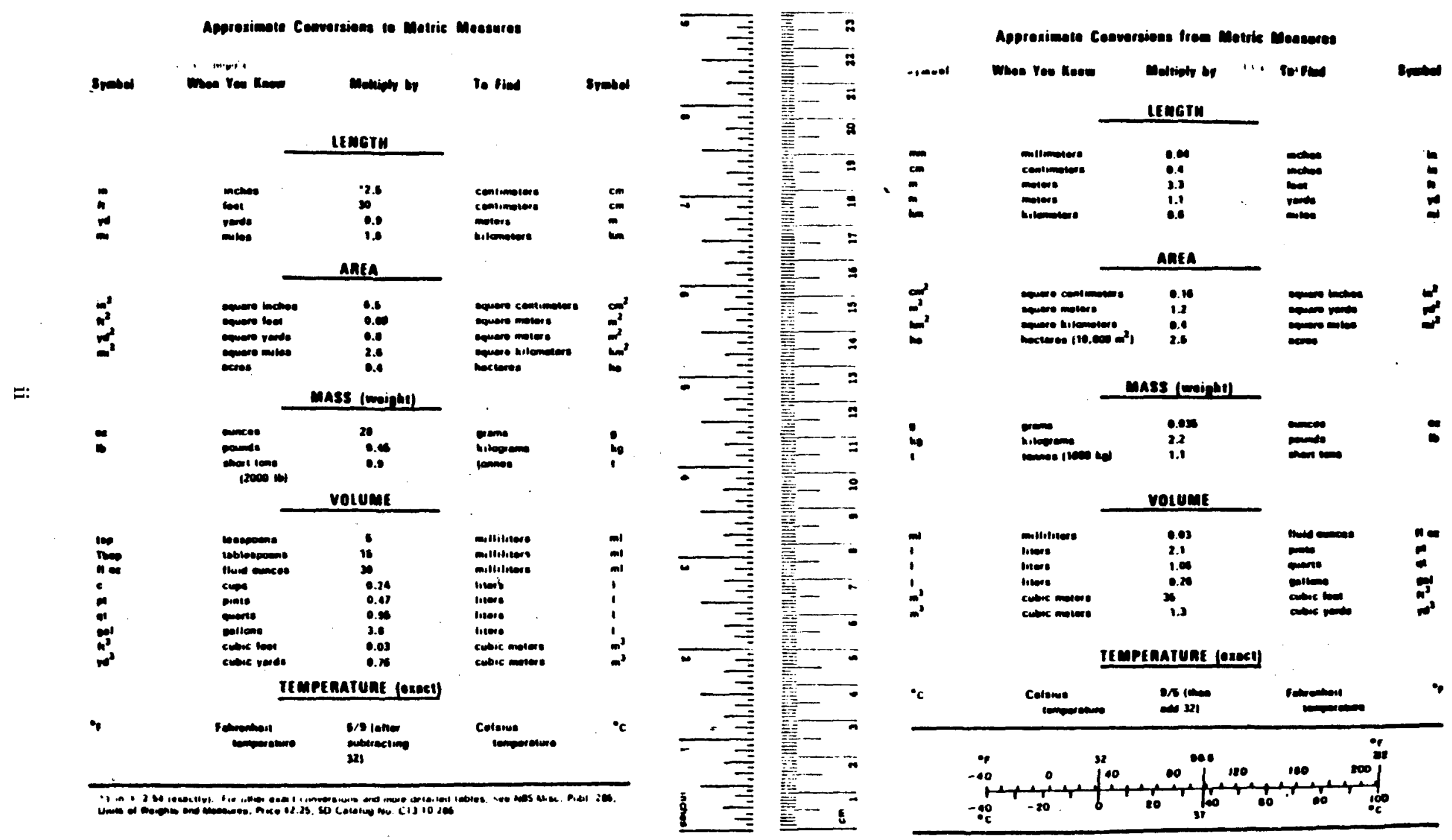




\section{FOREWORD}

The work described herein was undertaken as a part of a larger study of the impact of vehicle and traffic laws on pedestrian and bicycle accidents. The effort was supported by Contract No. DOT-HS-6-01411 with the U.S. Department of Transportation, National Highway Traffic Safety Administration (NHTSA). The first part of the contract, described in a separate report entitled "Evaluation of Existing Pedestrian and Bicyclist Regulations," catalogued a large set of vehicle and traffic law provisions and qualitatively assessed their potential impact on pedestrian and bicycle accidents. The current report is totally independent and covers an in-depth examination of the effects of adopting generally permissive ("Western Rule") Right-Turn-On-Red (RTOR) laws on subsequent pedestrian and bicycle/motor vehicle crashes.

The overall goal of this project was to reduce the uncertainty concerning the effects of RTOR on pedestrian and bicycle accidents, and to provide quantitative and qualitative descriptions of any safety problems identified. The statement of work for this contract specifically required the exclusive use of existing police accident data. Thus, no on-site investigations were conducted. By design, the study focused only on RTOR implementation effects in jurisdictions located east of the Mississippi River and was concerned solely with the effects of Western rule RTOR on pedestrian and bicyclist accidents. 


\section{ACKNOWLEDGMENTS}

The process of identifying suitable sites and gathering the volumes of associated accident data required the cooperation and, frequently, the direct participation of many individuals. The authors express their gratitude to all who assisted in the process and made this study of Right-Turn-On-Red (RTOR) possible.

In particular, we acknowledge the active participation and overall direction and coordination provided by the NHTSA staff, especially by Drs. Marvin M. Levy and Alfred J. Farina, Jr. Serving as Contract Technical Manager, Dr. Levy also was instrumental in identifying study contacts and establishing information lines. In particular, we appreciated Dr. Levy's prompt and effective initial contact of the NHTSA Regional Administrators which led to excellent working arrangements with all groups. Special thanks are also due Mr. Terry M. Klein of NHTSA for his review and comments regarding our draft report.

We also wish to express appreciation to the numerous individuals who played important roles in providing the data for this study. We regret that all individuals could not be named below but we would like especially to thank several key individuals who helped focus our data collection efforts in each of the various sites:

- Charles Bostick, New York State Department of Motor Vehicles

- Robert Farrow and Susan Konves, Ohio Bureau of Motor Vehicles

- Russell Fleming and William Joachim, Department of Motor Vehicles, Wisconsin Department of Transportation

- Georgia Jupinko, Bob McMillan and Kevin Winters, Ohio Department of Highway Safety

- James Peterson, Division of Highway Safety Coordination, Wisconsin Department of Transportation

- Maynard Stoehr, Office of the Governor's Highway Safety Representative, Wisconsin Department of Transportation

- Henry Wantoch, Milwaukee Safety Commission

- Donald Williamson, Office of the Regional Administrator, NHTSA Region $\mathrm{V}$ 
ADDENDUM

A major purpose of this project was to examine the effects of the Western Right-Turn-On-Red (RTOR) law upon pedestrian and bicyclist accidents at signalized locations. As indicated in the report there is a small, well-ciefined accident problem in hoth areas.

The raader is alerted to the fact that throughout this report the Contractor has chosen his words carefully when describing measures of RTOR accidents. In order to compare differences in pedestrian or bicyclist accident rates prior to and after implementation of the RTOR l.aw, an indirect measure - right-turning accidents at signalized locacions - was used. Prior to implementation of the lav most of the right-turning accidents were presumably on the green-signal phase, whereas atter iruplenentation, right-turning accidents occurred on hoth the green- and the red-signal phases. The more direct mensure -- RroR accidents on the red-signal phase -- was also used when the Contractor was determining the extent of the problem for pedestrians and bicyclists after implementation of the law. Both types of measures are needed to address specific issues.

The report findings show large percentage increases in right-turn accidents at signalized locations after RTOR (e.g., increases ranging from $43 \%$ to $107 \%$ for pedestrians, and increases ranging from $72 \%$ to $123 \%$ for bicyclists in the three states studied.) Given these increases in the two accident problems, it is also of interest to show their contribution to the total pedestrian and bicyclist problems in the states examined:

- As a percentage of all pedestrian accidents, right-turning accidents at signalized locations went from $1.47 \%$ (before RTOR implenentation) to $2.28 \%$ (after implementation), a $55 \%$ increase.

o As a percentage of all bicyclist accidents, right-turning accidents at signalized locations went from $1.40 \%$ (before implementation) to $2.79 \%$ (after implementation), a $99 \%$ increase.

These calculations were accomplished by dividing the total number of right-turning accidents at signalized locations in the thrce states by the total number of all pedestrian or hicyclist accidents in those states. 


\begin{tabular}{l|l}
\hline \hline CONTRACIOR & CONTRACT NUMBER \\
Dunlap and Associates, Inc. & DOT-HS-6-01411 \\
\hline $\begin{array}{l}\text { REPORT TITLE } \\
\text { The Effect of Right-Turn-On-Red on Pedestrian } \\
\text { and Bicyclist Accidents }\end{array}$ & REPORT DATE \\
\hline
\end{tabular}

REPORT AUTHOR(S)

David F. Preusser, William A. Leaf, Karen B. DeBartolo, Richard D. Blomberg

This study examined the pedestrian and bicyclist accident experience associated with "Western" Right-Turn-On-Red (RTOR) laws in selected jurisdictions. RTOR laws in the "Western" or "permissive" version allow the motorist to make a right turn on a red signal unless specifically prohibited by a sign. This form of RTOR is referred to as "Western" RTOR since it has long been common in the Western States or "permissive" RTOR since it generally permits the maneuver unless a sign prohibition is posted.

Although RTOR laws require the motorist both to stop and to yield to any pedestrian or approaching vehicle in the intersection before turning on red, it had been postulated that pedestrians and bicyclists might be at increased risk under Western RTOR because of the inherent attention conflict for the turning driver. In particular, since the driver preparing for a RTOR is typically watching for traffic from his left, he may not see a pedestrian or bicyclist coming from his right.

This concern over the possible negative impact of Western RTOR on pedestrians and bicyclists prompted the National Highway Traffic Safety Administration (NHTSA) in conjunction with the Federal Highway Administration (FHWA) to sponsor this research study. The study focused on accident experience in the States of New York (1974-78), Ohio (1974-79) and Wisconsin (1973-79) and in the City of New Orleans, Louisiana (1973-3/31/78). For comparison and to look at a long-standing Western RTOP situation, data from the City of Los Angeles, California (1973-78) were obtained and analyzed. A pre/post experimental approach was employed. The Box-Jenkins time series method was used as the primary analytic approach to determine changes in accident frequencies. In all, 123,530 pedestrian and 64,296 bicycle accident records were processed. Of these, several thousand were accessed, read and coded by project staff.

Two basic research questions were addressed by this study. First, the issue of whether pedestrian/ or bicyclist/motor vehicle accidents increased, decreased or stayed the same following adoption of Western RTOR was examined by analyzing right turn events at signalized locations, as determined from state computerized accident records. Each site was treated separately and time series analysis was used to compare the monthly distributions of events before and after the effective date of the Western RTOR law. Second,

(Continue on additional pages)

"PREPAREO FOR THE DEPARTMENT OF TRANSPORTATION, NATIONAL HIGHWAY TRAFFIC SAFETY ADMINISTRATION UNOER CONTRACT NO.: DOT-HS-6-01411. THE OPINIONS, FINOINGS, AND CONCLUSIONS EXPRESSEO IN THIS PUBLICATION ARE THOSE OF THE AUTHORS AND NOT NECESSARILY THOSE OF THE NATIONAL HIGHWAY TRAFFIC SAFETY AOMINISTRATION." 
the characteristics of pedestrian and bicyclist accidents involving vehicles turning right on red were considered. These descriptive analyses focused only on events after Western RTOR was adopted and used data extracted from hard-copy police accident reports.

This study found that the frequency of pedestrians and bicyclists struck by a motor vehicle turning right at a signalized location increased significantly after the adoption of Western RTOR. The magnitude of increase for each study site is shown below. Over one half of the accidents in the post period involved a vehicle turning right on a red signal. These accidents involving a vehicle turning right on a red signal accounted for $2.26 \%, 1.60 \%$ and $1.12 \%$ of all pedestrian accidents in Wisconsin, Ohio and New York (outside of New York City which prohibits RTOR), respectively. (The small sample size in New Orleans precluded the derivation of a stable estimate for that site.) The equivalent percentage for Los Angeles, which has had Western RTOR for over 30 years, was $2.70 \%$. For bicycles, the proportion of all accidents involving the motor vehicle turning right on red was $1.50 \%, 1.39 \%$ and $1.70 \%$ for Wisconsin, Ohio and New York (exclusive of New York City), respectively (no bicycle data were available for New Orleans or Los Angeles).

Pedestrian Accidents per Year Right Turning Vehicle at Signalized Location
Bicycle Accidents per Year Right Turning Vehicle at Signalized Location
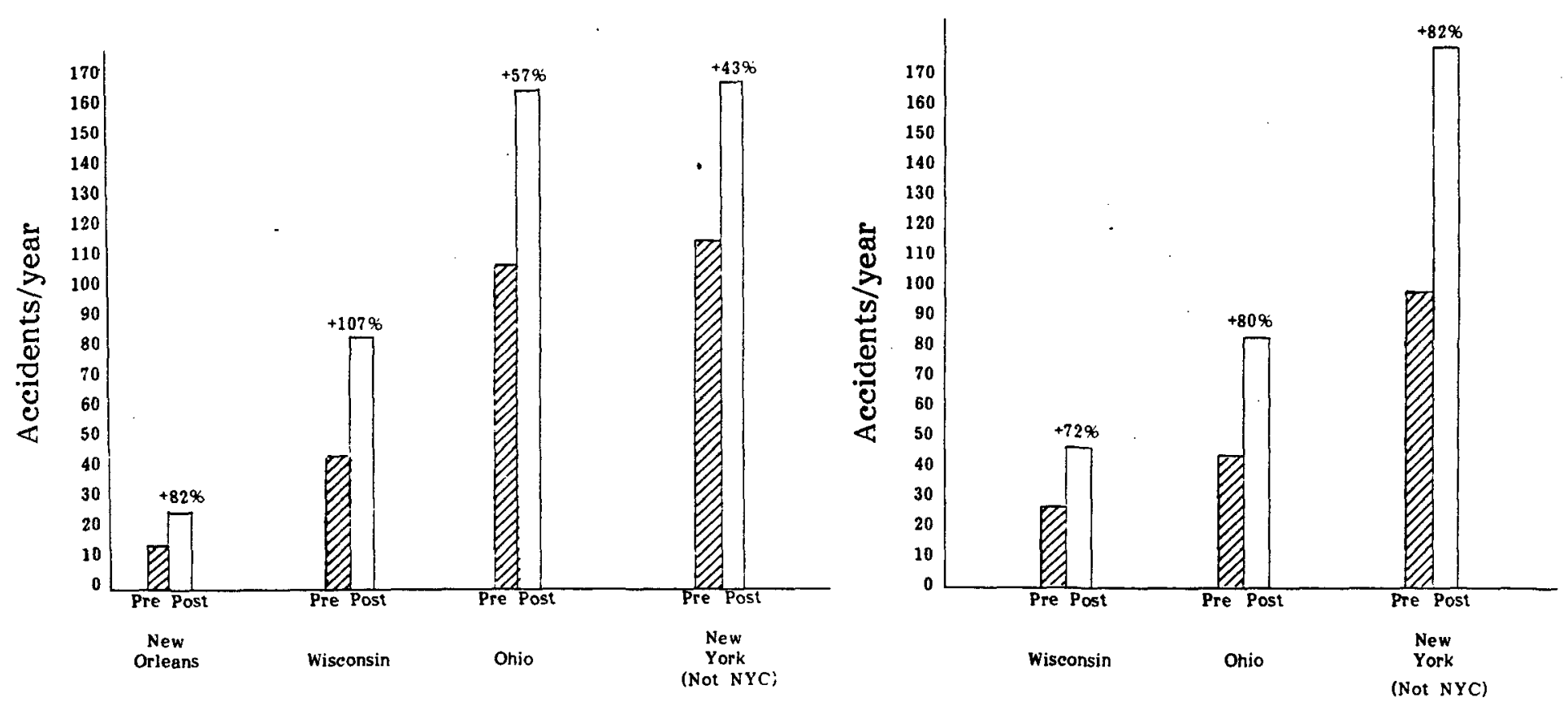
The time series analysis technique makes it possible to examine quantitatively potentially confounding effects which may have yielded or contaminated the observed results. Such effects of interest to this study were a general increase in pedestrian and bicycle accidents or an increase in just those which occurred at signalized intersections. In all cases, the adoption of Western RTOR was the only reasonable explanation for the observed phenomena. The best fitting time series model for each site was approximately a step function centered on the date Western RTOR became effective. Since three different dates are involved across the test sites ( 1 July 1975 for Wisconsin and Ohio, 1 January 1977 for New York, and 1 October 1976 for New Orleans), the time series results provide compelling evidence that the observed increases in right turn accidents were the result of instituting Western RTOR, and there were no comparable increases in signalized location crashes involving other vehicle maneuvers.

Analysis of more than 1,000 hard-copy accident reports involving a right turn on a red signal showed that most of the pedestrians (67\%) and bicyclists (75\%) were coming from the driver's right as the driver entered the intersection as opposed to the driver's left or perpendicular to the driver's direction of travel:
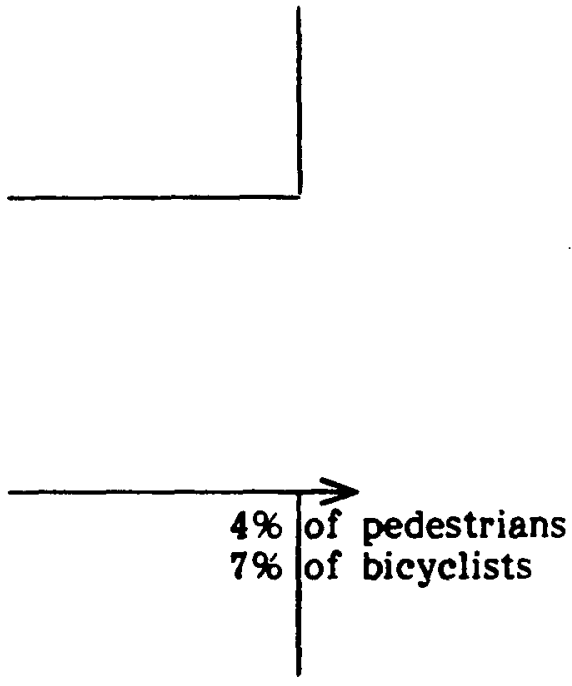
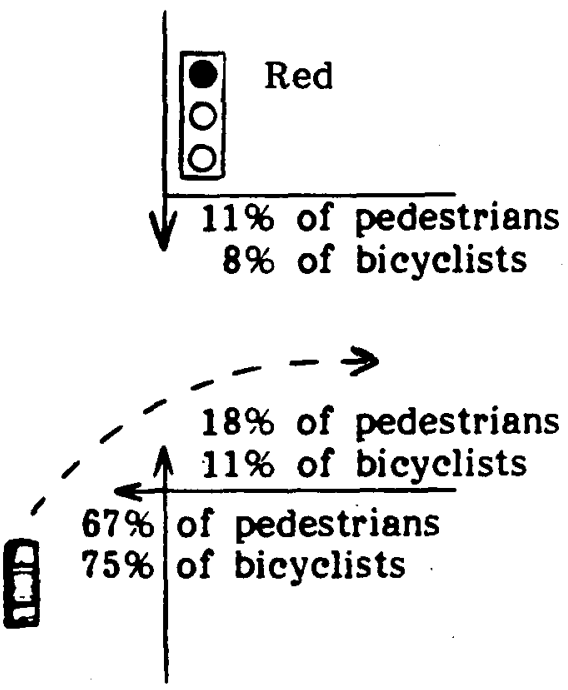

Pedestrians coming from the driver's right often reported that they saw the vehicle stopped for the light and never believed that it would just pull forward and hit them. Drivers report that they were looking left for a gap in traffic and never saw the pedestrian. The problem is virtually identical for bicyclists, although it should be noted that the majority of bicyclists coming from the driver's right were coming from the roadway (not the sidewalk) and thus were "wrong way" riding, i.e., riding on the left side of the street. It was also noted that few fatalities were associated with these accidents, likely because of the low speeds at impact. 
It can be concluded from this study that the adoption of Western RTOR resulted in an increase in both pedestrian/ and bicycle/motor vehicle accidents. The increase began as soon as the law became operative and probably persists as long as the law is in effect. Pedestrian and bicycle accidents involving a motor vehicle turning right on red constitute between $1 \%$ and 3\% of a jurisdiction's total pedestrian and bicycle accidents.

The study did not include countermeasure development but several potential countermeasure approaches were identified which seem worthy of additional research and development efforts. These are:

Bicyclist Education - Pursue efforts designed to foster riding with traffic (on the right side of two-way roadways) by bicyclists.

Pedestrian Education - Teach pedestrians to recognize and deal with the cues that a vehicle is about to turn right on red.

Warrants - Identify target intersection approaches for RTOR sign prohibitions based on pedestrian and bicycle accident considerations.

Traffic Engineering - Consider approaches such as an innovative exclusive pedestrian light phase, or right turn "box," which would move the pedestrian crosswalk behind the turning vehicle.

Finally, it should be noted that this investigation focused only on well defined components or aspects (pedestrian and bicyclist accidents) of the overall and larger impact of RTOR. It does not purport to advise on the overall utility of RTOR. Any total assessment of the value of RTOR would additionally have to address vehicle-to-vehicle accidents, travel time and energy costs, and other factors associated with RTOR implementation. Therefore this study should be considered as only one of the inputs needed to conduct a total assessment of the societal effects of RTOR. 
Technical Report Standard Title Page i

Foreword

Acknowledgments

Technical Summary

iii

I. INTRODUCTION 1

A. RTOR--Definition, History, Issues 1

B. RTOR--Overview of Accident Experience 4

II. METHOD 6

A. Measures 6

B. Site Selection $\quad 7$

C. Accident Data Acquisition/Reformatting 8

D. Coding of Accident Reports 9

E. Data Analysis 12

$\begin{array}{lll}\text { III. RESULTS } & 13\end{array}$

A. Accident Rate Descriptions 13

B. Time Series Statistical Testing 17

C. Dynamics of Right on Red Crashes 25

1. Pedestrians in Los Angeles 25

2. Pedestrians in New York, Wisconsin .
and Ohio

3. Bicyclists in New York, Wisconsin
and Ohio

IV. DISCUSSION 4$]$

A. Design Considerations $\quad 42$

B. Time Series 43

C. Nature of the Problem 43

D. Countermeasures 44

E. Conclusions 45 
TABLE OF CONTENTS (continued)

Page

APPENDIX A: RTOR Effective Dates in Eastern States

APPENDIX B: Accident Series Analyses

REFERENCES 
Table 1. Data Overview from New York, Wisconsin, Ohio New Orleans and Los Angeles

Table 2. New York Pedestrian Accidents

Table 3. New York Bicycle Accidents

Table 4. Accidents with Motor Vehicles Turning Right at Signalized Locations

Table 5. Description of RTOR Events in Los Angeles

Table 6. Pedestrian Age and Driver Sex by RTOR Accident Types in Los Angeles

Table 7. Light Phase by Accident Type for New York, Wisconsin and Ohio Pedestrian Crashes Under Western RTOR

Table 8. Distribution of Pedestrian Accidents Under Western RTOR, Vehicles Turning Right on Red Signal

Table 9. Description of Pedestrian Accidents in New York, Wisconsin and Ohio Under Western RTOR, Vehicles Turning Right on Red Signal

Table 10. Light Phase by Accident Type for New York, Wisconsin and Ohio Bicycle Crashes Under Western RTOR

Table 11. Description of Bicycle Accidents in New York, Wisconsin and Ohio Under Western RTOR, Motor Vehicles Turning Right on Red Signal

\section{FIGURES}

Figure 1. Data Collection Form

Figure 2. Types of RTOR pedestrian accidents coded in Los Angeles with percent of each type found in coding 526 such Los Angeles accidents

Figure 3. Direction and location for bicycle crashes involving a motor vehicle turning right on a red signal 


\section{INTRODUCTION}

The ability to make legal right turns on a red signal unless specifically prohibited by a sign is now a widespread, highly accepted practice across the United States. Right-Turn-On-Red (RTOR) is not only a popular convenience with the driving public but is also credited with increasing intersection capacities and saving a significant amount of fuel through reduced delays. Unfortunately, there are also concerns that RTOR results in an increase in accidents, particularly in those involving a pedestrian or bicycle and a motor vehicle. In response to this concern, the National Highway Traffic Safety Administration (NHTSA) in conjunction with the Federal Highway Administration (FHWA) decided to sponsor research to determine the specific impact, if any, of RTOR on the frequency of pedestrian and bicyclist crashes with motor vehicles. Since the desired RTOR research was clearly within the scope of a pre-existing contract entitled "Evaluation of Existing Pedestrian and Bicyclist Regulations," the investigation of RTOR was sponsored by means of a modification to Contract No. DOT-HS-6-01411. This is the final report of that research into the effects of $\mathrm{RTOR}$ on pedestrian and bicyclist accidents.

This report describes the research design, methodologies and results of a two-stage analysis employing both selected state accident data tapes and samples of hard-copy accident reports identified from the accident tapes. In general, the research design consisted of a comparison of the accident experience both before and after implementation of the Western RTOR Rule at selected sites. After extensive analysis, these data bases ultimately provided a previously unavailable detailed perspective of the effects of RTOR on the pedestrian and bicycle accident experience in certain locations.

This study indicates that there is a pedestrian and bicyclist accident problem associated with RTOR. Moreover, the problem is large enough to warrant further study and to support the development of appropriate countermeasures. This research establishes a factual basis for the previously unsubstantiated concern that RTOR is a hazard to pedestrians and bicyclists. However, it should be noted that this investigation focused only on a well defined component or aspect (pedestrian and bicyclist accidents) of the overall and larger impact of RTOR. Since the study was delimited to examining only pedestrian and bicyclist accident effects, it does not purport to advise on the overall utility of RTOR, per se. Any total assessment of the benefits of RTOR would necessarily include a larger accident context, travel time and energy costs, and other factors associated with RTOR implementation. This study should be considered as only one of the inputs needed to conduct a total assessment of the societal effects of RTOR.

\section{A. RTOR--Definition, History, Issues}

RTOR in the currently practiced "Western" or "permissive" version allows drivers to turn right on a red light after stopping and determining that it is safe to do so. According to the Uniform Vehicle Code (UVC) established by the National Committee on Uniform Traffic Laws and Ordinances (NCUTLO), the RTOR maneuver should be restricted by requiring the driver to stop first and then to yield to approaching vehicles and to all pedestrians within the intersection. Most states have adopted the UVC definition and treatment of RTOR which simply adds a subsection to the definition of the "steady red 
indication" found in $\$ 11-202$ (Traffic-control signal legend) of the Rules of the Road (NCUTLO, 1980) as given below.

\section{\$ 11-202-Traffic-control signal legend}

(c) Steady red indication

1. Vehicular traffic facing a steady circular red signal alone shall stop at a clearly marked stop line, but if none, before entering the crosswalk on the near side of the intersection, or if none, then before entering the intersection and shall remain standing until an indication to proceed is shown except as provided in subsection (c)3. (REVISED, 1975.)

2. Vehicular traffic facing a steady red arrow signal shall not enter the intersection to make the movement indicated by the arrow and, unless entering the intersection to make a movement permitted by another signal, shall stop at a clearly marked stop line, but if none, before entering the crosswalk on the near side of the intersection, or if none, then before entering the intersection and shall remain standing until an indication permitting the movement indicated by such red arrow is shown except as provided in subsection (c)3. (NEW, 1975.)

3. Except when a sign is in place prohibiting a turn, vehicular traffic facing any steady red signal moy cautiously enter the intersection to turn right, or to turn left from a one-way street into a one-way street, after stopping as required by subsection (c)1 or subsection (c)2. After stopping, the driver shall yield the right of way to any vehicle in the intersection or approaching on another roadway so closely as to constitute on immediate hazand during the time such driver is moving across or within the intersection or junction of roadwoys. Such driver shall yield the right of way to pedestrians within the intersection or an adjacent crosswalk. (REVISED AND RENUMBERED, 1975; REVISED, 1979.)

4. Unless otherwise directed by a pedestrian-control signal as provided in $\$ 11-203$, pedestrians facing a steady circular red or red arrow signal alone shall not enter the roadway. (REVISED AND RENUMBERED, 1975.)

The above defines the "permissive" RTOR rule--"permissive" since the maneuver is generally permitted "except when a sign is in place prohibiting a turn." Since the "permissive" version of RTOR has been popular in California and other western states, "permissive" RTOR became synonomous with "Western". RTOR. An alternative RTOR version restricted the RTOR maneuver to only those signalized locations where a sign explicitly allowed the motorist to turn right on red. This more restrictive version, found frequently in the eastern half of the country, has been termed "Eastern" RTOR. Currently, the elements of the Western RTOR rule apply throughout the continental U.S. except in New York City. Although California is credited with the earliest significant experience with RTOR, it is interesting that permissive RTOR was actually adopted much earlier in New York City. Permissive RTOR was part of the City's traffic regulations beginning in 1924 and was practiced "... in the teens when manually operated semaphores were used to direct traffic" 
(Hochstein, 1981). However, New York abandoned the practice in 1937. This is the same year in which California adopted the practice.

Although RTOR has been around in various implementation forms for many years, it did not spread rapidly across the country. This was due to a long-standing debate over the time-saving and other benefits of RTOR versus its overall degree of hazardousness. Those supporting RTOR felt its accident impact was neutral or negligible while citing strong arguments based on the assistance that RTOR gave to an expeditious traffic flow. The strongest argument was constructed from the delay reductions which accrued with RTOR. It appeared, wherever RTOR was implemented, intersection delays were reduced. The most complete study to date of the energy and travel time benefits of RTOR is the 1976 investigation by Alan M. Voorhees and Associates for the Federal Highway Administration (McGee et al., 1976). In this study, for example, the following time savings in the delay associated with waiting for a green signal before turning right were documented:

- $\quad 1.3$ seconds (9\%) saved in central business districts (CBDs) and an average of 7.7 seconds (39\%) saved in rural areas

- 4.3 seconds (26\%) saved during peak traffic hours with a slightly greater savings of 5.2 seconds $(38 \%)$ in off-peak hours

- 4.6 seconds $(30 \%)$ overall average savings

While the magnitude of these delay savings may seem small expressed on a per right-turning-vehicle basis, the savings become most impressive when multiplied by the many millions of right-turning maneuvers each day. When this fact is coupled with the recent national priority on fuel conservation, the economic benefits represented by such delay savings are estimated to be large. Although these issues are clearly beyond the scope of this investigation and, thus, of this report, they add an important perspective to understanding how $R T O R$ recently became a nationwide reality.

With fuel conservation growing in importance in the early to mid-70's, Western rule RTOR was selected as one of many community opportunities for achieving greater energy efficiency. Based on projected energy savings, the U.S. Department of Energy encouraged conservation practices nationally, and, thus, the states which had not already implemented RTOR did so. Also during this period, states which had been previously practicing the sign-permitted "Eastern" version of RTOR switched to the preferred (i.e., more energy efficient) "Western" or generally permissive RTOR. By 1977 virtually all states permitted RTOR at a very high percentage of all signalized intersections. A few states (e.g., Connecticut) did, however, initially sign-prohibit RTOR at many intersections although, with experience and public demands, many of these restrictions were later eliminated.

By the time most states were ready to implement RTOR, there was a good body of traffic engineering guidance available to help in identifying intersections warranting exclusion from RTOR. Although there were surely wide variations across the states in what constituted "acceptable" and "unacceptable" intersections for RTOR, there nonetheless was considerable 
agreement over the general criteria for allowing or excluding RTOR at individual intersections. Criteria are still being refined and updated. Much current variation among jurisdictions is understandably in the implementation or quantification of these criteria rather than in the basic criteria themselves. In general, RTOR is prohibited on any intersection where the maneuver is considered too hazardous or disruptive of orderly traffic flow, e.g., on intersections with five or more approaches, high speed traffic, complex signal phasing, short duration red phase, etc. Prohibition is accomplished by means of a sign, generally located next to the traffic signal, explicitly prohibiting PTOR from the approach facing the sign.

While delay savings and related fuel savings were the prime motivations for widespread promulgation of RTOR, traffic engineers could also point to improvements in intersection capacity, reduced auto emissions and to a more expeditious traffic flow. Often, a related benefit of RTOR was also noted, i.e., that the driver making an RTOR would then be facing a green signal after his turn while a driver making a turn on green would subsequently be delayed by facing a red signal.

\section{B. RTOR--Overview of Accident Experience}

There have been few large-scale studies which have examined the accident experience associated with Western RTOR. The three discussed below, which are likely the most widely known efforts, differed in their conclusions with respect to the existence of an effect of RTOR on vehicle-to-vehicle accidents and on the magnitude of the problem faced by pedestrians. None of these three studies specifically examined the changes in the frequency of bicycle/ motor vehicle crashes resulting from the adoption of Western RTOR. Cross and Fisher (1977), however, did define a unique bicycle/motor vehicle accident type which occurs when motorists turn right on red.

McGee et al. (1976) concluded that RTOR is associated with only a small number of accidents. In six separate accident studies which varied both with respect to jurisdiction and study methods, McGee et al. found some evidence that RTOR was a problem and some evidence that it was not a problem. The authors concluded that widespread adoption of Western RTOR would be associated with, at most, an insignificant increase in the number of accidents (or no increase in accidents). Two more recent studies have examined accidents across several states following widespread adoption of Western RTOR in the midwest and east. The American Association of State Highway and Transportation Officials (AASHTO, 1979) concluded that accidents did not increase overall at signalized intersections following the adoption of Western RTOR. However, there was a $37 \%$ increase in accidents involving right turning vehicles across the fourteen jurisdictions covered in their study. Zador et al. (1980) studied six states that changed to Western RTOR in the mid $19 \overline{70}, \frac{1}{\mathrm{~s}}$ as compared with three states that did not. These authors concluded that accidents involving a right turning vehicle at a signalized intersection increased by $21 \%$ following the adoption of Western RTOR.

Pedestrian accidents were examined in the above referenced studies, though pedestrians were not the specific research focus. McGee et al. (1976) reported a small increase in pedestrian accidents involving a right turning vehicle at selected intersections in Chicago following introduction of RTOR. AASHTO (1979) reported no overall increase in pedestrian accidents at 
signalized intersections following adoption of Western RTOR. However, the AASHTO study did not provide specific information on pedestrian accidents involving a right turning vehicle. Zador et al. (1980) reported a 57\% increase in pedestrian accidents involving a right tüning vehicle at a signalized intersection. These authors also concluded that this increase was most severe in urban areas and with elderly pedestrians. Accidents involving bicyclists were not specifically covered in these previous efforts.

It is clear from a review of the literature that the current study was needed to reduce the uncertainty surrounding the impact of RTOR on pedestrian accidents. It should also shed light for the first time on the bicycle/motor vehicle problem associated with the adoption of Western RTOR. It is also clear from the literature that the findings of this study with respect to pedestrians and bicyclists should not be indiscriminantly extended to other traffic units. 


\section{METHOD}

The overall objective of this study was to assess the effect of "Western" or permissive RTOR regulations on the frequency of pedestrian and bicyclist accidents with motor vehicles. Operationally, this overall objective had two quite separate components. First, there was a need to determine whether the introduction of Western RT.OR was associated with a change (increase or decrease) in the number of motor vehicle crashes involving pedestrians and bicyclists. This component or sub-objective was assessed by comparing the accident experience of states and areas within states prior to Western RTOR to the respective accident experience following Western RTOR. The primary analytic approach was time series analysis. Second, there was a need to determine the characteristics of pedestrian and bicycle crashes involving a motorist turning right on a red signal. The primary analytic approach to this sub-objective involved accessing, reading and coding relevant information from hard-copy accident reports involving vehicles turning right at signalized locations.

The paragraphs which follow detail the methods and procedures utilized in selecting states, accessing data and data coding. The selected states were New York, Ohio and Wisconsin. In addition, pedestrian accident data were available on a pre versus post basis from the City of New Orleans. Also available for comparison were pedestrian accident data from Los Angeles which has had Western RTOR for some time.

\section{A. Measures}

The primary measure used in this study for the purpose of assessing any increase or decrease in accidents following Western RTOR was the number of pedestrian and bicycle crashes in which the victim was struck by a right-turning motor vehicle at a signalized location. Whether the vehicle was turning right on a red signal or a green signal was not an issue when assessing any increase or decrease.

Prior to Western RTOR, it may be assumed that the vast majority of right turns were on green. Following adoption of Western RTOR, it may be presumed that many were still on green while others were made on red. Regardless, the vehicle maneuver that should have been most directly and logically affected by Western RTOR was the right turn at a signalized location. Right turn on green accidents may or may not have gone down following Western RTOR, and right turn on red accidents may or may not have gone up, but the primary measure is the total number of right turning accidents including right on green and right on red. In other words, the primary measure was whether the right turn at a signalized location was more or less safe with respect to pedestrians and bicyclists following Western RTOR.

It should also be noted that pedestrian and bicycle accidents involving left turning vehicles at signalized locations and other vehicle actions (primarily straight through) at signalized locations were also of interest. While Western RTOR would not necessarily affect pedestrian and bicycle accidents involving these maneuvers, it was still of interest to examine these data as a general measure of total signalized location activity and accident occurrence. 
The second objective of this study was to determine the characteristics of pedestrian and bicycle crashes that involved a vehicle turning right on a red signal. Accident counts and descriptive information from police accident reports for those crashes in which the presence of a red signal could be determined were the primary measure employed.

B. Site Selection

By design, candidate sites for inclusion in this study were those states east of the Mississippi adopting Western RTOR during the mid-1970's. (See Appendix A for a list of Western RTOR effective dates in states east of the Mississippi.) Needed were states which could provide a substantial amount of accident data for the period prior to Western RTOR as well as following Western RTOR. Also, most of these states went from the "Eastern" or sign permissive rule to the Western rule while Wisconsin, for instance, went from no RTOR provision to the full Western rule. It was of interest to include at least one state of each type.

While the sampling base was all Eastern states making the change in the mid-1970's, it is important to note that a secondary selection criterion was number of pedestrian and bicyclist accidents. In general, U.S. pedestrian accidents occur at a rate of about one per thousand population per year in urban areas, decreasing to one per two thousand or less in suburban and rural areas. Bicycle/motor vehicle accidents vary widely with climate and season of the year. However, a rate of about one per two to three thousand population per year can be expected. Also, at least prior to Western RTOR, only very few of the total pedestrian and bicyclist accidents involved a right turning vehicle at a signalized location and it was these right turning accidents which were the primary focus of this study. Preliminary data suggested that about one to two percent of pedestrian and bicycle accidents involved a right turning vehicle at a signalized location. This percentage was higher in urban areas where there are more traffic controls and lower in suburban and rural areas. Taking these factors into consideration, a state with, say, one million people might have 500-800 pedestrian accidents per year of which only five, ten or fifteen involved a right turning vehicle at a signalized location. Similarly, this state might have only 300-400 bicycle accidents of which only five involved a right turning vehicle, etc. Therefore, there was a clear preference for selecting the larger Eastern states which might have five or ten times the number of accidents as estimated in the above example.

Contacts were initiated with several states to determine the availability of the required data. This and other preliminary work led to the selection of New York, Ohio and Wisconsin as the primary study states. The City of New Orleans was added to this list since, through other ongoing Dunlap work for NHTSA, hard-copy pedestrian accident reports were available for the period encompassing the change in the Louisiana law. The three states represent the Northern tier east of the Mississippi River and the inclusion of New Orleans provided Southern representation. Also, while Ohio and New York went from Eastern rule to Western, Wisconsin went from no RTOR provision to the full Western rule. 


\section{Accident Data Acquisition/Reformatting}

The States of New York, Ohio and Wisconsin all permitted access to their computer accident records for a period of several years covering the transition to Western RTOR. Those records--provided to us as tape copies of the state accident files--were of value to the two major kinds of analyses being performed. First, they provided counts of relevant pedestrian and bicycle accidents before and after Western RTOR. These data allowed estimation of the change in accident rate associated with the law change. Second, they provided keys to the written accident reports. Access to the full descriptions of accidents involving right turn on red enabled fuller specification of the dynamics of such accidents.

Each state's accident data tapes were formatted in their own unique style. The first major activity involved reformatting the records to discard unwanted information and to retain the desired data in a representation common to all states and years.

New York State (but not New York City) went from Eastern to Western RTOR on I January 1977. Excluding New York City, the State's 1970 Census population was 10,346,021. It has major urban areas such as Buffalo, . Rochester, Syracuse and Albany/Schenectady as well as rural areas and extensive suburban areas such as found in Nassau and Westchester Counties. New York officials were asked to provide separate computer tape records for all pedestrian and all bicycle accidents occurring within the State for the period 1974 through 1978. These tape records were formatted and entered into our computers. Preliminary analysis showed a five year total of 45,292 pedestrian and 28,762 bicycle accidents outside of New York City involving a motor vehicle. Of these, 668 pedestrian (1.5\%) and 654 bicycle (2.3\%) accidents involved a right turning motor vehicle at a signalized location.

Ohio went from no RTOR law to Eastern RTOR on 3 July 1974 and then to Western RTOR on 1 July 1975. The State's population in 1970 was 10,657,423. As in New York, it has major urban centers such as Cleveland, Columbus, Cincinnati and Toledo as well as suburban and rural areas. Ohio officials were asked to provide a computer tape record of all crashes occurring in that State for the period 1974 to 1979 . Pedestrian and bicycle accidents were pulled from this tape and formatted for future computer processing. Preliminary analysis showed a total of 36,407 pedestrian and 21,841 bicycle accidents involving a motor vehicle over this six year period. Of these, 830 pedestrian (2.3\%) and 413 bicycle (1.9\%) accidents involved a right turning motor vehicle at a signalized location. Unfortunately, these preliminary analyses also showed some periods for which the data were incomplete. Specifically, the months of September, October, November and December of 1976 were largely missing from the tape thereby necessitating adopting estimation procedures for some of the analyses.

Wisconsin went from no RTOR provision to the full Western rule on 1 July 1975. The State's population in 1970 was $4,417,821$. It has one very large urban center, Milwaukee, several smaller cities, Madison, Green Bay, Racine, Kenosha, etc., as well as rural areas. Wisconsin officials were asked to provide the computer tape record for all traffic accidents for the period 1973 to 1979. Pedestrian and bicycle accidents were pulled from this tape and formatted for future computer processing. Preliminary analysis showed a total 
of 17,650 pedestrian and 13,687 bicycle accidents involving a motor vehicle over this seven year period. Of these, 477 pedestrian (2.7\%) and 285 bicycle (2.1\%) accidents involved a right turning motor vehicle at a signalized location.

Those state data files also provided accident report identifiers from which written accident reports could be accessed. Those reports allowed determination of which of the vehicle-turning-right-at-signal accidents were actually Right-Turn-On-Red and provided much detail about the accident dynamics.

For New Orleans and Los Angeles, our primary data source was an exhaustive search of all relevant written reports. For New Orleans, the data period surrounds Western RTOR introduction. To evaluate the change in accident rate from before RTOR to after RTOR, all vehicle-turning-rightat-signal accidents were tabulated and studied for their Right-Turn-On-Red subset. For Los Angeles, the full data period was covered by Western RTOR. Although the vehicle-turning-right-at-signal accident set was identified and tabulated, most of the Los Angeles analysis focused on the large sample of Right-Turn-On-Red accidents.

New Orleans, Louisiana, went from Eastern rule to Western on 1 October 1976. The City's population in 1970 was 593,471. It is an older city with a new convention center and several modern office buildings downtown plus suburban areas within the city limits to the north and east. Hard-copy accident reports for every reported pedestrian accident (not bicycle) were available for the period 1973 to early 1978. The total number of reports was 4,688 of which $84(1.8 \%)$ involved a motor vehicle turning right at a signalized location.

Los Angeles, California, has had Western RTOR since 1947. The City's population in 1970 was 2,816,061. While the city has "downtown" and otherwise congested intersections, it is spread over a wide area and consists largely of extensive urban and suburban residential neighborhoods with a mixture of commercial and industrial locations. Hard-copy accident reports for every reported pedestrian accident were read by project staff for the period 1973 to 1978 (this work was part of the evaluation of pedestrian safety messages under Contract No. DOT-HS-4-00952 from NHTSA). A total of 19,388 reports were reviewed. These reports were prepared in exceptional detail by Los Angeles Police Department personnel, and it was possible to reliably determine signal phase at the time of the crash. The results showed that 526 (2.7\% of all pedestrian accidents; $12.9 \%$ of all at signalized locations) involved a vehicle turning right on a red signal. An additional 406 accidents (2.1\% of all pedestrian accidents; $9.9 \%$ of all at a signalized location) involved vehicles turning right when the signal was other than red. While pre versus post comparisons were not possible in Los Angeles, these data are nonetheless valuable in providing a description of RTOR pedestrian accidents.

D. Coding of Accident Reports

The primary reason for accessing hard-copy reports was to develop a broad and detailed data base for determining and describing key characteristics of RTOR pedestrian and bicyclist accidents. The standard computer records of these accidents, for example, almost always cannot indicate whether the traffic signal was red or green or yellow when the 
motorist turned right. The narrative and diagram of the written accident report often contain such information, along with other details of the situation and actions leading to the crash.

Written accident reports were sought from New York, Ohio and Wisconsin. A list of accident report numbers was generated from the state accident tapes for each state. The list included only accidents which involved pedestrians or bicycles, signalized locations and right turning motor vehicles. These lists were submitted to officials of the respective states. Although reports from some early years in New York and Wisconsin were unavailable, over 2300 reports were read by Dunlap coders. In New York, hard-copy reports are held for approximately three years before transfer to long-term storage. Thus, New York officials were able to access reports only for the years 1977 and 1978. These reports were pulled and made available to staff members in Albany. In Wisconsin, accident reports for the period 1975 through 1979 were available. Those were copied by State personnel and sent to our offices in Connecticut. In Ohio, reports for the period 1974 to 1979 were available, were copied by State personnel and were sent to Connecticut.

In general, nearly all of the requested reports for the years listed were provided by the respective states and thus data loss from "missing" reports was minimal. However, not all of the accessed reports depicted a simple case of a vehicle turning right at a signalized location and hitting a pedestrian or a bicyclist. Some reports contained miscoded information, e.g., the vehicle was really turning left. For others, the coded information was correct, but the crash involved "highly atypical" circumstances such as the car turned right, hit a second car and one of the two vehicles left the roadway and struck a pedestrian on the sidewalk. It was necessary, for several analyses, to exclude these very atypical and miscoded events. For these reasons, the number of events entering each analysis can vary. In New York, 326 pedestrian events were requested from the State, of which 280 (86\%) were read, found to have involved a right turning vehicle at a signalized location and were not "highly atypical." Similarly, 359 bicycle events were requested of which 340. (95\%) were included in the analyses. In Wisconsin, 376 pedestrian events were requested of which 359 (95\%) entered the analyses; and 217 bicycle events were requested of which 205 (94\%) entered. In Ohio, 830 pedestrian events were requested of which 763 (92\%) were used; and 413 bicycle events were requested of which 390 (94\%) were read, found to have involved a right turning vehicle at a signalized location and were not "highly atypical."

Figure 1 shows the data collection form utilized by staff members to code the desired additional information. It will be noticed that traditional accident report data items such as time of day, location, driver age, etc., were not covered on this form. These items were already available from the state provided computer records and were not recorded a second time. Rather, the data shown in the Figure were merged with the already coded data to produce one larger crash record.

The Figure shows a full range of data items concerning crash characteristics and circumstances. The most important of these was signal phase facing the driver. In other words, was the maneuver a right-on-red. Also of critical importance was the directionality information shown on the second page under "Accident Description." This information specified the 


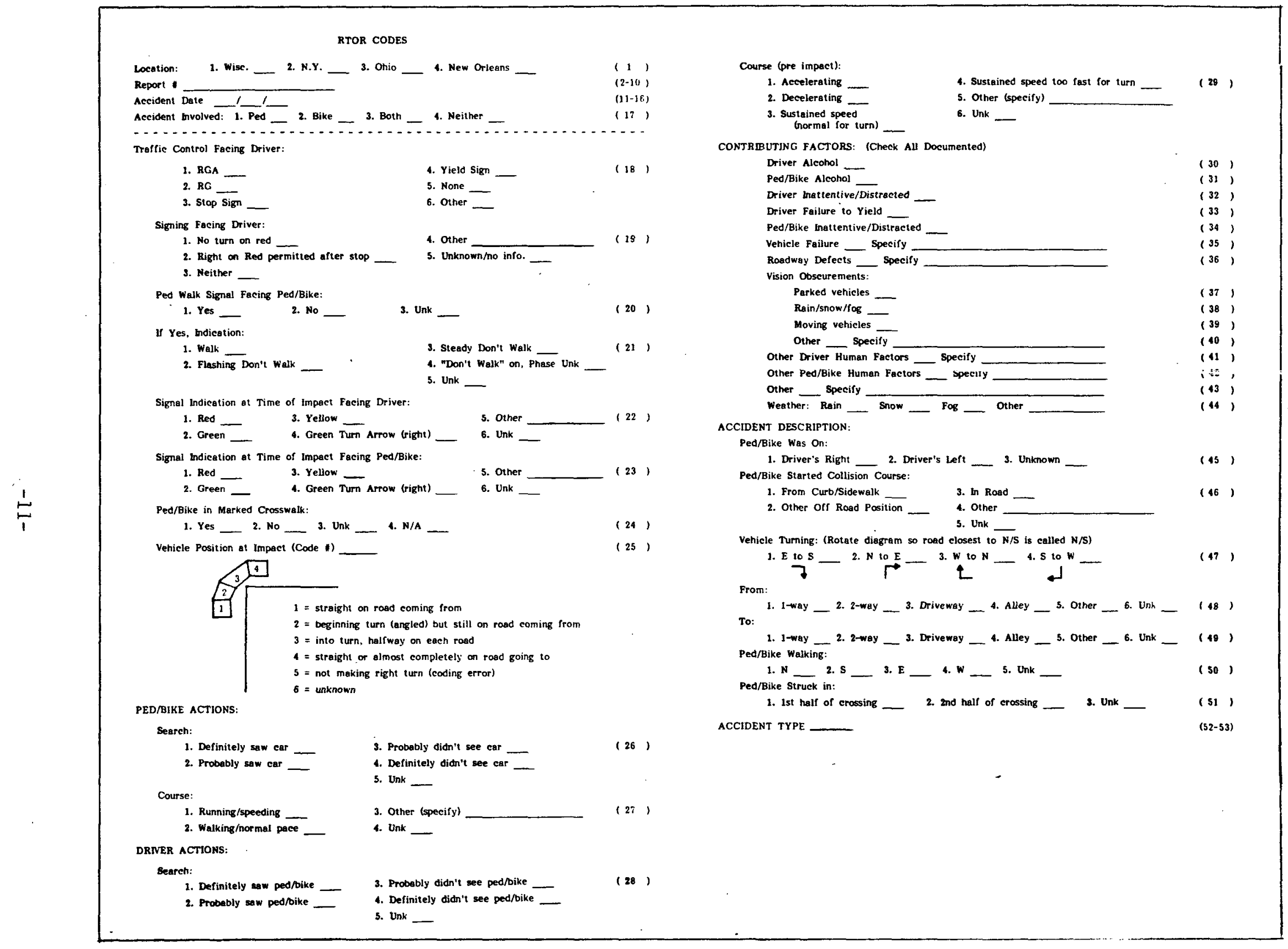

Figure 1. Data Collection Form 
relationship between the vehicle and pedestrian or bicycle paths just prior to the crash. All of the requested information could be found on some of the accident reports. However, some items could less often be reliably determined than others. The directionality or Accident Description information could nearly always be determined. Signal phase was available for about half to two-thirds of the events. Information on "No Turn" signs or pedestrian "Walk" signals was rarely available and the behavioral data under "Ped/Bike Actions" were rarely available reliably. In general, Los Angeles provided a highly detailed indication of light phase and the behaviors of involved parties with the other sites yielding somewhat less "richness" of data.

\section{E. Data Analysis}

The questions posed by this study can be thought of as falling into two classes. First, it was important to address the issue of whether accidents increased, decreased or stayed the same following adoption of Western RTOR. Second, whether the number of accidents increased, decreased or remained the same, it was important to examine the characteristics of pedestrian and bicycle accidents involving vehicles turning right on red. Western RTOR is now the law in all states and it was postulated that this specific vehicle maneuver could lead to special "accident types." Alternatively, accidents occurring with right-on-red could be sufficiently similar to the already identified "Vehicle Turn/Merge" accident type for pedestrians and "Motorist Turn/Merge" type for bicycles so as not to require further specification (Snyder and Knoblauch, 1971; Cross and Fisher, 1977).

Concerning accident increases or decreases, the analyses concentrated on right turn events at signalized locations as determined from the state computer records. Left turning accidents and accidents involving other vehicle maneuvers at signalized locations were considered primarily as control data. The basic analytical technique was time series analysis comparing monthly distributions of events both before and after the implementation of Western RTOR. Analyses involving summation or averaging of data across states were not considered. Rather, each state and the City of New Orleans were treated separately. Also, pedestrian and bicycle accidents were treated separately. Thus, the question of increase or decrease was addressed four times for pedestrians (New York, Ohio, Wisconsin, New Orleans) and three times for bicyclists (New York, Ohio, Wisconsin).

The question of accident characteristics was also addressed separately in the seven data sets listed above. In addition, pedestrian accidents were examined in Los Angeles which provided a large number of events as well as a site in which Western RTOR has been in place for some time. Analysis began by reading the hard-copy reports and coding the relevant information. Crosstabulations of the data were generated by computer and resulting distributions were reviewed. These descriptive analyses concentrated on post Western RTOR events since few hard-copy reports were available for the respective periods prior to the adoption of Western RTOR. 


\section{RESULTS}

This Chapter presents the results of this study. Section A below presents the basic raw accident rate data for pedestrian and bicyclist accidents involving a right turning vehicle at a signalized location. Section B provides the results from the time series analyses of the accident data. In these first two sections, the data on pedestrian and bicycle accidents with motorists turning right at signalized locations are examined from several viewpoints. Although the different approaches yield somewhat different numerical estimates of the size of the changes, all the results show a marked increase in pedestrian accidents within each of the four pedestrian data sets and an even greater general increase among bicycle accidents. Section $C$ below describes RTOR accident events and provides estimates of the degree to which the overall category of right-turning vehicle accidents at signals divide between turning-on-red and turning-on-green situations. An overall RTOR accident description from each of seven data sets is provided as well as a discussion of crash dynamics.

\section{A. Accident Rate Descriptions}

This section will examine right turn accidents at signalized locations expressed as a percentage of all pedestrian and all bicycle accidents. It will also discuss the absolute number of these crashes for the periods before and after the adoption of Western RTOR. Table 1 shows overall accident distributions from New York,* Wisconsin and Ohio for pedestrians and bicyclists and from New Orleans and Los Angeles for pedestrians. These results show that only one to two percent of all pedestrian and bicycle crashes involved a right turning vehicle at a signalized location before introduction of Western RTOR. Thus, while the total number of crashes was quite large, the number which could logically be affected by Western RTOR was a relatively small subset of this total.

The first set of data shown in the Table is for pedestrian crashes in New York State exclusive of New York City. For the period 1974-1976, prior to Western RTOR, approximately $1.25 \%$ of all pedestrian crashes involved a right turning vehicle at a signalized location. For 1977 and 1978, when Western RTOR was the law, approximately $1.82 \%$ involved a right turning vehicle at a signalized location. This represents a 45\% increase in the proportion of these types of events. In absolute terms, New York averaged 114 of these events per year during the baseline period and 163 during the post period for an increase of 49 crashes per year.

The second set of data covers bicycle/motor vehicle crashes in New York over the same period, also exclusive of New York City. During the 1974-1976 baseline period, approximately $1.69 \%$ of these events involved a vehicle turning right at a signalized location. For the 1977-1978 post period the figure was $3.20 \%$. This represents a $90 \%$ increase. In absolute terms, New York averaged 98.3 of these events per year pre-Western RTOR and 179.5 post for an increase of 81.2 crashes per year.

* In general, New York City is excluded from all data cited for New York in this report because Western RTOR is not permitted in New York City. 
Table 1. Data Overview from New York, Wisconsin, Ohio, New Orleans and Los Angeles.

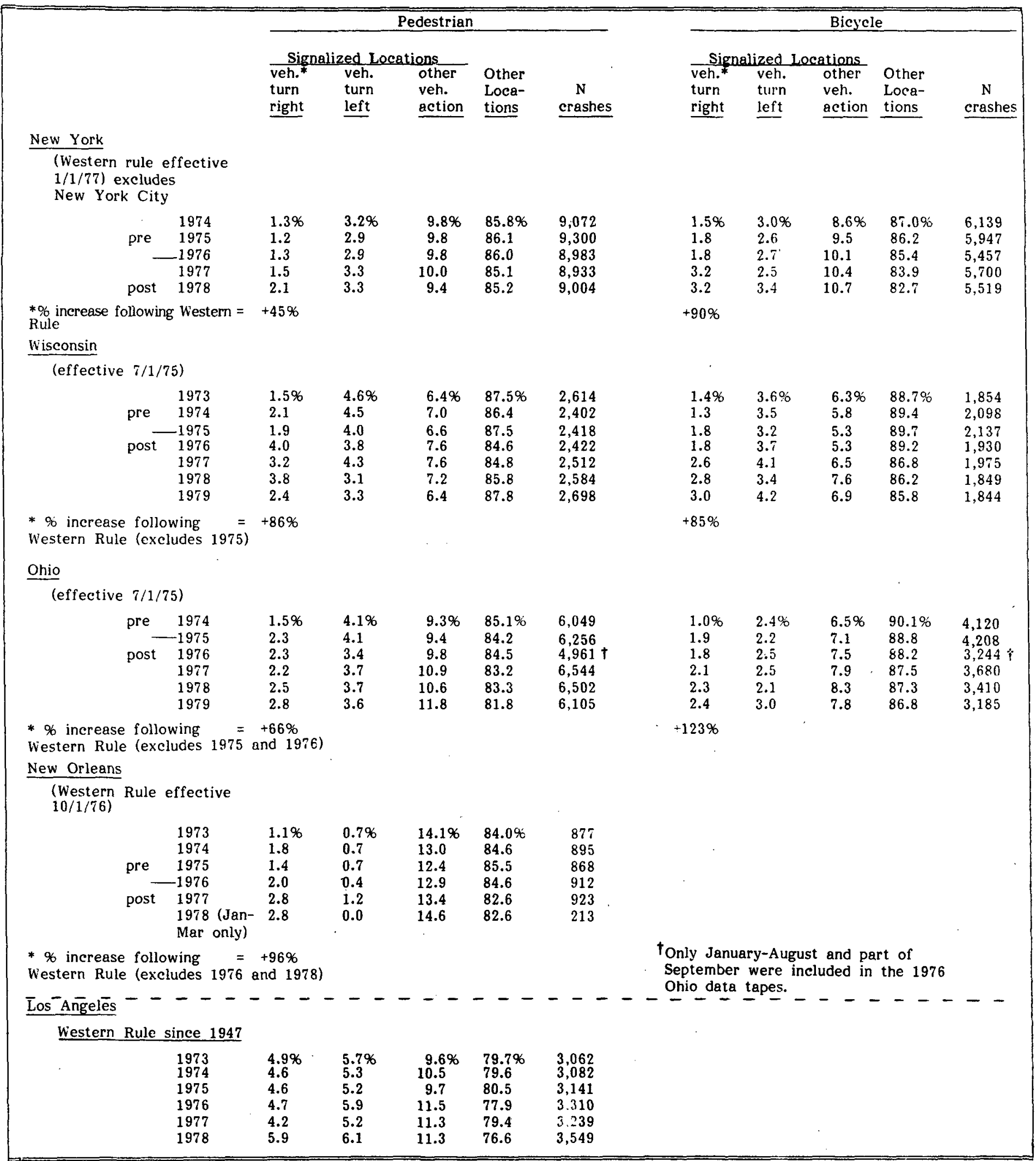


The third set of data covers pedestrian crashes in Wisconsin. For the period 1973-1974, which was prior to Western RTOR (or any RTOR, for that matter), approximately $1.81 \%$ of all Wisconsin pedestrian crashes involved a vehicle turning right at a signalized location. Western RTOR was adopted in mid-1975, and for the period 1976-1979 approximately $3.36 \%$ of all Wisconsin pedestrian crashes involved a right turning vehicle at a signalized location. This represents an increase of 86\%. In absolute terms, the 1973-1974 average was 45 crashes and the 1976-1979 average was 85.2 crashes for an increase of 40.2 crashes per year.

The fourth set of data covers bicycle/motor vehicle crashes in Wisconsin. During 1973-1974, approximately $1.37 \%$ of these events involved a right turning vehicle at a signalized location. The comparable figure during 1976-1979 was 2.53\%. This represents an increase of 85\%. In absolute terms, the 1973-1974 average was 27 crashes and the 1976-1979 average was 48 crashes for an increase of 21 crashes per year.

The fifth set of data covers pedestrian crashes in Ohio. For 1974, which was prior to Western RTOR, approximately $1.50 \%$ of all pedestrian crashes involved a vehicle turning right at a signalized location. Western RTOR was implemented in mid-1975 and there was a severe data loss for several months in late 1976. For the abbreviated post period of 1977-1979, the results showed that approximately $2.50 \%$ of the pedestrian accidents involved a vehicle turning right at a signalized location. This represents an increase of $66 \%$ over 1974. In absolute terms, there were 91 of these crashes in 1974 as compared with an average of 159.3 for the period 1977-1979, for an increase of 68.3 crashes per year.

The sixth set of data covers bicycle crashes in Ohio. During 1974, approximately $1.02 \%$ of these crashes involved a vehicle turning right at a signalized location. For the period 1977-1979, the comparable figure was $2.27 \%$. This represents an increase of $123 \%$. In absolute terms, there were 42 of these crashes in 1974 as compared with an average of 77.7 crashes during the 1977-1979 period for an increase of 35.7 crashes per year.

The next data set covers pedestrian crashes in New Orleans. During the period 1973-1975, which was prior to Western RTOR, approximately $1.44 \%$ of all pedestrian crashes involved a vehicle turning right at a signalized location. Western RTOR was adopted in October 1976. During 1977, the only full year for which data are available following Western RTOR, the comparable figure was $2.82 \%$. This represents a $96 \%$ increase. In absolute terms, there was an average of 12.7 crashes during the 1973-1975 baseline period as compared with 26 crashes in 1977 for an increase of 13.3 crashes per year.

Overall, the foregoing descriptions show a large increase in right-turnat-signal accidents, for both pedestrians and bicycles. In each of the seven data sets, every baseline year has fewer accidents involving a right turning vehicle at a signalized location than every year following Western RTOR. Increases for pedestrian crashes range from a low of $45 \%$ in New York to a high of $96 \%$ in the smaller New Orleans data set. Increases for bicycle 
crashes range from $85 \%$ in Wisconsin to $90 \%$ in New York to $123 \%$ in Ohio. Each of these increases was statistically significant, as described below. Also, in New York and Ohio, increases in bicycle accidents far exceeded the increases observed for pedestrian accidents.

Also shown in the Table are pedestrian crashes in Los Angeles for the years 1973-1978. These data should be relatively stable since Los Angeles has had Western RTOR for over 30 years. The percentage of crashes with the vehicle turning right at a signalized intersection was relatively high, $4.81 \%$ of all accidents. The percentage was consistently high for all the enumerated years, although there was a slight dip in 1977 and a slight rise above the mean in 1978 .

Separate analyses were also conducted examining the twelve months immediately before and immediately after the implementation of Western RTOR. Compared to the previous analyses, these deal with fewer data but examine time periods closer together, reducing the potential effect of long-term trends and focusing on the impact of Western RTOR immediately after implementation. These analyses included the "change" years (1975 in Wisconsin and Ohio and 1976 in New Orleans) which were excluded above. The results are shown below:

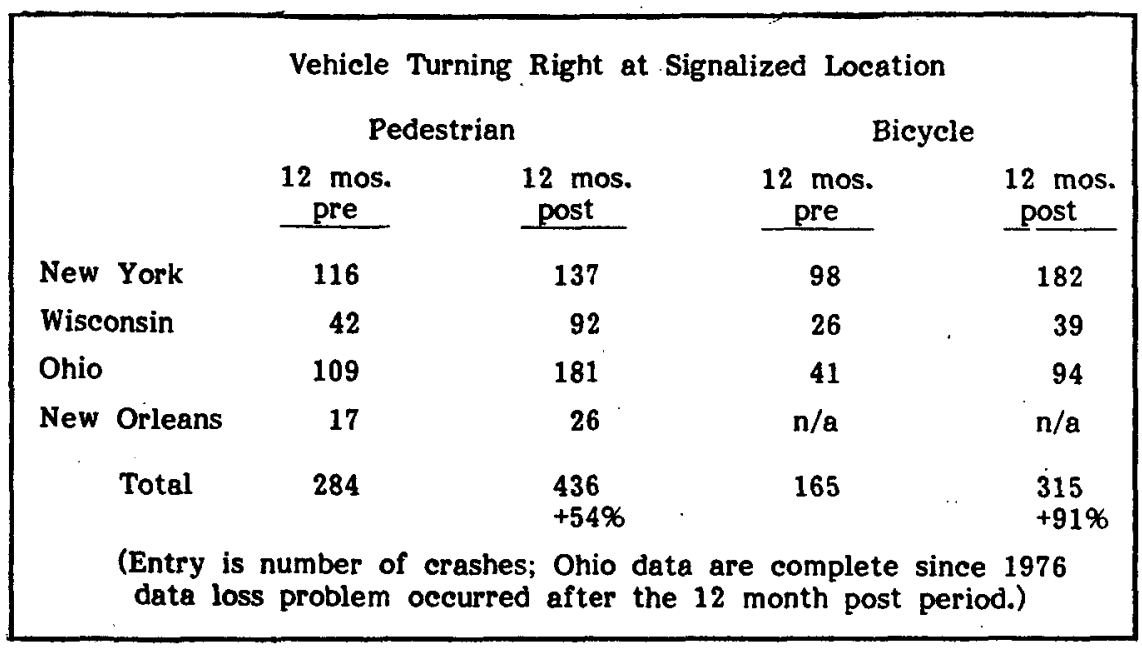


These results indicate that the negative effects of Western RTOR, in terms of pedestrians and bicycle crashes, begin within the first twelve months following implementation. The results presented earlier indicated that these negative effects are present one to three years following implementation. Results also show that Los Angeles, which has had Western RTOR since 1947, is experiencing a substantial number of right-on-red pedestrian crashes some thirty years following implementation (2.7\% of all Los Angeles pedestrian accidents, 1973-1978, involved a vehicle turning right on a red signal).

\section{B. Time Series Statistical Testing}

While the accident rate differences pre and post are striking, the changes need to be tested for their statistical significance. The data can be aggregated conveniently as monthly accident totals, yielding between 63 (New Orleans) and 84 (Wisconsin) data points divided between baseline and Western RTOR conditions.

Because the data were ordered by month and year, the analyses centered on Box-Jenkins time series techniques (Box and Jenkins, 1976). The central concerns of the analyses were to determine whether the changes in right-turn-at-signal accidents were statistically significant and to document the magnitude of the changes in the context of other factors influencing the data.

The analyses followed two steps. First, accident results were displayed as numbers of accidents per month with monthly (i.e., seasonal) mean differences removed. This eliminated a frequently large source of variability which was unrelated to the test hypotheses but confounded their evaluation. Second, Box-Jenkins analysis procedures (Box and Jenkins, 1976) were used on the raw accident data to isolate specific time-sequence components of data variation, such as trends and seasonal swings, and to determine simultaneously the size and statistical significance of changes due to Western RTOR.

One major question about the introduction of any new law is the "shape" or timing that its effects may follow. With Western RTOR, one might anticipate several possibilities. For example, accidents might be extraordinarily high just after Western RTOR took effect--because people took time to learn how to do it safely; or very low at first--because people only gradually adopt the maneuver. Also, the accident change might persist for many years, or it might decay as experience overcomes any initial problems. Box-Jenkins time series analysis allowed all these possibilities to be explored, although data fluctuations and availability placed some limits on the precision with which the alternatives could be evaluated and the time span over which effects could be examined.

As the several data sets were being analyzed, it became clear that the best fitting shape for the relationship between the introduction of Western RTOR and accident rates was the simplest: a step function, or an abrupt change in accident rate coincident with the beginning of Western RTOR and persisting throughout the data collection periods. This relationship was appropriate for all the datasets. Even for the New York pedestrian accident series, which objectively did not show a major increase in accidents until the second year under Western RTOR, the step function provided a statistically adequate fit to the data. In the other six data series, the immediate step function was optimal. Other forms of relationships were investigated, and to 
the extent that some of them fit the data well they are reported in Appendix B along with the step function models.

The fact that a step function provided the best fit between Western RTOR and accident rates suggests, but does not prove, a simple causal relationship. The existence of a step function which adequately fits the data does, however, tend to confirm the validity of the analyses presented in the preceding section. These analyses used different subsets of the accident data to estimate accident level shifts attributable to Western RTOR.

Overall, the time series analysis showed the statistical significance of the accident rate changes and estimated the shape and magnitude of those changes. The step function adequately related Western RTOR to all the accident series, and was the optimum statistical model in virtually all cases. For some series, the data showed additional fluctuations or patterns not readily explained in terms of a pre-RTOR/post-RTOR distinction. For those data series, additional time series analyses were performed to yield quantitative descriptions of those patterns.

All these analyses are described in detail in Appendix B, together with a more complete discussion of the methods employed. The results are summarized below as they relate to the accident effects of Western rule RTOR. The reader should note that the percentage increases discussed below are based on the change in pre-to-post accident means arising from the time series analysis. These means include seasonal adjustments as appropriate. Because these increases are based on adjusted absolute numbers of accidents involving a motorist turning right at a signalized location, they may differ from those presented earlier which were based on the percentage of all pedestrian or bicycle accidents.

New York State. Several accident series were analyzed for New York State in order to assess the impact of Western RTOR in portions of the State and to replicate the analytical steps for accident series which are logically unrelated to Western RTOR. They are summarized in Tables 2 and 3 . The series means are shown, in average accidents/month, and the yearly deviations from the means are also shown. To provide an initial index of the effect of Western RTOR, the average deviations from the mean are given for all of the period prior to Western RTOR (1974-1976) and for the period after the law change (1977 and 1978), and the percent change from the pre mean to the post mean is also shown. The statistical significance of the patterns is discussed below.

The primary series used to assess the effect of Western RTOR were those pedestrian and bicycle accidents with the motor vehicle turning right at a signalized location in "outstate" New York (i.e., other than New York City). For pedestrians, the post data showed a 43\% increase over the baseline mean. The baseline years were stable at 9.5 accidents/month, with a smooth increase through 1977 (11.4 accidents/month) to 1978 (nearly 15.8 accidents/month). By Box-Jenkins analyses, the increase in accidents of about 4 accidents/month averaged over the post-RTOR period was statistically significant. (All effects described as statistically significant in this section satisfy two-tailed tests of significance in the Box-Jenkins analysis, with $p<.05$.) In the time series models, the pattern of residuals (i.e., actual accident frequencies less frequencies estimated from the models) increased from 1977 to 1978, showing 
Table 2. New York Pedestrian Accidents

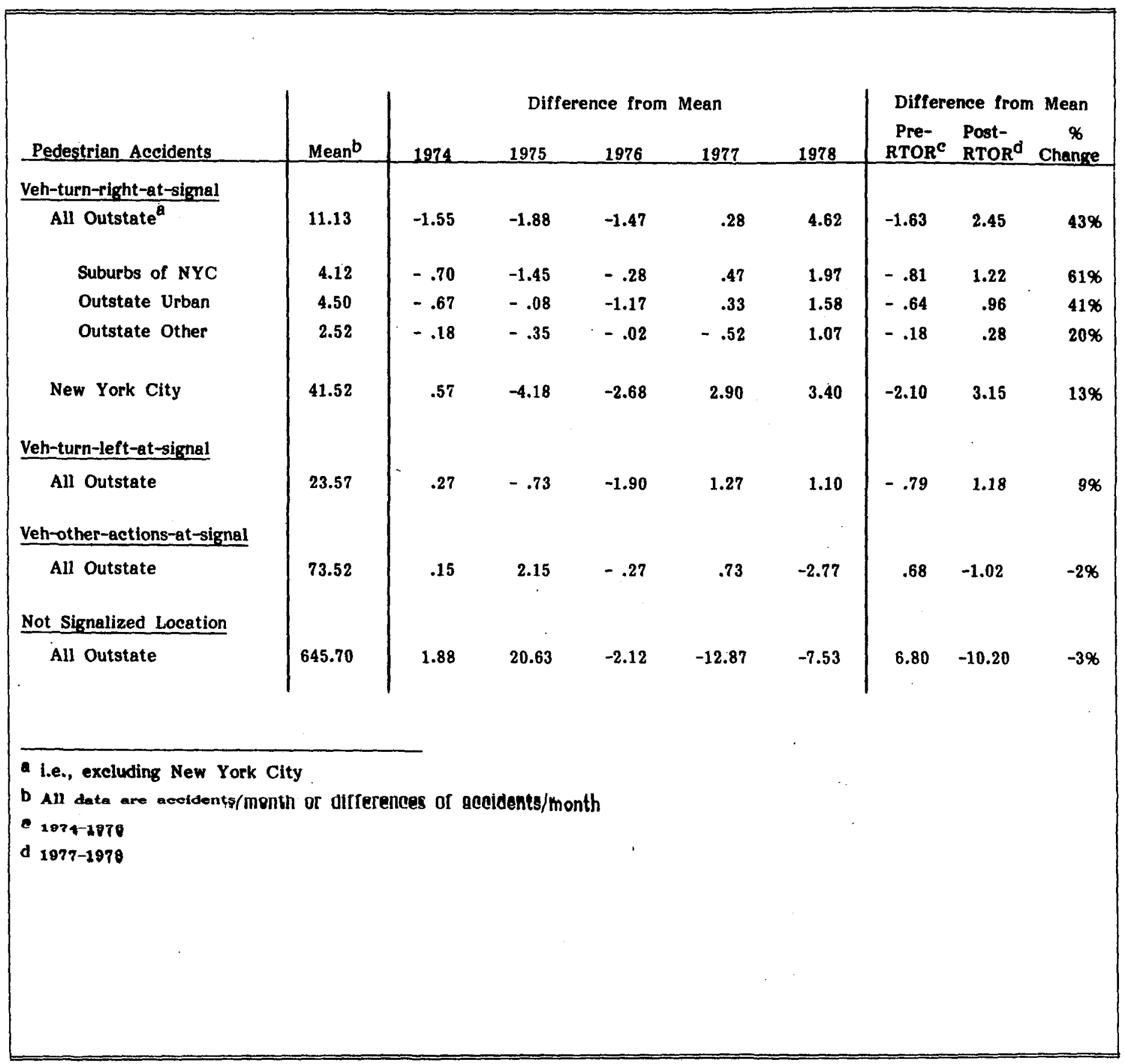


Table 3. New York Bicycle Accidents.

\begin{tabular}{|c|c|c|c|c|c|c|c|c|c|}
\hline & & & Diffe & ce from & ean & & Differ & nce from & Mean \\
\hline Bicycle Accidents & Mean ${ }^{b}$ & 1974 & 1975 & 1976 & 1977 & 1978 & $\begin{array}{c}\text { Pre- } \\
\text { RTOR }^{\mathrm{c}}\end{array}$ & $\begin{array}{l}\text { Post- } \\
\text { RTOR }^{\text {d }}\end{array}$ & $\begin{array}{c}\% \\
\text { Change }\end{array}$ \\
\hline Veh-turn-right-at-signal & & & & & & & & & \\
\hline All Outstate ${ }^{\mathrm{q}}$ & 10.88 & -3.30 & -2.05 & -2.72 & 4.28 & 3.78 & -2.69 & 4.03 & $82 \%$ \\
\hline Suburbs of NYC & 4.97 & -2.05 & -1.55 & -1.38 & 2.87 & 2.12 & -1.66 & 2.49 & $125 \%$ \\
\hline Outstate Urban & 3.65 & -.98 & -.73 & -.57 & .93 & 1.35 & -.76 & 1.14 & $66 \%$ \\
\hline Outstate Other & 2.27 & -.27 & .23 & -.77 & .48 & .32 & -.27 & .32 & $30 \%$ \\
\hline New York City & 10.85 & -2.18 & -.10 & .73 & 1.07 & .48 & -.52 & .78 & $13 \%$ \\
\hline Veh-turn-left-at-signal & & & & & & & & & \\
\hline All Outstate & 13.57 & 1.68 & -.90 & -1.23 & -1.48 & 1.93 & -.15 & .22 & $3 \%$ \\
\hline Veh-other-actions-at-signa & & & & & & & & & \\
\hline All Outstate & 47.05 & -3.13 & .03 & -1.13 & 2.12 & 2.12 & -1.41 & 2.12 & $8 \%$ \\
\hline Not Signalized Location & & & & & & & & & \\
\hline All Outstate & 407.82 & 36.85 & 19.18 & -19.48 & -9.23 & -27.32 & 12.18 & -18.28 & $-7 \%$ \\
\hline
\end{tabular}

\footnotetext{
a i.e., excluding New York City

c .1974-1976

d $1977-1978$

b All data are accidents/month or differences of accidents/month
} 
that the 1978 accident data were at a higher level than the 1977 data (the effect was nearly significant; $p<.10$ ).

The effect in bicycle accident statistics was similar but more pronounced. For outstate vehicle-right-at-signal accidents, the baseline rate was steady at about 8.2 accidents/month. The rate was also steady in the post-RTOR period, but at about 14.9 accidents/month, a jump of $82 \%$. The time series models confirmed the increase of about 6.7 accidents/month to be statistically significant. The proportionate increase was about the same in the colder months (October-April) as in the warmer months (May-September), even though the base rate of accidents was more than four times as great in the warm weather period as in the cold. Unlike the pedestrian data, the bicycle data showed an immediate jump in accidents coincident with the start of Western RTOR, and the bicycle accident levels in 1977 and 1978 were nearly identical.

To get a more detailed picture of the increases in accidents in outstate New York, the accident series were split into thirds. The first, Suburbs of New York City, included Long Island--Suffolk and Nassau Counties--and Westchester and Rockland Counties. The Outstate Urban Counties covered the cities of Buffalo (Erie), Rochester (Monroe), Syracuse (Onondaga), Schenectady (Schenectady), and Albany-Troy (Albany, Rensselaer). The Other Outstate areas included rural counties and counties with small urban concentrations but no large cities.

For both bicycle and pedestrian accidents, the largest increase in accidents occurred in the Suburbs of New York City, the next largest increase in Outstate Urban Counties, and the smallest increase in the Other Outstate areas. In the suburban counties, pedestrian accidents averaged $61 \%$ higher in the post-RTOR period, although most of the increase was in 1978. Suburban county bicycle accidents showed an increase of $125 \%$. In the major outstate urban counties, pedestrian accidents rose in 1977 and again in 1978; the average two year increase was $41 \%$ over the baseline period. Bicycle accidents in the same area were $66 \%$ higher than the baseline period. All these differences were statistically significant.

In the Other Outstate areas, pedestrian accidents rose sharply in 1978 after dropping slightly in 1977, the first year after Western RTOR became legal. The average increase, $20 \%$, was not statistically significant. Taken alone, the 1978 increase of $53 \%$ over baseline would be statistically significant but would require an interpretation that, although Western RTOR was legal in 1977, it was not practiced until 1978 in these areas of the state. Bicycle accidents in the same areas were higher than baseline in both 1977 and 1978, by an average of about $30 \%$; the difference, consistent with the other bicycle accident series although somewhat smaller, did reach statistical significance.

In summary, the areas of New York State in which Western RTOR was introduced showed a large and significant increase in both pedestrian and bicycle accidents at signalized locations involving motorists who turned right. The effect was most pronounced in counties around New York City, still large in outstate counties with large urban concentrations, and present but not always statistically significant in the counties which were rural or had only small urban centers. Consistently, bicycle accidents showed about the same level of accident increase in the first year under Western RTOR (1977) as in 
the second (1978). Pedestrian accidents, however, showed a large increase in 1978 but an accident value in 1977 that was midway between the baseline (1974-1976) and 1978 levels.

Other accident series from New York were also analyzed and are also summarized in Tables 2 and 3. They represent "comparison" series of pedestrian and bicycle accidents, ones selected from the same state, the same data tapes, and the same years but differing in location or motorist action. Because they do not involve motorists turning right at signalized locations under Western RTOR, they would not be expected to show a sharp increase (or decrease) in accidents coincident with the introduction of Western RTOR in New York State (other than New York City) in 1977. They would be expected, however, to show the effects of factors leading to general accident rate increases or decreases which might also be reflected in the data series analyzed above. If such patterns were found, the sole attribution of the large accident rate increases to the RTOR situation would have to be reconsidered.

In New York City, Western RTOR never went into effect. Pedestrian accidents with vehicle-right-at-signal nevertheless rose by $13 \%$ from baseline to the 1977-1978 time period. The value was statistically significant but much smaller than the increase $(61 \%)$ in the adjacent suburban counties. For New York City bicycle accidents with vehicle-right-at-signal, the 1977-1978 time period rates were also $13 \%$ higher than in the baseline. This increase was best described as a general upward trend rather than as an abrupt change coincident with the start of Western RTOR elsewhere in New York State.

In all of New York State except New York City, comparison accident series were tested for three distinct accident subsets. Accidents with vehicles turning left at signalized locations test, perhaps, the indirect effect of Western RTOR on the most complex maneuver commonly made at intersections. Only a tiny number of left turns are legally made on red lights under the Western RTOR, i.e., at intersections of two one-way streets. Thus, an increase in accidents involving left turns under Western RTOR might be interpreted as meaning that Western RTOR made traffic patterns significantly more complex at signalized locations and hence, generally more hazardous. For pedestrian accidents under these conditions, there was a $9 \%$ rise in accidents from the baseline period to the Western RTOR period. The increase was much less than that seen in accidents with right turning vehicles and failed to reach statistical significance. Bicycle accidents went up $3 \%$ over the same period, but the change cannot be logically related to the introduction of Western RTOR and was not statistically significant.

Also tested in outstate New York were pedestrian and bicycle accident series involving all other vehicle actions at signalized locations and all those at other locations. For pedestrian accidents, there was a slight decrease in accidents of these two types, $2 \frac{\circ}{\circ}$ and $3 \frac{\circ}{\circ}$, respectively. The variations were not related to the time of introduction of Western RTOR and were not significant. Bicycle accidents went up $8 \%$ for other vehicle actions at signalized locations. Although the effect tracked the introduction of Western RTOR, it was small and not statistically significant. At other locations, bicycle accidents decreased by $7 \%$. Because of unstable baseline and post-RTOR yearly values, however, the decrease is not interpretable--and of marginal statistical significance. It should be noted that there is no consistent evidence to support a general rise in bicycling in outstate New York over the 
data collection period, one which might explain or temper the RTOR relationship. In fact, the accident data support the conclusion of generally steady bicycling activity from 1974 through 1978.

Thus, examination of other pedestrian and bicycle accident series for outstate New York and New York City show that there was no general increase in accidents from the baseline (1974-1976) period to the 1977-1978 period. With the introduction of Western $R T O R$, accident rates did increase significantly for both pedestrian and bicycle crashes involving motor vehicles turning right at signalized locations. These increases represent a net rise of perhaps $1 \frac{0}{0}$ in all New York pedestrian and bicycle accidents. Other pedestrian and bicycle accidents at signalized locations, those involving all other motor vehicle actions, showed minimal changes, as did all pedestrian and bicycle accidents not at signalized locations. Finally, within New York City where Western RTOR did not become legal, pedestrian and bicycle accidents with motorists turning right at signals showed a relatively slight increase from 1974-1976 to $1977-1978$.

Wisconsin, Ohio and New Orleans, Louisiana. As described in a prior section, there were large increases in pedestrian and bicyclist accidents with vehicles turning right at signals in these jurisdictions associated with the introduction of Western RTOR. The data for the five accident series (only pedestrian accident data were available for New Orleans) are summarized in Table 4. Unlike New York, the data shown here did not always fall into full-year clusters. Because there were significant seasonal cycles in the data-within the series, some months had consistently fewer or more accidents than average--an adjustment was made in the calculations of pre- and post-RTOR deviations. Each monthly accident tally was adjusted by subtracting from it the mean of all data for that month. Those monthly deviations were then averaged to give pre- and post-RTOR mean differences which were independent of the highs or lows of seasonal cycles.

Over the period of data for Wisconsin and Ohio, this country underwent two severe gasoline shortages which drastically reduced driving. The periods were roughly October 1973-April 1974 and May 1979-September 1979. Steps were taken in the Box-Jenkins time series analyses to compensate for these shortages, which may have reduced accident levels noticeably, so that they did not bias the evaluation of Western RTOR. Because of the limited amount of data directly applicable to the accident impact of the gas shortages, tests of the significance of those effects, although conducted, were of extremely low statistical power and therefore are not reported.

Wisconsin accident data were available for seven years, 1973 through 1979, of which the first two and one-half years were prior to the introduction of Western RTOR. Pedestrian accidents at signals with vehicles turning right averaged about 3.4 accidents per baseline month and rose $107 \%$ to over 6.9 accidents per month after Western RTOR. Although the number of accidents varied somewhat from year to year, there was no systematic increase or decrease within the post-RTOR period. There was a drop in accidents of about 0.7 accidents/month during the gasoline shortage.

The similar series of bicycle accidents in Wisconsin rose $72 \%$, from a baseline average of 2.3 accidents/month to a post-RTOR average of about 4.0 accidents/month. Except for a slight dip in accidents during 1976, the rate 
Table 4. Accidents with Motor Vehicles Turning Right at Signalized Locations.

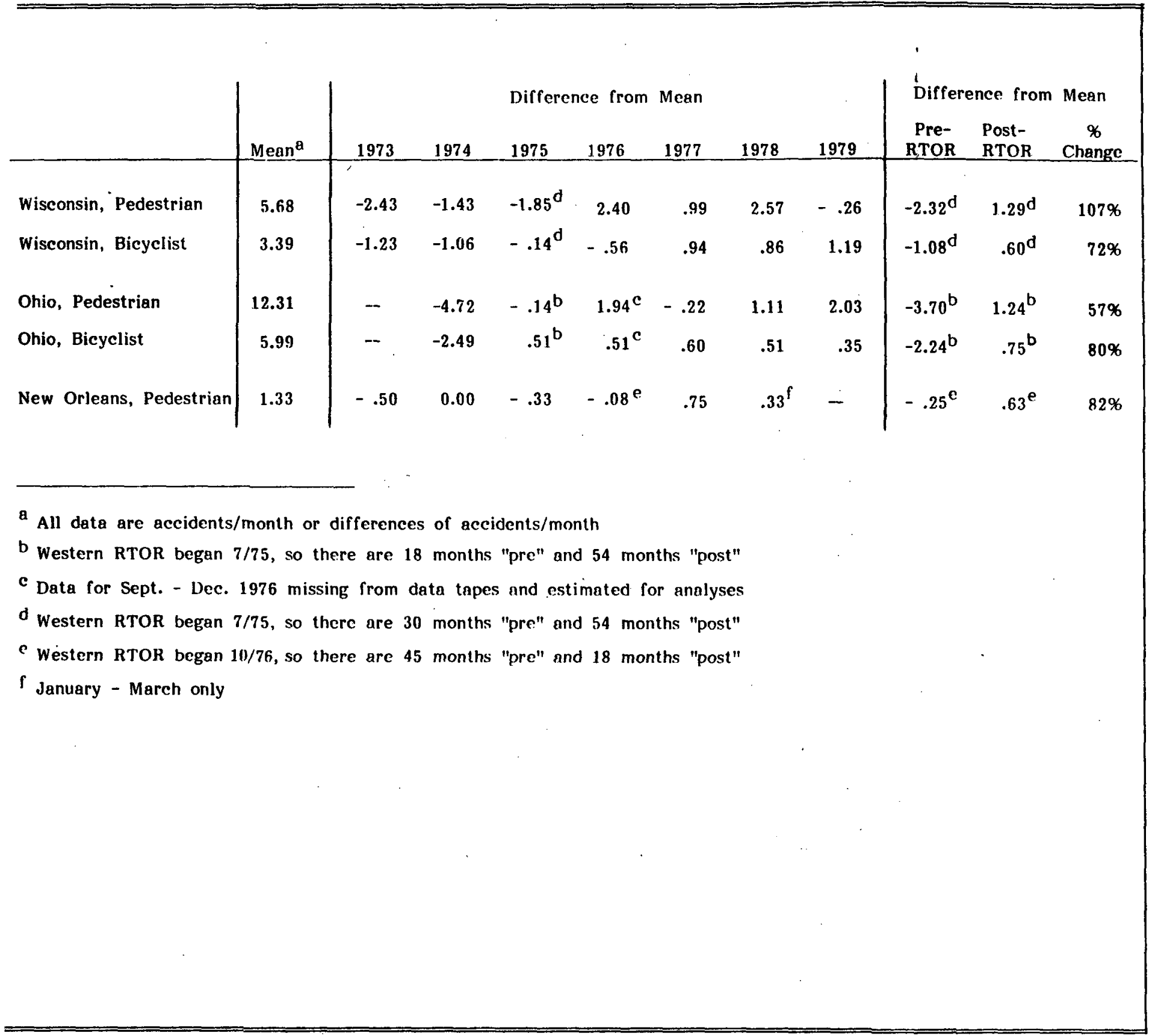


was steady throughout the years after the introduction of Western RTOR. There was virtually no change in accident rate associated with the gas shortage.

In Ohio, pedestrian accidents at signals with vehicles turning right averaged 8.6 accidents/month before Western RTOR and rose 578 to a stable average of more than 13.5 accidents/month in the 54 months after Western RTOR. The difference was highly significant. Although accidents declined almost 2 accidents/month during the periods of gasoline shortage, the amount of accident rate increase associated with Western RTOR did not vary according to whether or not the gas shortage was included in the time series model estimation.

Bicycle accidents in Ohio at signals with vehicles turning right showed very similar patterns over time. The baseline rate of about 3.75 accidents/month rose $80 \%$ to a value of over 6.7 accidents/month throughout the period under Western RTOR; the difference was statistically significant. The gas shortage was associated with a drop of less than one accident/month.

In New Orleans, pedestrian accidents were collected for 63 months, from January 1973 through March 1978. Western RTOR was in effect for only the last 18 months of this time period, beginning with October 1976. Accidents with right-turning vehicles at signals averaged only 1.1 accidents/month before RTOR but rose $82 \%$ to 2.0 accidents/month after RTOR. Although the overall accident rate was quite low, the difference was statistically significant.

In all data series surveyed, then, there was observed a large and statistically reliable increase in pedestrian and bicycle accidents at signalized locations with striking vehicles turning right. Except for New York pedestrian accidents, which rose somewhat gradually, the accident rates rose in a single step, from a baseline level to a distinctly higher level, at the introduction of Western RTOR. In New York, alternate accident series were examined to determine whether the effects of Western RTOR extended to accidents other than those involving right turns at signals. No such rate changes were observed.

C. Dynamics of Right on Red Crashes

1. Pedestrians in Los Angeles

Los Angeles has had Western RTOR for over 30 years. Pedestrian accident reports from Los Angeles (City only) were accessed and read by Dunlap staff as part of an ongoing evaluation effort in that City. The accessed data covered all police reported pedestrian crashes for the period 1973 to 1978. Specific procedures for coding, etc., have been discussed elsewhere (see Blomberg et al., in process). The data set covers 19,383 events within the Los AngeTes Police Department's jurisdiction (excludes freeway events covered by the California Highway Patrol and five events for which year was unknown) of which 933 (4.81\%) involved a vehicle turning right at a signalized location. For 526 of these (2.71\%) it was clear that the maneuver was performed on a red signal. The coding procedures in this effort were not specifically designed for RTOR but nevertheless included the following RTOR "accident types:" 
RTOR-left

RTOR-right

RTOR-across
RIGHT TURN ON RED-LEFT:

Pedestrian crossing from left to right in front of a driver turning right on red

RIGHT TURN ON RED-RIGHT: Pedestrian crossing right to left in front of a driver turning right on red

RIGHT TURN ON RED-ACROSS:

Pedestrian crossing parallel to driver's original path before he made a right on red, i.e., victim struck crossing street into which driver turned

Of the three types, RTOR-right was by far the most prevalent and accounted for $361(69 \%)$ of the identified right-on-red events. These three types are diagrammed in Figure 2 .

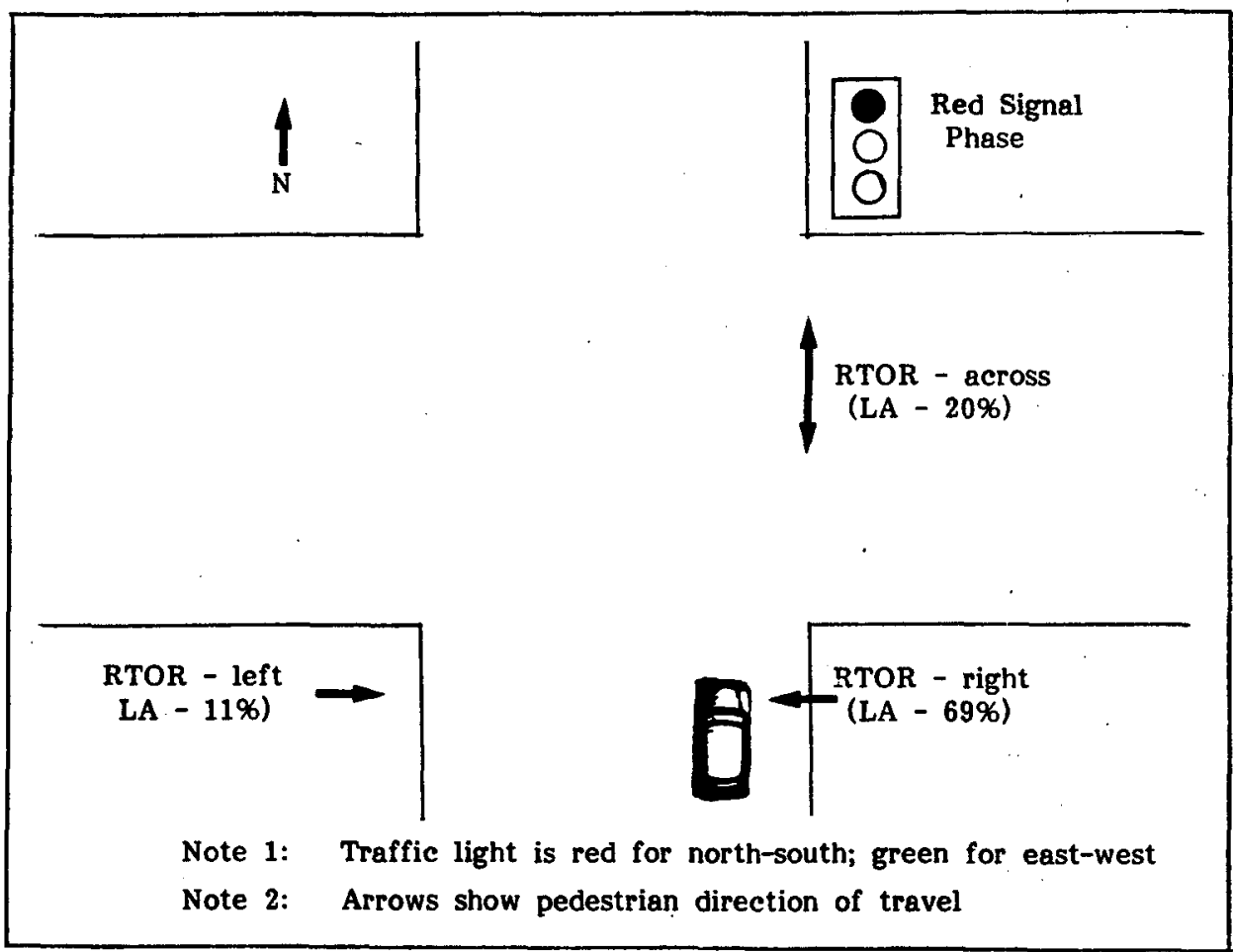

Figure 2. Types of RTOR pedestrian accidents coded in Los Angeles with percent of each type found in coding 526 such Los Angeles accidents. 
For both RTOR-left and RTOR-right, the pedestrian is crossing on a green signal and may even have a "Walk" light. The RTOR-across situation involves a pedestrian crossing against the traffic signal. The incidence of RTOR-across is relatively low (20\%) probably because Los Angeles pedestrians generally do obey traffic signals. The RTOR-left situation is also an infrequent crash event $(11 \%)$. This may be partly due to the fact that the vehicle is turning away from pedestrians on the left and partly because the driver's attention is turned to the left looking for a gap in traffic and thus he has a greater opportunity to see any pedestrians.

The dynamics of the situation suggest that RTOR-right should be particularly dangerous. Simply, a driver stopped at a red light and preparing to make a right turn is typically looking left to find a gap in traffic such that the right turn can be made safely. The driver has difficulty seeing a pedestrian crossing from the right directly in front of the vehicle. When later asked about the accident, drivers will typically say "I never saw her." It is likely that the driver does not even know he has struck a pedestrian in many of these cases. Pedestrians typically say "He was there, stopped for the light, and he just pulled out and hit me." In other words, the pedestrian is crossing on the green signal, sees the car and doesn't believe it would just pull out. The driver, looking left, never sees the pedestrian about to cross from his far right.

Several analyses were performed comparing descriptive information for "left," "right" and "across" types of events. The results showed that the following variables did not discriminate among the three types of RTOR crashes in Los Angeles:

$\begin{array}{ll}\text { Month } & \text { Driver Age } \\ \text { Time of Day } & \text { Pedestrian Sex } \\ \text { Day of Week } & \text { Pedestrian Injury Severity } \\ \text { Vehicle Type } & \text { Road Type }\end{array}$

Table 5 shows the distribution for some of these variables collapsed across the three RTOR event types. The results showed that RTOR pedestrian crashes tended to be weekday events with the highest incidence on Monday, Tuesday and Wednesday. They were also daylight events with about half occurring between noon and 6:00 P.M. Injury severity tended to be low with most events resulting in either moderate (43\% "minor, but visible") or slight (50\% "complaint only") injuries. Pedestrians were most often hit by passenger cars in business/commercial areas. Drivers were primarily male with an overrepresentation of hit and run. Their median age was 31.8 years. Female pedestrians were somewhat more common than male.

Three of the crash characteristic or descriptive variables did show differences across the three RTOR accident types. First, as shown in Table 6, there were differences related to pedestrian age. Adult pedestrians, especially 45 years of age and older, were more often involved in the RTOR-right event while children and teenagers had relatively less involvement in RTOR-right and more involvement in RTOR-left and RTOR-across. Compared to other types of accidents at similar locations, however, all RTOR accidents involved pedestrians of a very wide age range. Fully $27 \%$ were 19 
Table 5. Description of RTOR Accidents

in Los Angeles.

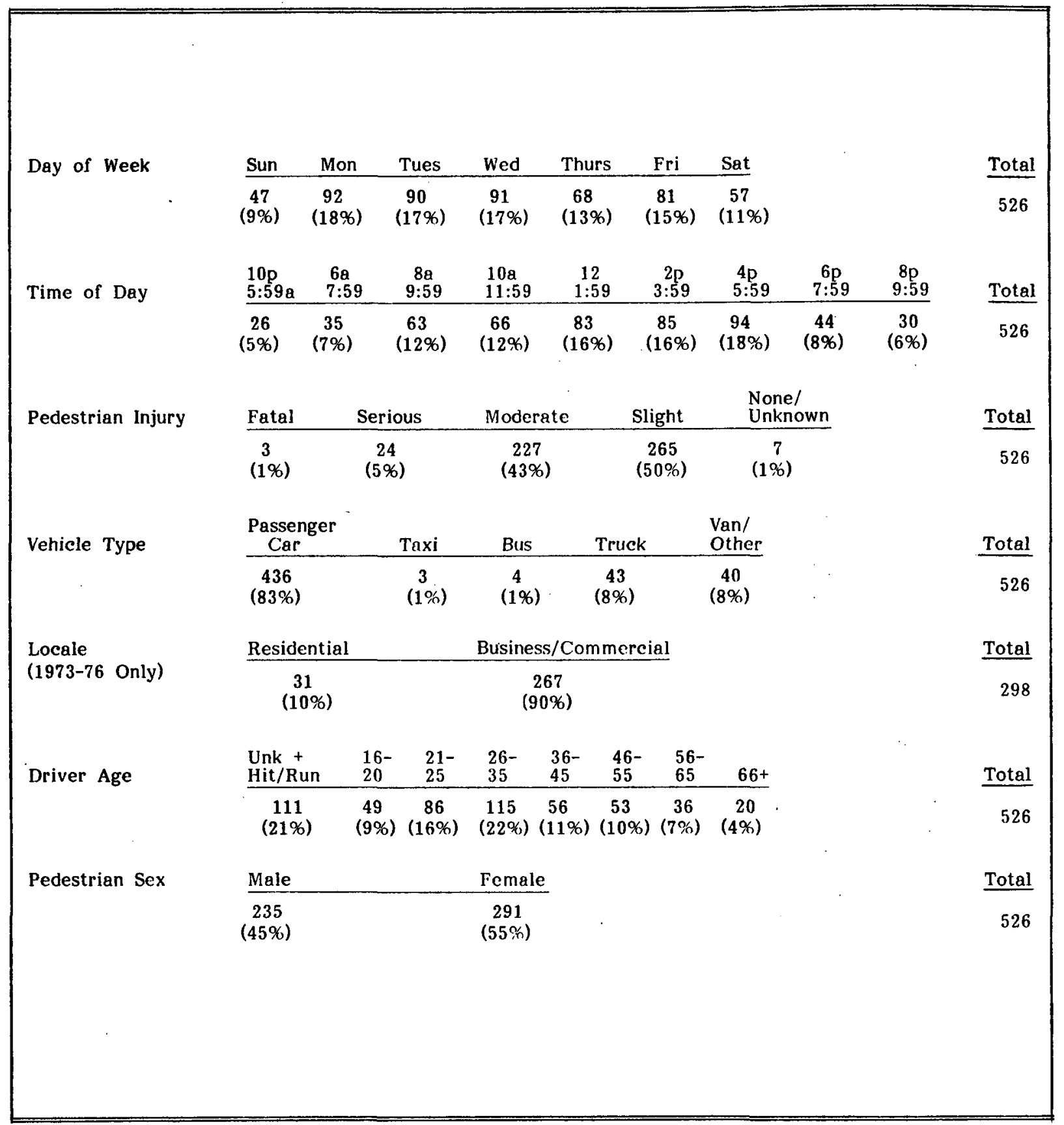


Table 6. Pedestrian Age and Driver Sex by RTOR Accident Types in Los Angeles.

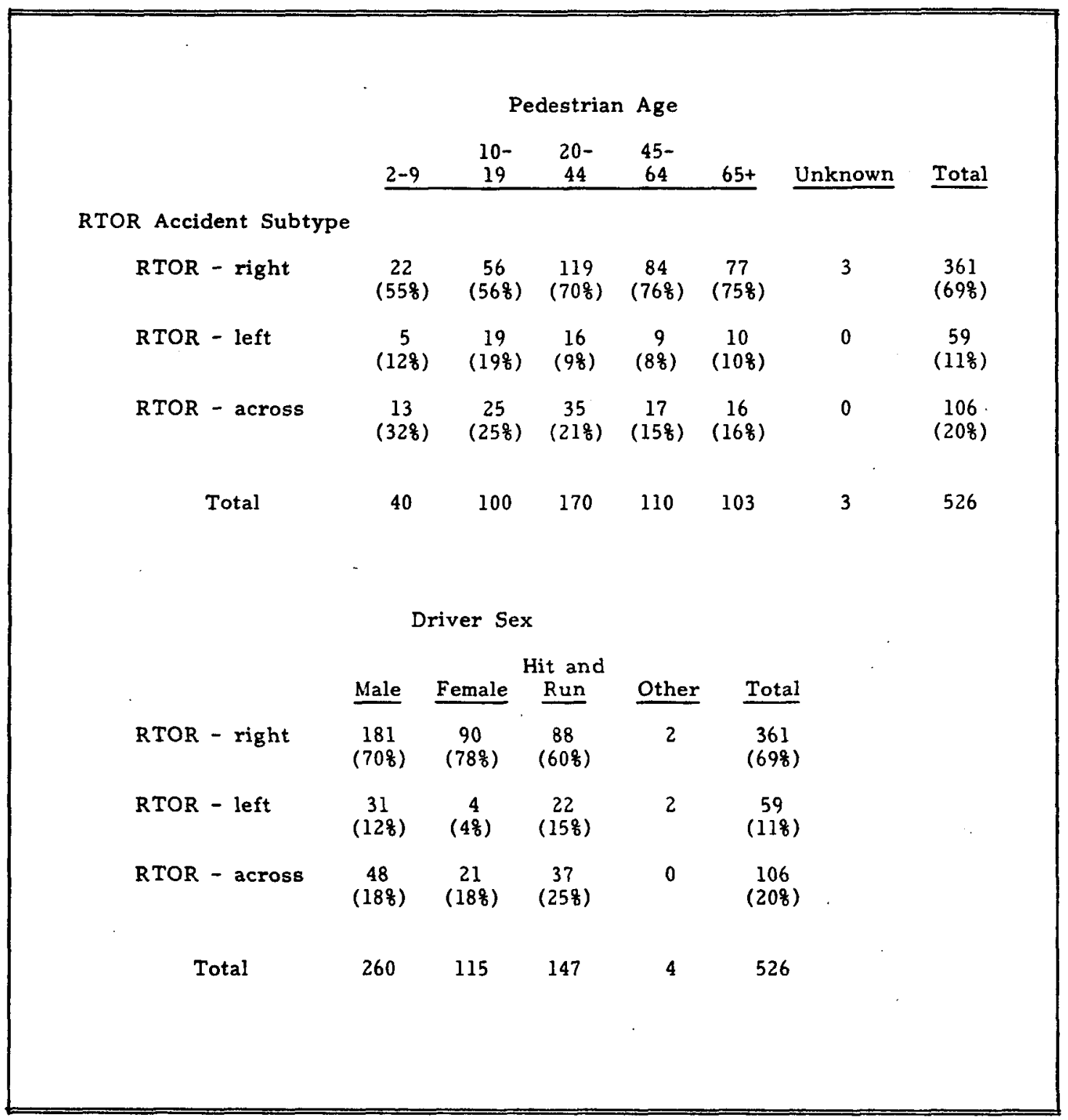


years of age or less and 20\% were 65 years of age or older. Second, also shown in Table 6, there was an effect related to driver sex which included the category of driver hit and run. Simply, hit and run drivers were less likely to be involved in the RTOR-right event while female drivers were less likely to be involved in the RTOR-left event. The third variable related to the RTOR types was weather. Simply, there was a tencency for the RTOR-left events to be associated with rain and wet road surfaces. This finding is consistent with the idea that the driver should see a pedestrian coming from the left except, perhaps, during bad weather or poor visibility conditions.

In summary, the Los Angeles data cover an urban location where Western RTOR has been in place for a considerable period. Accident patterns should be stable, or at least more stable than in those eastern states recently adopting Western RTOR. The results show that RTOR pedestrian accidents do occur with considerable frequency. The primary threat or danger in the RTOR situation is RTOR-right which involves a driver looking left for a gap in traffic, finding a gap and pulling out into the path of a pedestrian crossing from the far right in front of the previously stopped vehicle. The pedestrian, crossing on a green signal, does not suspect that the driver will pull out. These events tend to occur on weekday afternoons in business or commercial areas. Pedestrians include all ages and typically suffer low to moderate severity injuries.

\section{Pedestrians in New York, Wisconsin and Ohio}

As discussed in Chapter II, accident reports from Niew York, Wisconsin and Ohio were accessed and read by project staff. Each accessed report was identified, through computer codes, as involving a vehicle turning right at a signalized location. While several data items were collected from these reports, the most important items were "light phase facing driver" (i.e., was it a right turn on red) and the "directional analysis" which showed the pedestrian and bicycle paths relative to the vehicle. As a general rule, the police accident reports from New York, Ohio and Wisconsin did not provide the level of detailed crash information that was contained in the Los Angeles reports. Therefore, many data points were coded as "unknown" or "not available." Occasionally, accident reports confirmed an other-than-red or green signal facing the driver, e.g., yellow, green arrow or pedestrian only signal phase. Nevertheless, sufficient information was available to replicate many of the analyses shown above for Los Angeles. It should also be noted that for New York, Wisconsin and Ohio, the RTOR accident types were expanded such that "RTOR-across" was separated into "up" and "down." For "up," the pedestrian or bicyclist was moving away from the vehicle (north in Figure 2) and for "down" the pedestrian or bicyclist was moving toward the vehicle (south in Figure 2).

Table 7 shows accident geometry (the RTOR-accident types) by light phase facing driver for the requested pedestrian reports from New York, Wisconsin and Ohio following the introduction of Western RTOR. The results showed that the light phase was unknown for one-third or more of these crashes and that the accident geometry could not be determined for some of the others. Nevertheless, where these items were available, it can be seen that the majority of the crashes occurred on the red phase and the majority of red phase crashes were RTOR-right. Further, on the green signal phase, the "right" problem dropped substantially and was replaced by "up" and "down." 
Table 7. Light Phase by Accident Type for New York, Wisconsin and Ohio Pedestrian Crashes Under Western RTOR.

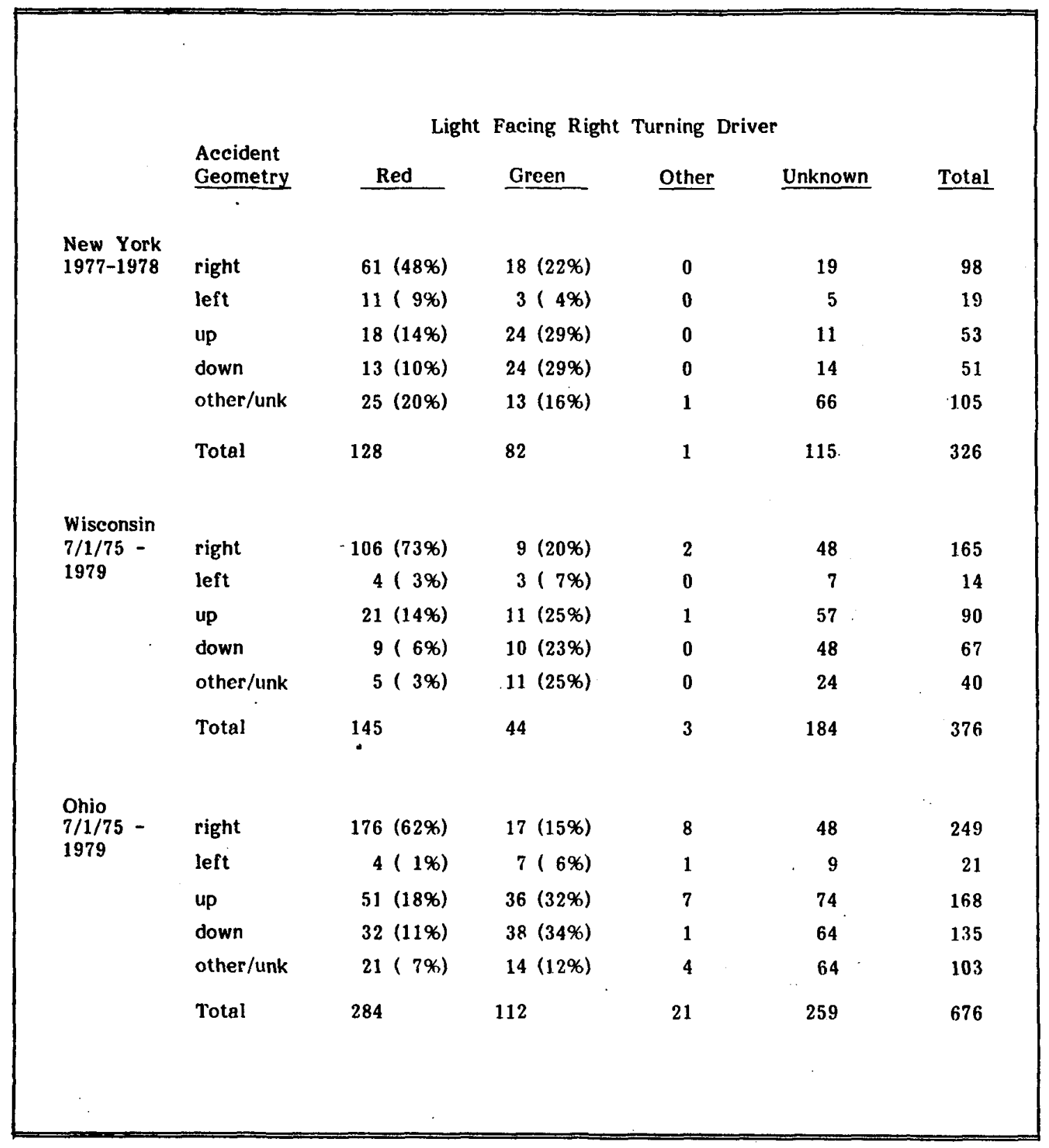


In New York, 326 post-RTOR pedestrian reports were requested from the State. Of these, 128 (39\%) showed a red light facing the driver; 82 (25\%) showed a green light; and light phase was either unknown or other for the remainder. The red phase events parallel Los Angeles in that most were "right," least were "left" and some were "up" and "down." The green phase events showed a very different pattern. "Up" and "down" were most prevalent, which is consistent with the fact that when the light facing the driver is green, the light facing pedestrians on the "up" and "down" (i.e., "across") leg of the intersection is also green. In Wisconsin, 376 post-RTOR pedestrian accident reports were requested from the State. Of these, 145 (39\%) showed a red light facing the driver; 44 (12\%) showed a green light; and the remainder were either light phase unknown or other. Accident geometry was similar to that discussed above for New York. In Ohio, 676 post-RTOR pedestrian accident reports were requested from the State. Of these, 284 (42\%) showed a red light facing the driver; 112 (17\%) showed a green light; and the remainder were either light phase unknown or other. Accident geometry (i.e., RTOR-right on red, "up" and "down" on green) was similar to that found for New York and Wisconsin. Also in Ohio, 153 reports were requested for the period prior to Western RTOR. Of these, 12 ( $8 \%$ ) showed a red light facing the driver; 46 (30\%) showed a green light and the remainder were other or unknown.

In Los Angeles, based on careful reading of detailed accident reports, 526 pedestrian accidents were coded as right-on-red; this was over $56 \%$ of the total of 933 events involving vehicles turning right at signals. In New York, Wisconsin and Ohio from $35 \%$ to $49 \%$ of the events involved unknown signal phases. Nevertheless, it is of interest to estimate the actual percentage of vehicle-turning-right-at-signal accidents which involved right-on-red. This number, if known accurately, would not only document the full magnitude of the RTOR accident type but also allow estimation of the change in RTOG (right turn on green) accidents coincident with the introduction of the Western RTOR rule. This latter estimation permits apportioning the observed RTOR crash magnitude between a net increase in total accidents and a substitution of RTOR crashes for RTOG.

Many estimation procedures are plausible. The one utilized here distributed the "unknown" light phase accidents for each accident geometry in each state among the "red," "green" and "other" categories proportionally to the frequencies actually there. For example, in the first row of Table 7, the 19 unknowns were split according to the 61:18:0 ratio in the other categories, or 15:4:0, to produce an adjusted reduced row of $76: 22: 0$. In the fifth row, the 66 unknowns were apportioned according to the known frequencies of $25: 13: 1$, for an adjusted reduced row of $67: 35: 3$. This procedure is based on the principle that accidents of unknown phase are distributed as are known-phase accidents of the same geometry. The estimates produced by this procedure are quite similar to ones generated by the procedures of either ignoring the unknowns or splitting them equally between "red" and "green" and were used because they made use of more classification information.

In outstate New York, the estimation procedures described above led to an estimated $61 \%$ of the right-at-signal pedestrian accidents as RTOR, 38\% were RTOG, and $1 \%$ were "other." (e.g., yellow, traffic control officer, arrows, etc.). This translated into about $8.3 \mathrm{RTOR}$ accidents/month in outstate New York. In Wisconsin, the right-at-signal pedestrian accidents 
were estimated to be $69 \%$ RTOR, 30\% RTOG and $2 \%$ "othex." In the post period, then, about 4.8 accidents/month were RTOR in Wisconsin. For Ohio in the post period, it was estimated that about $64 \%$ of the right-at-signal pedestrian accidents, or 8.7 accidents/month, were RTOR, 31\% were RTOG and 6\% were "other." With this information, it was possible to derive estimates as to the percentage of all pedestrian and bicycle accidents under the Western RTOR law which involved a vehicle turning right on red. These percentages were $1.12 \%, 1.60 \%, 2.26 \%$ and $2.71 \%$ of all pedestrian accidents in New York, Ohio, Wisconsin and Los Angeles, respectively. These percentages were $1.39 \%, 1.50 \%$ and $1.70 \%$ of all bicycle accidents in Ohio; Wisconsin and New York, respectively.

The results in Table 8 cover the post period reports from each state which involved motor vehicles turning right on red signals. The samples are not strictly comparable because each was taken from a larger sample with varying proportions of "unknown phase" (which are excluded from the Table) and because the Los Angeles reports were not separated into the "up" and "down" accident subtypes. Nevertheless, the distributions are quite similar across jurisdictions, with about two-thirds RTOR-right and the rest split between, in their order of representation, RTOR-up, RTOR-down and RTOR-left.

Several analyses were conducted to describe the New York, Wisconsin and Ohio RTOR pedestrian events. Table 9 shows the results for some of these analyses. This Table is similar to Table 8 in that it covers only vehicle turning right on a red signal and excludes "unknown" and atypical events. These results, in all three states, show that male drivers were more often involved than females. However, also in all three states, the pedestrian was more often female. The striking vehicle in these events was most often a passenger car including station wagons. The median age of drivers was about 30 years; the median age for pedestrians was nearly 40 years although pedestrians of all ages, including very young and old, were involved. Other analyses showed that, as in Los Angeles, these events tended to occur on weekday afternoons. Injury severity, while difficult to compare across several state coding schemes, was low to moderate: in New York, all pedestrians were listed as "injured." In Wisconsin, 10 (2 cases) were fatal, 6\% were "serious," $28 \%$ were "visible" and 64\% were "claimed." In Ohio, less than 1\% were fatal (1 case), 2\% were "incapacitating," 35\% were "visible," $50 \%$ were "claimed" and 10\% were "no" or "not stated." Each state was broken into large cities, smaller towns, etc., or densely populated counties versus rural counties, etc. The results showed that $R T O R$ accidents were far more frequent in densely populated areas possibly because there are more traffic signals and/or possibly because there is more pedestrian traffic or vehicle traffic. However, there did not seem to be any major differences between the nature of the accidents in large cities and small towns. It appears that the problems confronting drivers and pedestrians in the RTOR situation are similar whether the traffic signal is in a large city or a small town.

In summary, New York, Wisconsin and Ohio have recently implemented Western RTOR. Police accident reports for vehicles turning right at signalized locations under the Western $R T O R$ rule were accessed and read. Often, the reports did not supply sufficient information to determine the actual light phase just prior to the crash. However, where light phase could be determined, it was red by a ratio of about two-to-one. Under a red signal,

$$
32.5
$$


Table 8. Distribution of Pedestrian Accidents Under Western RTOR, Vehicles Turning Right on Red Signal.

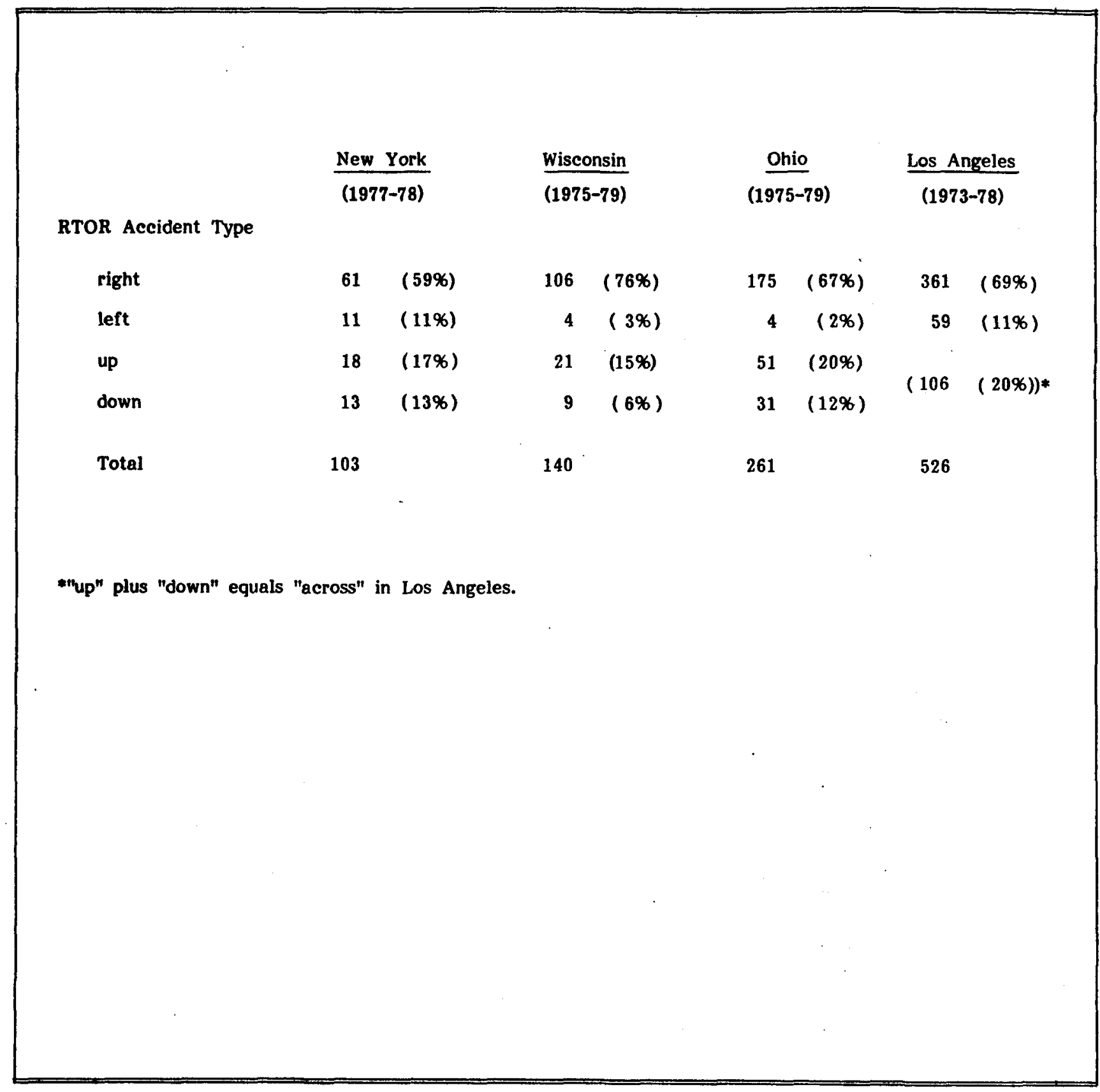


Table 9. Description of Pedestrian Accidents in New York, Wisconsin and Ohio Under Western RTOR, Vehicles Turning Right on Red Signal.

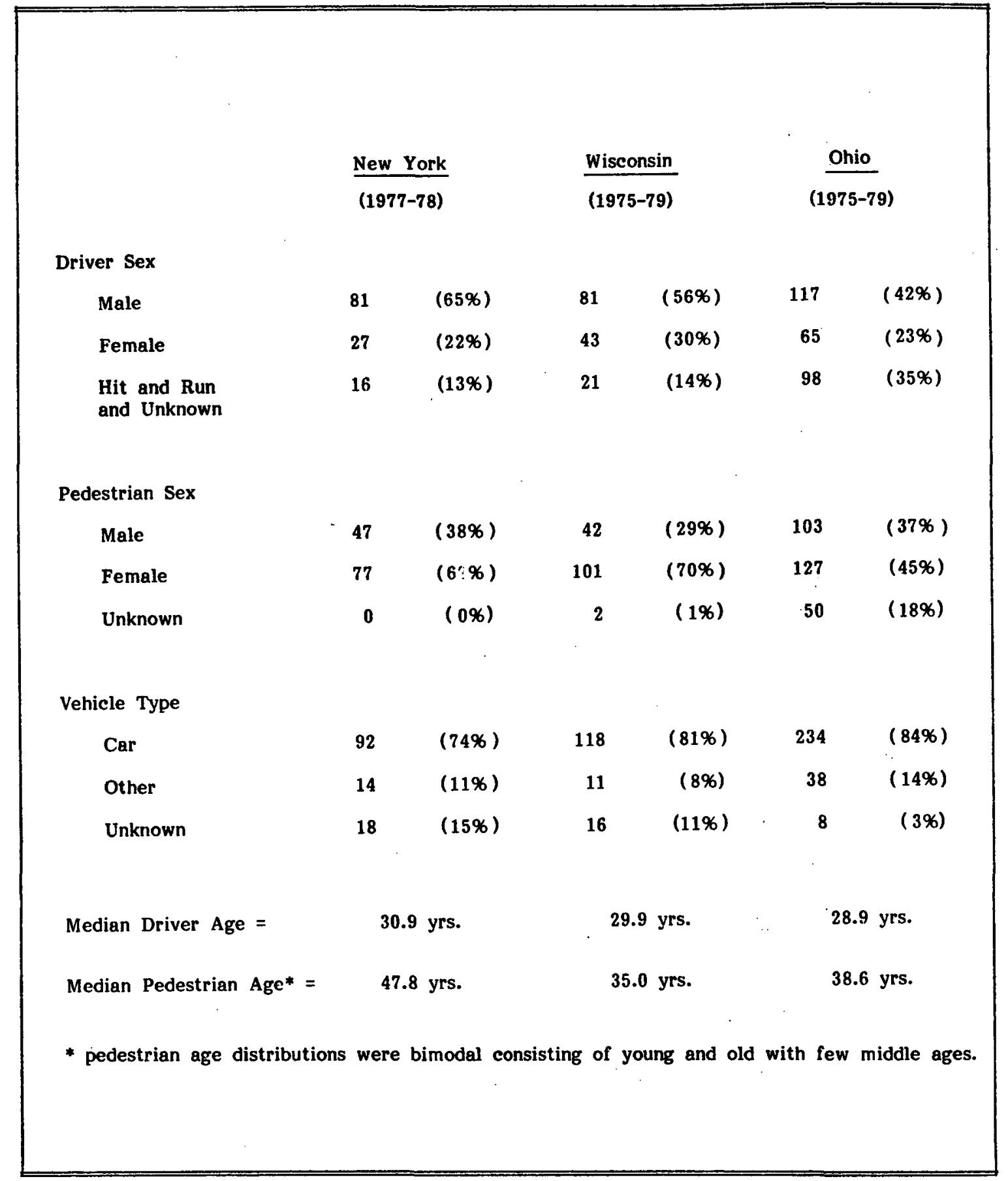


RTOR-right was by far the most common accident geometry. Under green, pedestrians were most often hit as the vehicle exited the intersection with the "up" and "down" accident geometry occurring about equally often. Further analysis of the red situation showed that it typically involved a male driver in his thirties striking a female pedestrian, and most crashes occurred in the afternoon and resulted in low pedestrian injury severities. RTOR events in New York, Wisconsin and Ohio appear quite similar to the Los Angeles events discussed in the previous section.

\section{Bicyclists in New York, Wisconsin and Ohio}

Police accident reports involving bicyclists from New York, Wisconsin and Ohio were accessed and read using the same procedures as discussed above for pedestrians. As with pedestrians, "light phase facing driver" and the "directional analysis" were the most important items. Further, it was important to know whether the bicyclist's collision course originated from the sidewalk or from the roadway. It should be noted that the question of accident geometry as a valid criterion for RTOR accident subtyping was reconsidered for the bicycle events and it was felt that the types developed for pedestrians were also appropriate for bicycles. The bicycle accident typing work done by Cross and Fisher (1977) did contain an RTOR accident type referred to as "Type 10, Motorist Turn-Merge: Intersection Controlled by Signal." All of the Type 10 Cross and Fisher accidents were right-on-red and they report $85 \%$ RTOR-right and 15\% RTOR-left (p. 219). Not surprisingly, none of the Cross and Fisher Type 10 accidents involved a fatality, suggesting that RTOR bicycle accidents, as RTOR pedestrian accidents, tend to be of low injury severity.

Table 10 shows accident geometry by light phase facing the driver for the requested bicycle reports from New York, Wisconsin and Ohio following the introduction of Western RTOR. Unfortunately, light phase was "unknown" for about half of the crashes and accident geometry could not be determined for some of the others. Nevertheless, as with pedestrians, it can be seen that the majority of "known" lights were red and the majority of red phase crashes were RTOR-right. Also, as with pedestrians, the "right" problem was much less predominant on the green phase and was replaced by "up" and "down."

In New York, 359 post-RTOR bicyclist reports were requested from the State. Of these, 66 (18\%) showed a red light facing the driver; 49 (14\%) showed a green light and the remainder were other or unknown. The red phase events were predominately RTOR-right and the green phase events were divided between "right," "up" and "down." This pattern of results is similar to the pattern found for pedestrians struck by vehicles turning right at signalized locations. In Wisconsin, 217 post-RTOR bicyclist reports were requested from the State. Of these, 61 (28\%) showed a red light facing the driver, 28 (13\%) showed a green light and the remainder were other or unknown. Accident geometry was again similar to that found for pedestrians. In Ohio, 355 post-RTOR bicyclist reports were requested. Of these, 131 (37\%) showed a red light facing the driver; 53 (15\%) showed a green light and the remainder were other or unknown. Accident geometry was again similar. Also in Ohio, 58 bicyclist reports were requested for the period prior to Western RTOR. Of these, 4 (7\%) showed a red light facing the driver, 22 (38\%) showed a green light and the remainder were other or unknown. 
Table 10. Light Phase by Accident Type for New York, Wisconsin and Ohio Bicycle Crashes Under Western RTOR.

\begin{tabular}{|c|c|c|c|c|c|c|}
\hline \multirow[b]{2}{*}{. } & \multirow[b]{2}{*}{$\begin{array}{l}\text { Accident } \\
\text { Geometry }\end{array}$} & \multirow[b]{2}{*}{ Red } & \multicolumn{2}{|c|}{ Facing Right Turning } & \multicolumn{2}{|l|}{ Driver } \\
\hline & & & Green & Other & Unknown & Total \\
\hline \multirow[t]{6}{*}{$\begin{array}{l}\text { New York } \\
1977-1978\end{array}$} & right & $38(58 \%)$ & $13(27 \%)$ & 4 & 81 & 136 \\
\hline & left & $5(8 \%)$ & $5(10 \%)$ & 2 & 10 & 22 \\
\hline & up & $6(9 \%)$ & $12(24 \%)$ & 1 & 43 & 62 \\
\hline & down & $7(11 \%)$ & $11(22 \%)$ & 0 & 36 & 54 \\
\hline & other/unk & $10(15 \%)$ & $8(16 \%)$ & 0 & 67 & 85 \\
\hline & Total & 66 & 49 & 7 & 237 & 359 \\
\hline \multirow{6}{*}{$\begin{array}{l}\text { Wisconsin } \\
7 / 1 / 75- \\
1979\end{array}$} & & $44(770)$ & $7(250)$ & 1 & 23 & 75 \\
\hline & left & $4(7 \%)$ & $3(11 \%)$ & 0 & 7 & 14 \\
\hline & up & $6(10 \%)$ & $11(39 \%)$ & 1 & 48 & 66 \\
\hline & down & $4(7 \%)$ & $1(4 \%)$ & 0 & 31 & 36 \\
\hline & other/unk & $3(5 \%)$ & $6(21 \%)$ & 0 & 17 & 26 \\
\hline & Total & 61 & 28 & 2 & 126 & 217 \\
\hline \multirow{6}{*}{$\begin{array}{l}\text { Ohio } \\
7 / 1 / 75- \\
1979\end{array}$} & right & 90 (69\%) & $18(34 \%)$ & 4 & 30 & 142 \\
\hline & left & $8(6 \%)$ & $4(8 \%)$ & 0 & 8 & 20 \\
\hline & up & 14 (11\%) & $15(28 \%)$ & 2 & 77 & 108 \\
\hline & down & $7(5 \%)$ & $14(26 \%)$ & 0 & 34 & 55 \\
\hline & other/unk & $12(9 \%)$ & $2(4 \%)$ & 1 & 15 & 30 \\
\hline & Total & 131 & 53 & 7 & 164 & 355 \\
\hline
\end{tabular}


The results in Table 10 cover all post-period requested reports. Light phase was unknown for many events and a few involved highly atypical situations such as car-hits-car-hits-bicyclist. Unlike pedestrians, most bicyclists originated their collision course from in the roadway as opposed to from the sidewalk. Figure 3 separates the "from roadway" and "from sidewalk" events and deletes unknowns and atypical crashes. All events shown in the Figure involve a vehicle turning right on a red signal during the Western RTOR or post period. The Figure shows, across all three states, that RTOR-right was the major problem for bicyclists as it was for pedestrians. Overall, 75\% of these "known" and "typical" crashes were of the RTOR-right type. In all cases (right, left, up and down) more bicyclists began their collision course from the roadway than from the sidewalk. The $75 \%$ RTOR-right was composed of $47 \%$ from the roadway and $28 \%$ from the sidewalk. It should be noted, however, that this difference came from New York and Ohio. In Wisconsin, only 5 RTOR-right events originated from the roadway while 35 originated from the sidewalk.

Conceptually, the RTOR-right problem for bicyclists is similar to the problem for pedestrians. The motorist is looking left for a gap in traffic and the bicyclist does not believe that the motorist would just pull out against the light. However, there are some important differences. First, the bicyclist is typically moving faster than a pedestrian in the same situation. This is particularly true for a bicyclist coming from the roadway. Second, the bicyclist coming from the roadway is engaged in "wrong way riding" on the left side of the street, illegally against the flow of traffic. The bicyclist, therefore, is coming from an especially "unexpected and unusual" location from the motorist's point of view.

Following the procedure described above for pedestrian accidents, the unknown signal phase bicycle accidents were redistributed to estimate the proportion of RTOR, RTOG and "other" accidents making up all the motor-vehicle-turning-right-at-signal bicycle accidents. For outstate New York, it was estimated that $53 \%$, about 7.9 accidents/month, were RTOR, $42 \%$ were RTOG and nearly 5\% were "other." In Wisconsin, the estimates were $61 \%$ (about 2.4 accidents/month) RTOR, 37\% RTOG and $2 \%$ "other." In Ohio during the post period, it was estimated that $61 \%$ of the motorist-turn-right-at-signal accidents, ( 4.1 accidents/month) were RTOR, $35 \%$ were RTOG and $4 \%$ were "other."

Several analyses were conducted to describe the New York, Wisconsin and Ohio RTOR bicycle events. Table 11 shows the results for some of these analyses. The data presented in this Table cover only events for which the driver was turning right on a red signal and "atypical" events are excluded. The results show that, as with pedestrians, RTOR bicycle events more often involved male motor vehicle drivers. The bicyclist victim was also typically male though the percentage of female bicyclists was higher in this accident than in other bicycle/motor vehicle crashes. Median driver age was between 32 and 38, somewhat higher than with pedestrians. Median bicyclist age was approximately 15 years, somewhat high when compared to all bicycle/motor vehicle accidents. Median bicyclist age in the Cross and Fisher (1977) non-fatal sample of bicyclists involved in motor vehicle crashes was approximately 13.7 years. Approximately half to two-thirds of these RTOR crashes occurred between noon and 6:00 p.m. Injury severity, while difficult 

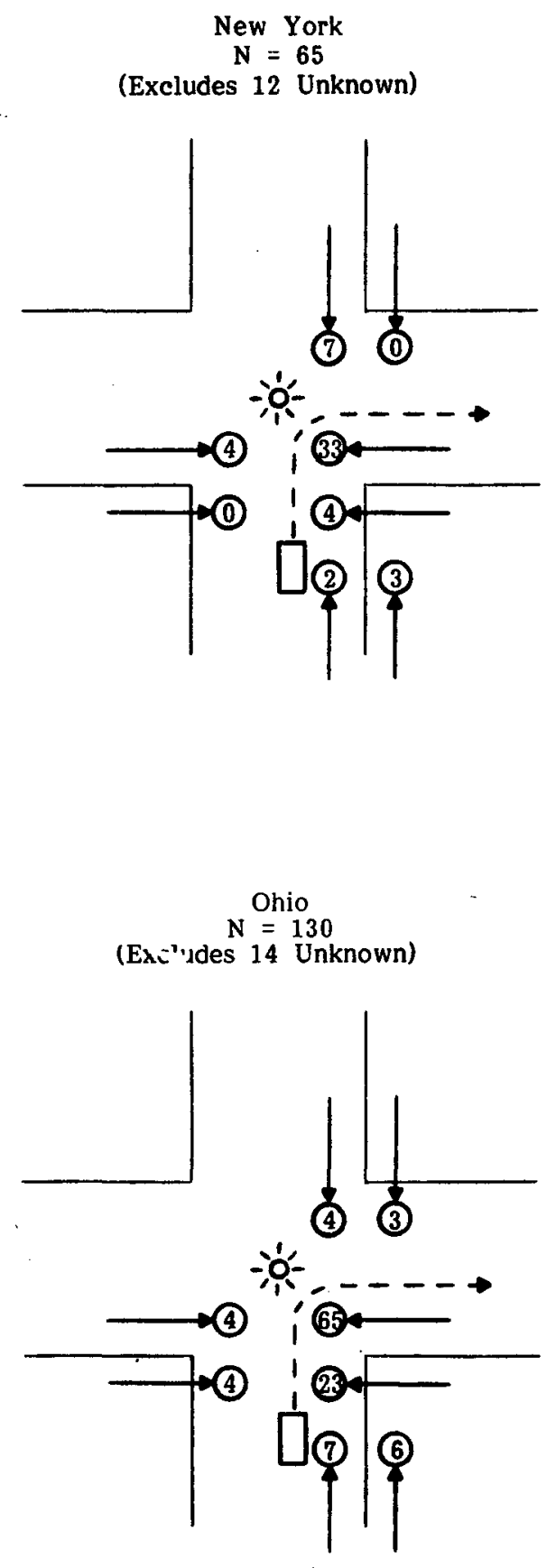
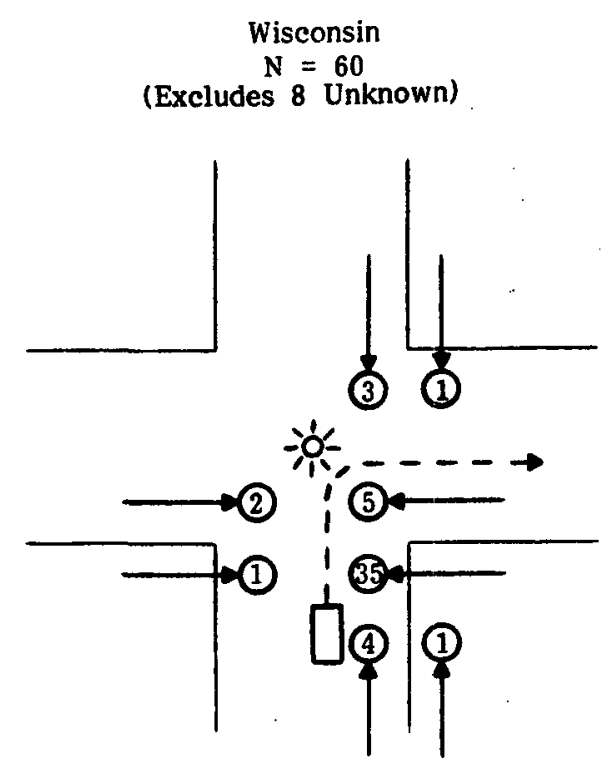

Combined Shown in Percent - $\quad N=221$

(Excludes 34 Unknown)
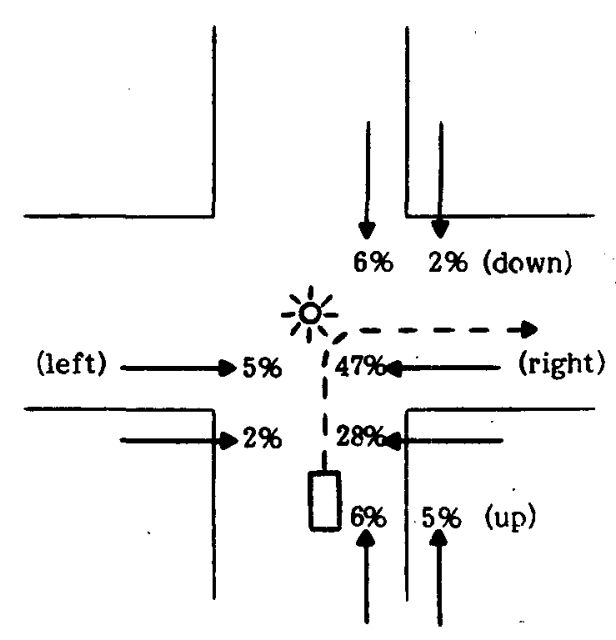

Figure 3. Direction and location for bicycle crashes involving a motor vehicle turning right on a red signal. 
Table 11. Description of Bicycle Accidents in New York, Wisconsin and Ohio Under Western RTOR, Motor Vehicles Turning Right on Red Signal.

\begin{tabular}{|c|c|c|c|c|c|c|}
\hline Driver Sex & \multicolumn{2}{|c|}{$\frac{\text { New York }}{(1977-78)}$} & \multicolumn{2}{|c|}{$\frac{\text { Wisconsin }}{(1975-79)}$} & \multicolumn{2}{|c|}{$\frac{\text { Ohio }}{(1975-79)}$} \\
\hline Male & 40 & $(62 \%)$ & 36 & $(60 \%)$ & 59 & $(45 \%)$ \\
\hline Female & 23 & $(35 \%)$ & 19 & $(32 \%)$ & 42 & $(32 \%)$ \\
\hline $\begin{array}{l}\text { Unknown } \\
(+ \text { Hit and Run })\end{array}$ & 2 & $(3 \%)$ & 5 & $(8 \%)$ & 29 & $(22 \%)$ \\
\hline \multicolumn{7}{|l|}{ Bicyclist Sex } \\
\hline Male & 46 & $(71 \%)$ & 35 & $(58 \%)$ & 67 & $(52 \%)$ \\
\hline Female & 19 & $(19 \%)$ & 24 & $(24 \%)$ & 42 & $(32 \%)$ \\
\hline Unknown & 0 & $(0 \%)$ & 1 & $(2 \%)$ & 21. & $(16 \%)$ \\
\hline \multicolumn{7}{|l|}{ Vehicle Type } \\
\hline Car & 61 & $(94 \%)$ & 53 & $(88 \%)$ & 109 & $(84 \%)$ \\
\hline Other & 2 & $(3 \%)$ & 5 & $(8 \%)$ & 18 & $(14 \%)$ \\
\hline Unknown & 2 & $(3 \%)$ & 2 & $(3 \%)$ & 3 & $(2 \%)$ \\
\hline Median Driver Age $=$ & \multicolumn{2}{|c|}{35.2 yrs. } & \multicolumn{2}{|c|}{37.7 yrs. } & \multicolumn{2}{|c|}{32.3 yrs. } \\
\hline Median Bicyclist Age $=$ & \multicolumn{2}{|c|}{15.9 yrs. } & \multicolumn{2}{|c|}{14.4 vrs. } & \multicolumn{2}{|c|}{14.2 yrs. } \\
\hline
\end{tabular}


to compare across several state injury severity coding schemes, was low to moderate. None of the studied RTOR bicycle events resulted in a fatality. In New York, all were listed as "injury." In Wisconsin, 10\% were "serious" injury, 40\% "visible," $40 \%$ "claimed" and 10\% none. In Ohio, 36\% were "visible injury," 35\% "claimed injury," $19 \%$ "no injury" and $10 \%$ not stated.

In summary, police accident reports for vehicles turning right at signalized locations under the Western RTOR rule and striking pedestrians or bicyclists were accessed and read. Often, the reports did not supply sufficient information to determine the actual light phase just prior to the crash. However, where the light phase could be determined, it was red by a ratio of about two to one. As with pedestrians, the red signal phase was most often associated with RTOR-right. In New York and Ohio, these RTOR-right events more often involved wrong-way riding bicyclists entering the intersection from the roadway as opposed to from the sidewalk. On the green signal phase, the accident geometry was most often "up" or "down" followed by "right." Further analysis of the red situation showed that it typically involved a male driver about 35 years old striking a male bicyclist about 15 years old during the afternoon and resulted in low injury severities. In general, the bicycle accident situation is quite similar to the pedestrian situation discussed above. Drivers, about to turn right on a red signal, are looking left for a gap in traffic and never see the bicyclist coming from their right. Bicyclists, usually riding the wrong way, facing traffic, are traveling through the intersection on a green signal and don't expect cross street traffic to pull into the intersection for a right turn. The result is a low speed bicycle/motor vehicle crash. 


\section{DISCUSSION}

Prior to the mid 1970's, only a few states had RTOR in its Western or permissive version. From about 1974 to 1977, many more states joined those with Western RTOR such that by 1980 the maneuver was permitted everywhere in the United States except in New York City or where specifically prohibited by a traffic control device. The first question addressed by this study was whether or not this change to Western RTOR was associated with a change in the number of pedestrian and bicyclist accidents. The answer was clearly yes. Four pedestrian and three bicycle accident data bases all showed statistically significant increases in the number of crashes involving a right turning vehicle at a signalized location. These increases, ranging from $43 \%$ to over $100 \%$, could be directly attributed to the adoption of Western RTOR.

The amount of these increases in crashes involving a right turning motor vehicle at signalized locations was calculated in three different ways. First, the percentage of all crashes involving a right turning vehicle at a signalized location was calculated for each data base both before and after Western RTOR (see Table 1). These percentages during the pre period for both pedestrians and bicyclists ranged from about $1 \%$ to $2 \%$ of all crashes. In the post period, the proportions ranged from about $1.5 \frac{\circ}{\circ}$ to $4 \%$. The percentage increases in these proportions, pre to post, were 45\%, 66\%, 86\% and $96 \%$ for pedestrians in New York, Ohio, Wisconsin and New Orleans, respectively. For bicyclists, the percentage increases were $85 \%, 90 \%$ and $123 \%$ in Wisconsin, New York and Ohio, respectively.

The second method used to calculate the magnitude of these increases was simply to compare the number of these crashes per month (with seasonal variation extracted) both before and after Western RTOR (see Tables 2-4). The percentage increases in the monthly averages using this method were 43\%, $57 \%, 82 \%$ and $107 \%$ for pedestrians in New York, Ohio, New Orleans and Wisconsin, respectively. For bicyclists, the percentage increases were $72 \%$, $80 \%$ and $82 \%$ in Wisconsin, Ohio and New York, respectively.

A third method used to examine the amount of these increases was to represent them as increases in the absolute numbers of crashes per month (see Tables 2-4). Obviously, using this method, large data bases such as New York and Ohio should show large increases and small data bases (e.g., New Orleans) should show small increases almost regardless of the percentages shown above. Nevertheless, these absolute increases were $0.88,3.61,4.08$ and 4.94 for pedestrian accidents per month in New Orleans, Wisconsin, New York and Ohio. Together, these increases total 13.51 accidents per month or 162.12 accidents per year across these four jurisdictions with a population base of about 26 million. For bicyclists, these absolute monthly increases were $1.68,2.99$ and 6.72 for Wisconsin, Ohio and New York, respectively. Together, these increases total 11.39 accidents per month or 136.68 accidents per year across the three jurisdictions with a population base of about 25 million.

The present study was also designed to examine the characteristics of pedestrian and bicycle crashes at signalized locations involving a right turning motor vehicle. In particular, it was of interest to estimate the number of right turn crashes under the Western RTOR law which were right turn on red 
as compared with right turn on green. The results for pedestrian accidents suggested that approximately $60 \%-65 \%$ were on red, approximately $35 \%$ on green and the remainder involved other signal indications such as turn arrows and traffic officers. The results for bicycle accidents suggested that approximately $55 \%-60 \%$ were on red, nearly $40 \%$ were on green and the remainder were other signal indications. It was also estimated that $1.12 \%$, $1.60 \%, 2.26 \%$ and $2.71 \%$ of all pedestrian accidents in New York, Ohio, Wisconsin and Los Angeles, respectively and 1.39\%, 1.50\% and $1.70 \%$ of all bicycle accidents in Ohio, Wisconsin and New York, respectively involved a vehicle turning right on a red signal.

\section{A. Design Considerations}

It should be noted that this study focused primarily on right turns at signalized locations while other authors have chosen to examine all signalized intersection activity. Right turns are obviously the most proximate measure since it is the right turn maneuver which is directly affected by the law. All intersection activity is a much more global measure; it is affected by many factors, and right turns are only one of its components. Nevertheless, it was possible that Western RTOR produced some changes in pedestrian and bicycle accidents not involving right turning motor vehicles. In fact, signalized locations are complex and interactive and permitting one maneuver could influence drivers engaged in some other maneuver. For this reason, signalized location data in the current study were analyzed in several different ways looking for other pedestrian and bicycle accident changes that might have been associated with the implementation of Western RTOR. As discussed in Chapter III, Section B, no systematic changes were found. Thus, it would appear that focusing only on right turns as a primary measure did provide a sensitive estimate of the impact of Western RTOR for pedestrians and bicyclists.

It should also be noted that the availability of the RTOR maneuver may have prompted some drivers to alter their route selection such that they are now making more right turns at signalized locations than they made prior to Western RTOR. In other words, increases in the absolute number of right turns at signalized locations could have contributed to the observed accident increases. However, it is not likely that changes in route selection influenced the findings to any significant degree. First, it seems unrealistic to suggest driver route planning changes that could occur within days of Western RTOR implementation and lead to $50 \%-100 \%$ increases in right turns at signalized locations. Such changes would have to have been that large and that rapid to account for the observed changes in the accident data. Second, even if such driver route changes had occurred and were accounting for the reported RTOR effects, they should have affected all road users equally, but they apparently did not. Zador et al. (1980) reported vehicle (only) crashes to have increased by only $20 \%$ and the AASHTO (1979) estimate for vehicles was only $37 \%$.

Estimates of accident increases for pedestrians and bicyclists range from 43\% to $123 \%$ from the current study and 57\% from Zador for pedestrians. Thus, pedestrians and bicyclists seem to have been unusually affected. Nevertheless, there remains the possibility that some of the observed increases could be accounted for by driver route selection changes. However in the absence of pre/post on-street observational (exposure) data to measure the actual rates of right turns at signalized locations, it is impossible to estimate 
the influence of this factor. Further, even if some route changes did occur, their effect may simply have been to increase pedestrian and bicycle RTOR accidents and need not necessarily have been associated with accident decreases for some other type of accident.

\section{B. Time Series}

One truly surprising finding in the current study was that the accident increases found were both immediate and continuing. It was as if the number of right turning accidents jumped up to some new level, $50 \frac{0}{0}-100 \frac{0}{5}$ higher than the old level, as soon as Western RTOR became effective and stayed there throughout the data collection period. Specifically, the best-fitting time series models tended to be simple step functions in which accident frequency steps up to some new level immediately following Western RTOR adoption. This was quite contrary to traditional expectations which predicted some implementation period as drivers began using the maneuver; followed by a learning period as drivers, pedestrians and bicyclists became familiar with it; followed by some steady or continuing level of performance. While all of these stages may have occurred, they must have happened very quickly since the accident data showed an immediate increase which remained relatively constant thereafter. The one exception to this result was for pedestrian accidents in New York which rose only slightly in the first year followed by a sharp rise in the second year after Western RTOR implementation. Also, the Los Angeles data provide further evidence that RTOR accidents continue with considerable frequency well beyond the two, three and four year periods after RTOR adoption covered in this study.

\section{Nature of the Problem}

The secondary objective of this study was to describe pedestrian and bicycle RTOR accident events. Descriptive information was of value regardless of whether the absolute number of crashes had increased, decreased or remained the same. In particular, there was interest in identifying any new pedestrian or bicycle accident types or situations associated with the RTOR maneuver. The results clearly showed that "RTOR-right" (vehicle starting turn with victim crossing from right-to-left in front of it) is such a special accident situation with specific inherent dangers for both pedestrians and bicyclists. Drivers, looking left for a gap in traffic simply do not see pedestrians and bicyclists coming from their right. Pedestrians, in particular, are lulled into a false sense of security when they see the stopped vehicle and begin their crossing with a green light and, perhaps, a "Walk" signal. Pedestrians apparently do not realize that the driver is looking left and could move forward at any moment.

The RTOR-right situation can arise at any signalized intersection, urban or rural. It typically occurs on weekday afternoons and typically produces a low injury severity event. No single pedestrian age group predominates. The pedestrian is female in a small majority of cases. The bicyclist is typically a teenaged male. Drivers, as in most pedestrian and bicycle accidents, are typically male with a median age of about 30 to 35 years.

While the present results add a great deal of specificity to the description of RTOR events, it should be noted that RTOR accidents had also been identified by previous researchers. For pedestrians, Snyder and Knoblauch 
(1971) identified "Right Turn Attention Conflict Reduction" as a possible countermeasure area. They specifically suggested "removal of right turn on red," "pedestrian barrier if right turn on red needed" and "pedestrian--only signal phase." For bicyclists, Cross and Fisher (1977) identified a specific bicycle accident--"Problem Type 10, Motorist Turn-Merge: Intersection Controlled by Signal." Cross and Fisher stated that: "In all cases of this type, the motorist came to a complete stop at a signalized intersection, searched for traffic approaching from the left in the near traffic lanes, and proceeded to make a right-turn-on-red." These Type 10 accidents were divided $85 \%$ RTOR-right and 15\% RTOR-left. Also, Cross and Fisher interview data showed that: "In 86\% of the cases, the bicyclist observed the motor vehicle, but proceeded through the intersection with the faulty assumption that he had been or would be detected by the motorist."

\section{Countermeasures}

The focus of this study was not countermeasure development. Nevertheless, the present results do suggest certain areas where countermeasures should be considered. One possibility, of course, would be to repeal the RTOR statutes. However, this is not likely now that Western RTOR is in place in all 50 states.and drivers have become accustomed to it. Further, pedestrians and bicyclists are only one part of the overall situation. Any repeal effort must also consider fuel savings, possible air pollution benefits, reduced travel delay as well as single and multiple vehicle crashes. Also, it may be possible to solve much of the pedestrian and bicycle RTOR safety problem through countermeasures short of outright repeal. Further analysis and development of potential countermeasures in the following four areas appears beneficial:

Bicyclist Education - The RTOR bicycle problem begins with wrong-way riding. Many bicyclists do not understand the problems in wrong-way riding and the need to ride on the right side of the roadway. Right side riding could be fostered through public education, in-school training and/or enforcement of existing rules of the road. Public education messages, training materials (a fourth grade curriculum and guidance to parents and police) and a model regulation to combat wrong-way riding have already been designed under another NHTSA contract (DOT-HS-7-01726, Blomberg et al., in process). Therefore, this countermeasure area can be explored expeditiously by completing the development of these countermeasures, testing them and, if successful, promulgating them.

Pedestrian Education - The pedestrian, about to enter a RTOR-right situation, is often provided with a variety of cues. The vehicle may be oriented towards a right turn, the vehicle's right directional signal may be flashing or the driver may be looking left. Pedestrians can possibly be taught to look for these cues and, if any are present, the pedestrian can possibly be convinced to delay crossing until the next green light, wait until the vehicle is gone, establish eye contact with the driver, or cross behind the vehicle which could potentially turn right (even though this might mean leaving a crosswalk).

Warrants - Western RTOR specifically provides for sign prohibitions on
certain intersection
approaches.
Existing warrant recommendations 
suggest that these signs should be used in locations which have significant pedestrian traffic. It is suggested that these warrants be further researched so as to identify target locations more specifically in terms of relevant parameters and to include bicycle traffic.

Traffic Engineering - RTOR could be modified through traffic engineering approaches to provide a compromise between the mobility, etc., benefits and the engendered pedestrian and bicycle safety problems. One such approach would be to utilize a signal phase during which pedestrians would have exclusive use of the intersection. Vehicular movements would be governed by a red signal in all directions and an illuminated RTOR prohibition. Thus, during normal vehicular movements under a green signal on one leg of the intersection, say north/south, RTOR would be permitted on the other, e.g., east/west, and all pedestrian movements would be prohibited by "Don't Walk" signs. While pedestrians were permitted to cross, no vehicular movements, including RTOR, would be allowed.

Another engineering approach would be to provide a RTOR "box" at intersections. Under this scheme, the pedestrian crosswalk would be set back about 25 feet from the intersection to allow sufficient space for the right turning vehicle to stop after clearing the crosswalk. Since pedestrians would be crossing behind the turning vehicle, they would be protected from it. Moreover, drivers traversing the crosswalk to get to the "box" would only have to search forward and slightly to each side for vehicular, pedestrian and bicycle threats. Thus, there would be a greater likelihood of detecting a threat than in the current RTOR situation in which the driver is focusing the majority of his attention to the left to find a gap in traffic.

These approaches and others with an engineering orientation are currently only at the idea stage but appear worthy of further exploration.

Theoretically, there is a fifth countermeasure area concerning drivers. Drivers could be informed of the RTOR-right problem and/or of the requirement that they proceed only when it is safe. Unfortunately, there is evidence (Blomberg et al., in process) that the driver's task in this situation is already overly demanding, and it is likely that admonitions for additional searching will not have any effect. While driver education could be tried, the expected benefits from this approach do not appear as great as from bicyclist and pedestrian education. Simply, education alone cannot remove an overload, although it might teach a driver about the hazards of the RTOR situations. However; the complete or even significant avoidance of right turns on red is not viewed as a reasonable educational objective. Therefore, only minimal benefit could be expected from any attempt to modify driver behavior in the RTOR situation.

\section{E. Conclusions}

The results of this study clearly show that Western RTOR has produced a significant problem for pedestrians and bicyclists. While the associated accidents result in few fatalities and generally low injury severities, they may constitute between $1 \frac{\circ}{\circ}$ and $3 \frac{\%}{\circ}$ of a state or city's total pedestrian or bicyclist 
accidents. Repeal of Western RTOR is not likely, nor should it be undertaken without also considering the full range of RTOR effects including accidents involving vehicles (only), fuel savings, delay savings, etc. Nevertheless, in the absence of repeal, the pedestrian and bicycle problem should be considered in any future RTOR deliberations, and it appears beneficial to undertake the development of specific pedestrian and bicycle RTOR accident countermeasures. The opportunity for the identification of successful countermeasures is enhanced by the relative commonality of precipitating and predisposing factors in RTOR pedestrian and bicyclist accidents. The vast majority of the crashes can be categorized as RTOR-right, a situation in which the victim, coming from the driver's right, is never detected because the driver is looking to his left for a gap in traffic. Initial countermeasure efforts appear best directed at this predominant sub-type and, for reasons cited above, should likely concentrate on bicyclist and pedestrian education as well as altering traffic engineering parameters. 


\section{APPENDIX A}

The following is a list of the Eastern states showing the effective date of their RTOR law and the status of RTOR prior to the Western rule:

Western RTOR

Effective Date
Prior Status of RTOR $\underline{\text { State }}$

New England

Maine

New Hampshire

Vermont

Massachusetts

Connecticut

Rhode Island

$\underline{\text { Mid-Atlantic }}$

New York (not NY City)

New Jersey

Pennsylvania

South Atlantic

Delaware

Maryland

Virginia

West Virginia

North Carolina

South Carolina

Georgia
$05 / 01 / 78$

$11 / 01 / 75$

$07 / 01 / 77$

$01 / 01 / 80$

$07 / 01 / 79$

$07 / 01 / 76$

$01 / 01 / 77$

$01 / 06 / 77$

$07 / 01 / 77$

$05 / 05 / 76$

$07 / 01 / 78$

$01 / 01 / 77$

$05 / 24 / 75$

$07 / 01 / 74$

$05 / 16 / 77$

$07 / 01 / 75$
Eastern rule

Eastern rule

Eastern rule

Prohibited

Eastern rule

No RTOR law

Eastern rule No RTOR law No RTOR law

Eastern rule Eastern rule Eastern rule No RTOR law No RTOR law Eastern rule Eastern and Western depending on county population

South Central
$08 / 18 / 76$

$07 / 01 / 76$

$03 / 23 / 76$

$06 / 22 / 74$

$10 / 01 / 76$

North Central

Ohio

$07 / 01 / 75$

$07 / 01 / 74$

$01 / 01 / 74$

$08 / 13 / 74$

$07 / 01 / 74$

1972

$07 / 01 / 75$

$03 / 01 / 76$
No RTOR law Eastern rule Eastern rule No "signal" defined Eastern rule 


\section{APPENDIX B}

\section{Accident Series Analyses}

Summarized in this Appendix are the monthly accident series relevant to the impact of the Western-style Right Turn on Red law. There are described eight pedestrian and eight bicycle accident series from New York State, one pedestrian and one bicycle accident series from Ohio and Wisconsin and one pedestrian series from the City of New Orleans.

Each series is presented in full and brief summaries of two types of analyses are also given.

Analysis of Variance (ANOVA). Each accident series forms a rectangular year by month matrix. This was analyzed by a standard two-way ANOVA procedure. Because the data were collected according to a time sequence, it is unlikely that all the assumptions of data independence which ANOVA requires are met. However, the main effect and interaction terms of the ANOVA are useful descriptors of the data and provide guidelines for the interpretation of subsequent analyses. Specifically:

- The year $x$ month interaction mean square is a rough estimate of the residual squared standard error in a good-fitting time series model because the interaction term is an estimate of the variability in the monthly accident data after the year and month main effects are subtracted.

- The month main effect F-ration and its attendant significance level provide a measure of the strength of the seasonal cycles in the data-the tendency for accident rates to be consistently high or low during particular months or seasons of the year. A large month effect here means that an adequate time series model is likely to have to make major seasonal adjustments.

- The year main effect F-ration and significance level are preliminary estimates of whether Western RTOR has had an effect on accident rates. Although this test is general and not precisely aligned with the presence or absence of the intervention, a high F-ration points to significant variation which may be correlated with the introduction of Western RTOR. Conversely, an F-ratio near or below 1.0 is an indication that it is highly unlikely that Western RTOR has had any impact.

Both main effect interpretations suffer when the meaningful Western RTOR on/off periods do not precisely align with year boundaries.

Box-Jenkins time series analysis. Several kinds of models were fit to each accident time series. The adequacy of a time series model to fit its data is measured by two primary statistics: The residual standard error, a measure of the differences between the actual data and the data points predicted by the model; and the degree to which those differences, or residuals, have no timedependent patterns. The residual standard error is shown as SE residual in the time series table. The time-independence of the residuals is labeled " $Q$ " in the table; it is essentially a $x^{2}$ measure of the first 25 or so lag correlations of 
the residual series. To evaluate the $Q$ statistics, their degrees of freedom are shown along with the probability that the lag correlations could form a residual series without systematic time-dependent fluctuations.

In general, for better time series models, SE residual values should be low and $Q$ values should be equal to or less than their degrees of freedom.

For each series, up to five types of "models" are summarized. The first two are simply initial descriptions of the accident data to aid the development of precise models. They are:

- None-i.e., the original data series.

- (1-B $\left.\mathrm{B}^{12}\right)$--i.e., the series formed by annual differencing-subtracting from each datum the datum for the same month in the preceding year (if known). This series is 12 data shorter than the original series.

The models themselves were developed under an iterative procedure by which initial models were hypothesized and tested, and as necessary parameters were added or subtracted and the amended models were tested until the final versions were satisfactory. For each series, a model was developed which directly tested the hypothesis that Western RTOR produced an immediate and stable change ("increase") in monthly accident rates. The general form of this kind of model was:

$$
Y_{t}=x X_{t}+N_{t}
$$

where

$$
\begin{aligned}
\mathrm{Y}_{\mathrm{t}}= & \text { original data series values, accident frequencies by month } \\
\mathrm{X}_{\mathrm{t}}= & \text { a dummy transfer series representing RTOR (values of } \mathrm{X}_{\mathrm{t}} \text { were } \\
& \text { all } 0 \text { before Western RTOR and } 1 \text { after its introduction) } \\
\mathrm{x}= & \text { the parameter to be determined by the analysis representing the } \\
& \text { empirical change in monthly accident frequencies } \\
\mathrm{N}_{\mathrm{t}}= & \text { the ARIMA estimate of the accident frequencies }
\end{aligned}
$$

The $\mathrm{N}_{\mathrm{t}}$ ("noise") estimate may include autoregressive, integration and/or moving average components. With monthly accident data, a likely form for the ARIMA portion of $\mathrm{N}_{\mathrm{t}}$ is:

$$
\frac{\left(1-\theta_{\left.12^{B^{12}}\right)}\right.}{\left(1-\mathrm{B}^{12}\right)} \mathrm{a}_{\mathrm{t}}
$$

where

$B=$ the "backshift operator" (e.g., $\left.B\left(a_{t}\right)=a_{t-1}, B^{2}\left(Y_{t}\right)=Y_{t-2}\right)$

$a_{t}=$ the residual; i.e., the actual accident frequency minus the value projected for time period $\underline{t}$ based on the equation and the frequencies 
for time periods 1 to $\underline{t}-1$.

Because the actual data frequently failed to line up to the ideal cyclic pattern, the actual noise models often contained more or fewer parameters than the ideal.

Often, this was the only intervention model needed to describe an accident series. In cases where it was not, it is labelled "Hypothesis Model" in the remainder of the appendix. When this model did not adequately reflect the actual pattern of accident frequencies, a second "Descriptive Model" was also provided. In the descriptive model, emphasis was placed on selecting the model form and parameters which most completely fit the observed data pattern, whether or not the result was directly relevant to the RTOR test. These descriptive models are of only indirect interest in the task of assessing Western RTOR.

In New York, where three full years of baseline data existed, separate models were developed for the pre-RTOR years of 1974-1976. These models were then used to forecast accident frequencies for 1977 and 1978, and the forecasts were compared with the actual accident frequencies. In all cases, the differences between actual and forecast accident figures confirmed both the statistical significance and the magnitude of RTOR accident effects determined from the anova and the intervention analyses. The pre-RTOR models are listed for the New York accident series.

All Box-Jenkins time series analyses reported below were done using computer programs developed by Dr. David J. Pack. For all analyses, "backforecasting" was used-a procedure which estimates data prior to the actual data series for smoother and more effective parameter value fitting.

For further information on time series analysis, see for example Box and Jenkins, 1976, or McCleary and Hay, 1980. 
Pedestrians in New York State (Not New York City),

Signalized Locations with Vehicle Turning Right.

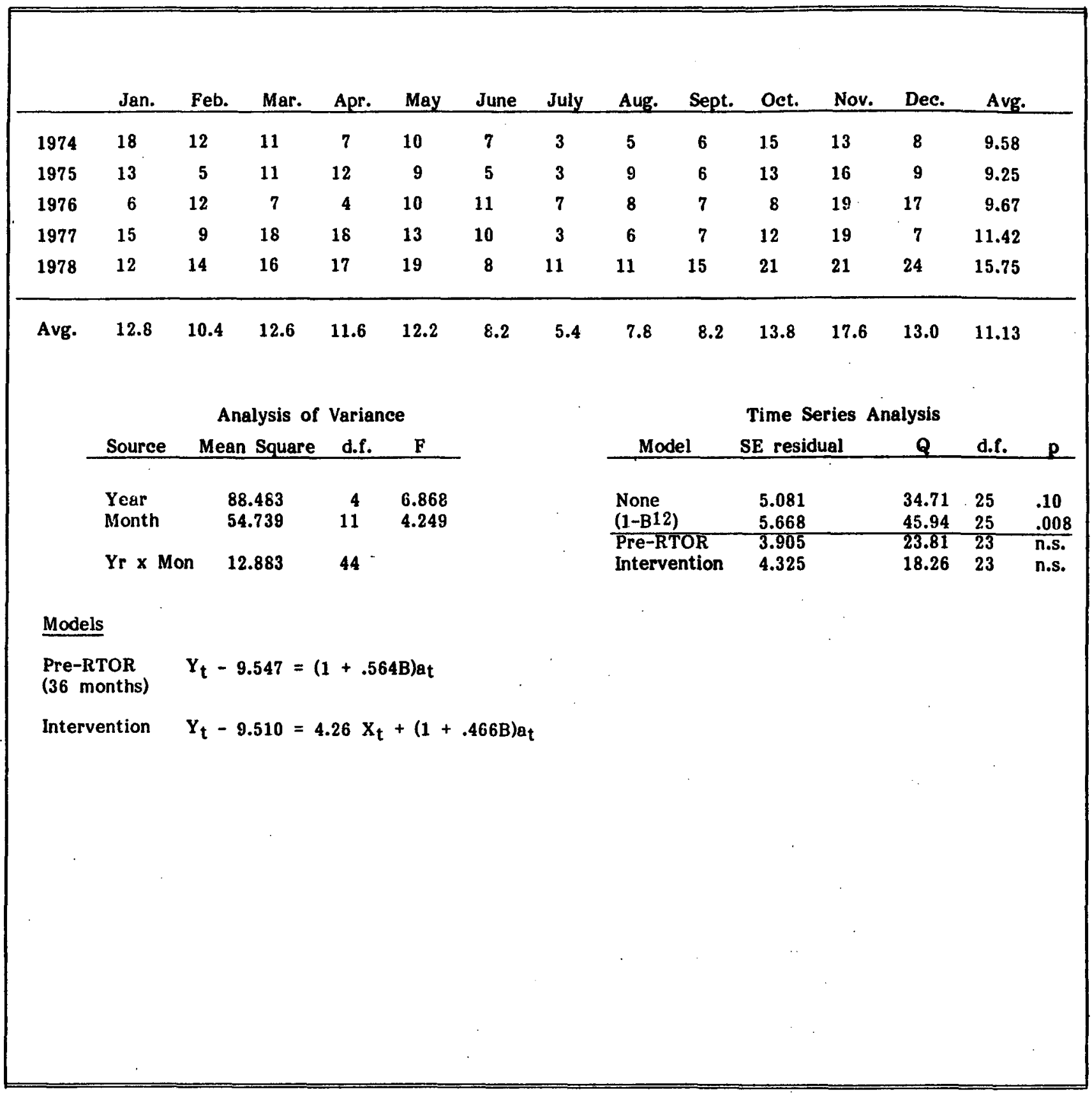


Pedestrians in Suburbs of New York City,

Signalized Location with Vehicle Turning Right.

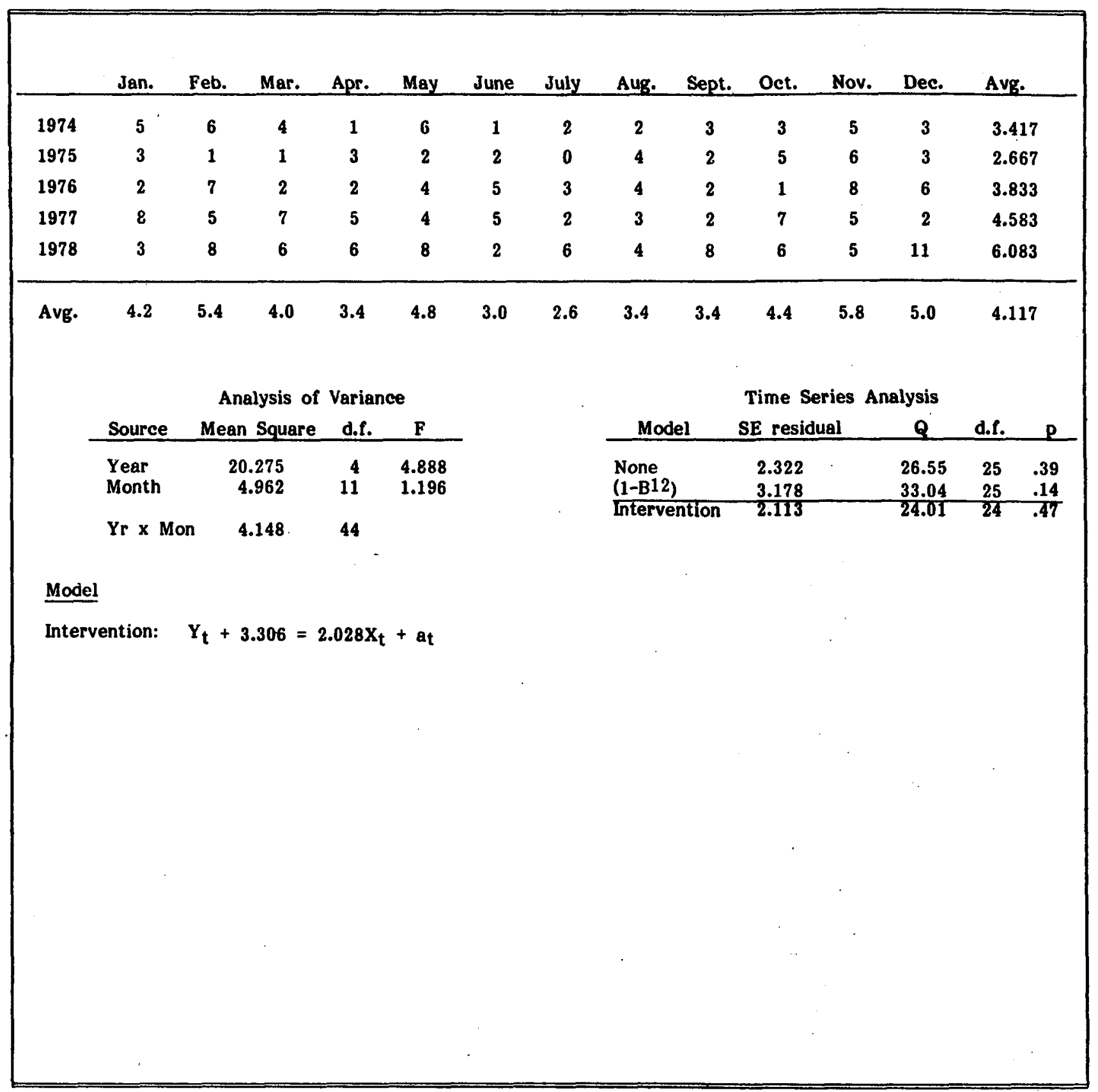


Pedestrians in New York Upstate Urban,

Signalized Location with Vehicle Turning Right.

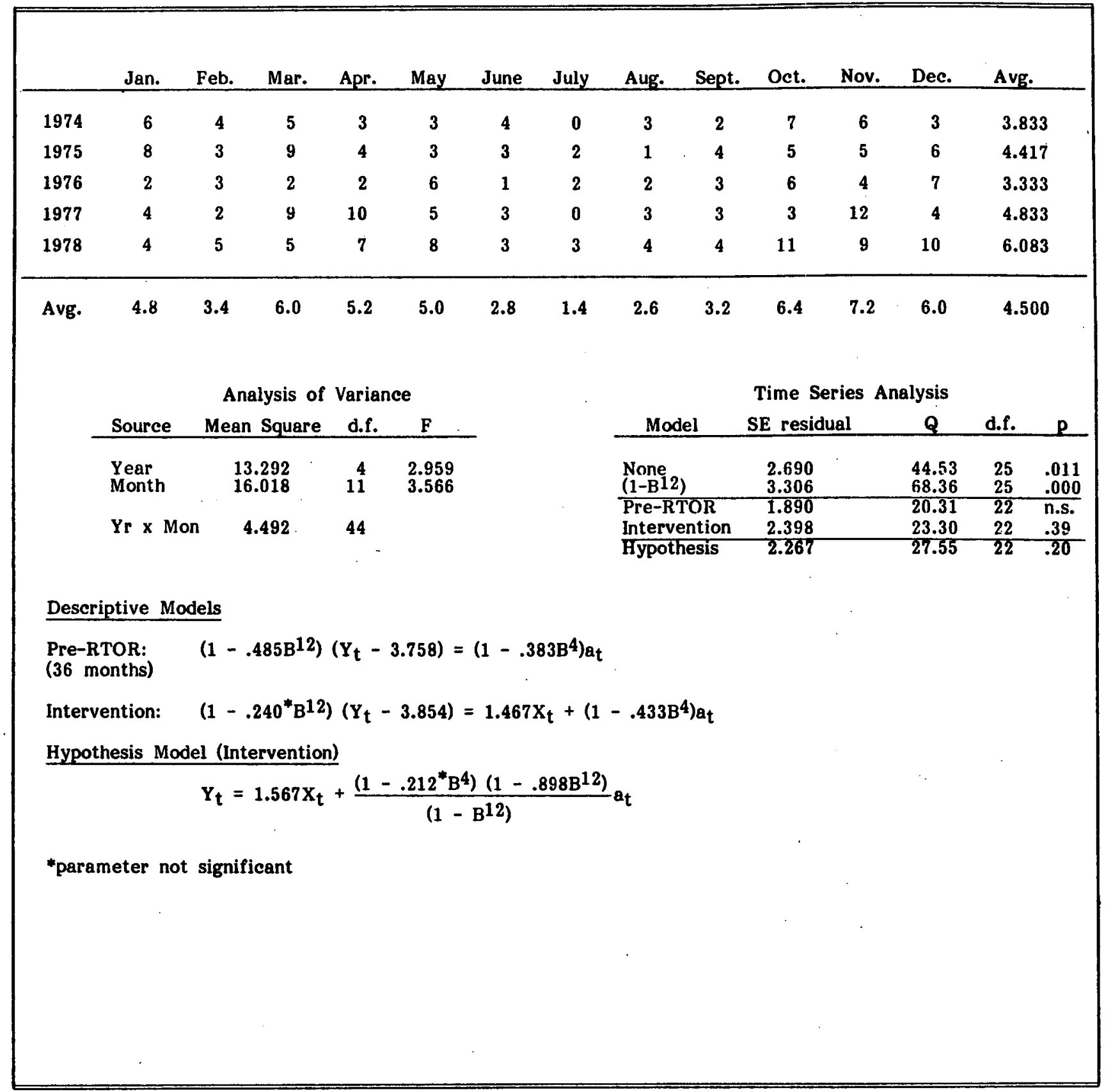




\section{Pedestrians in New York Upstate Other,}

Signalized Location with Vehicle Turning Right.

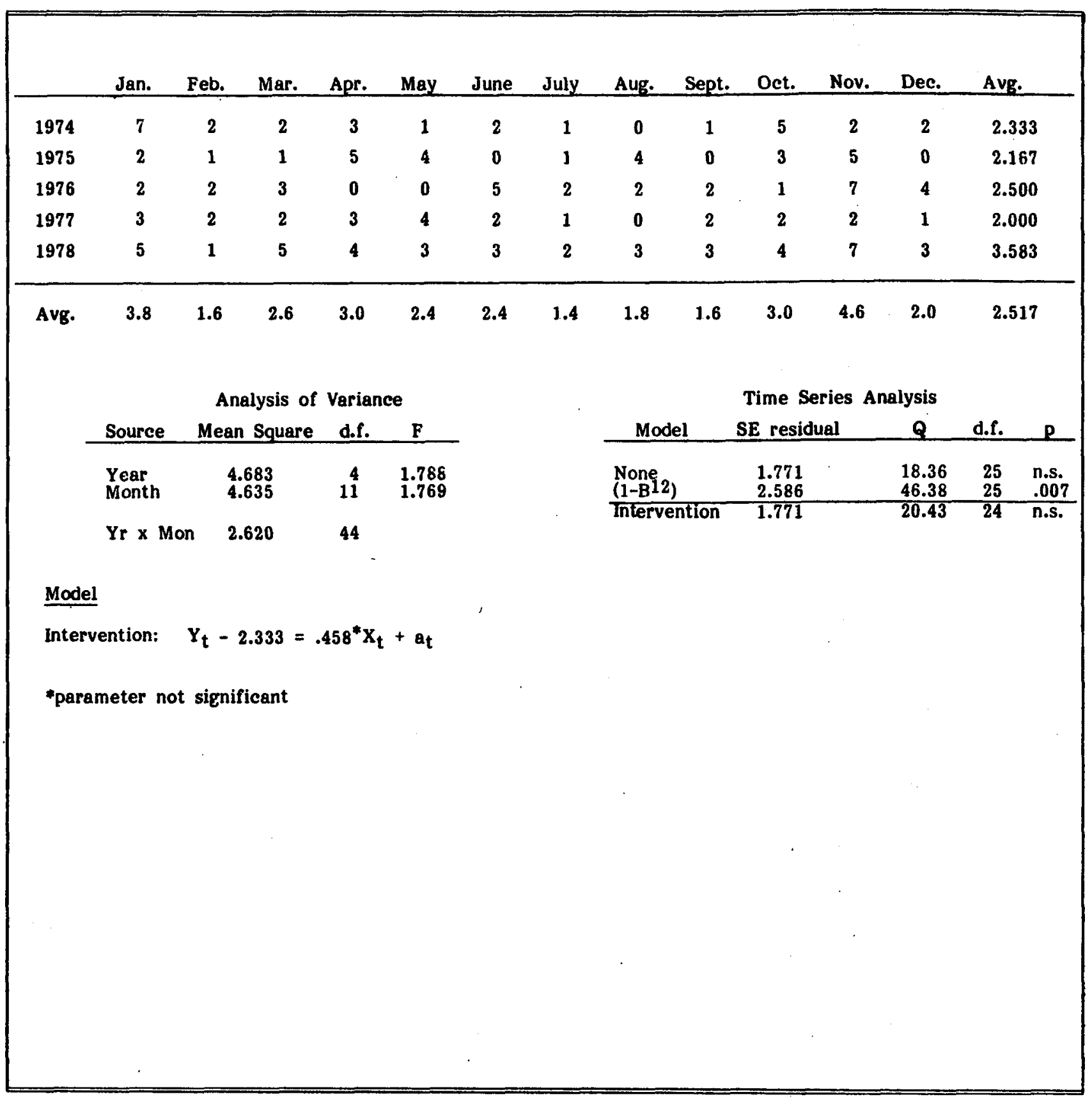




\section{Pedestrians in New York State (not New York City), Signalized Location with Vehicle Turning Left.}

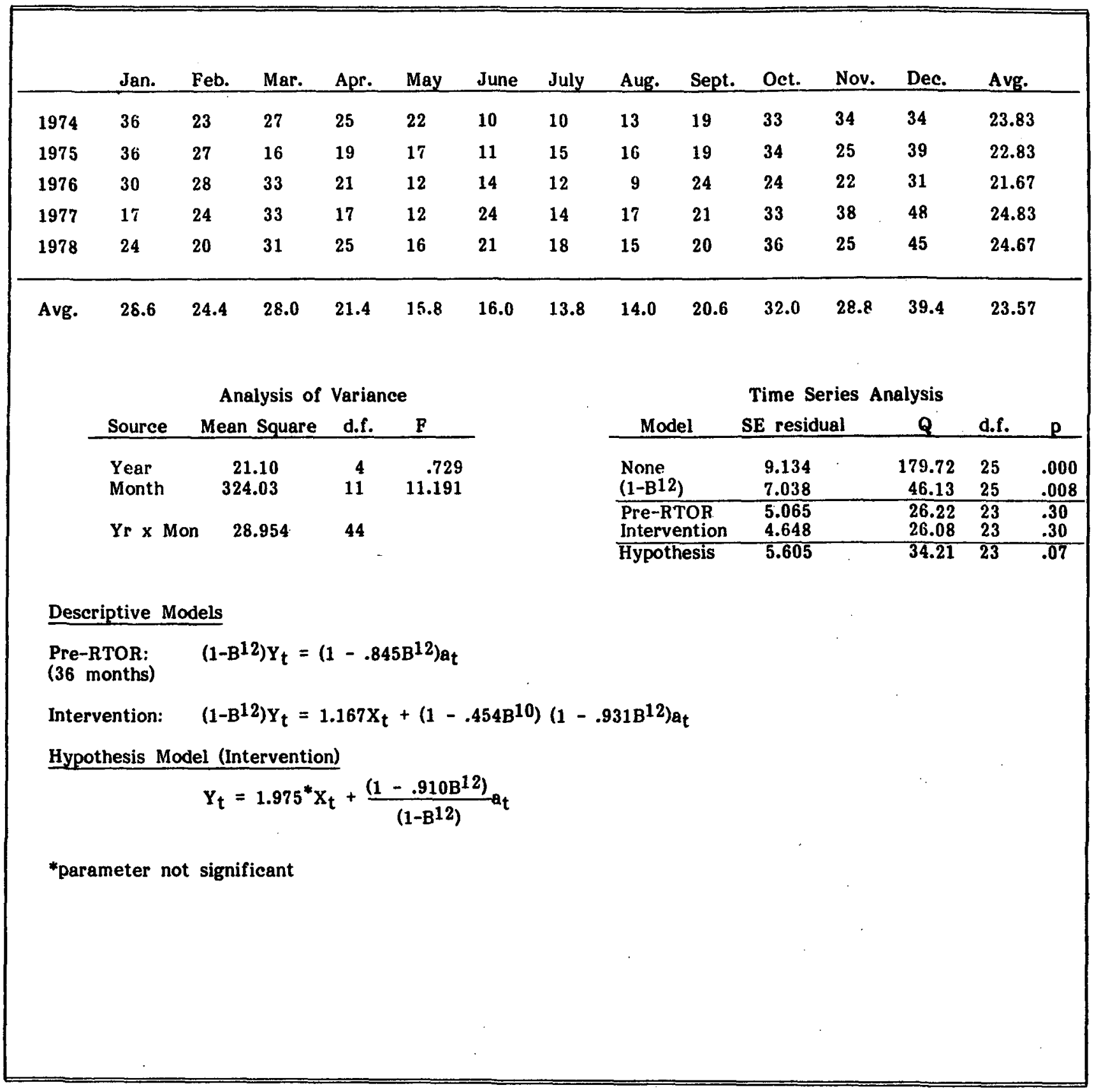


Pedestrians in New York State (not New York City),

Signalized Location with Other Vehicle Actions.

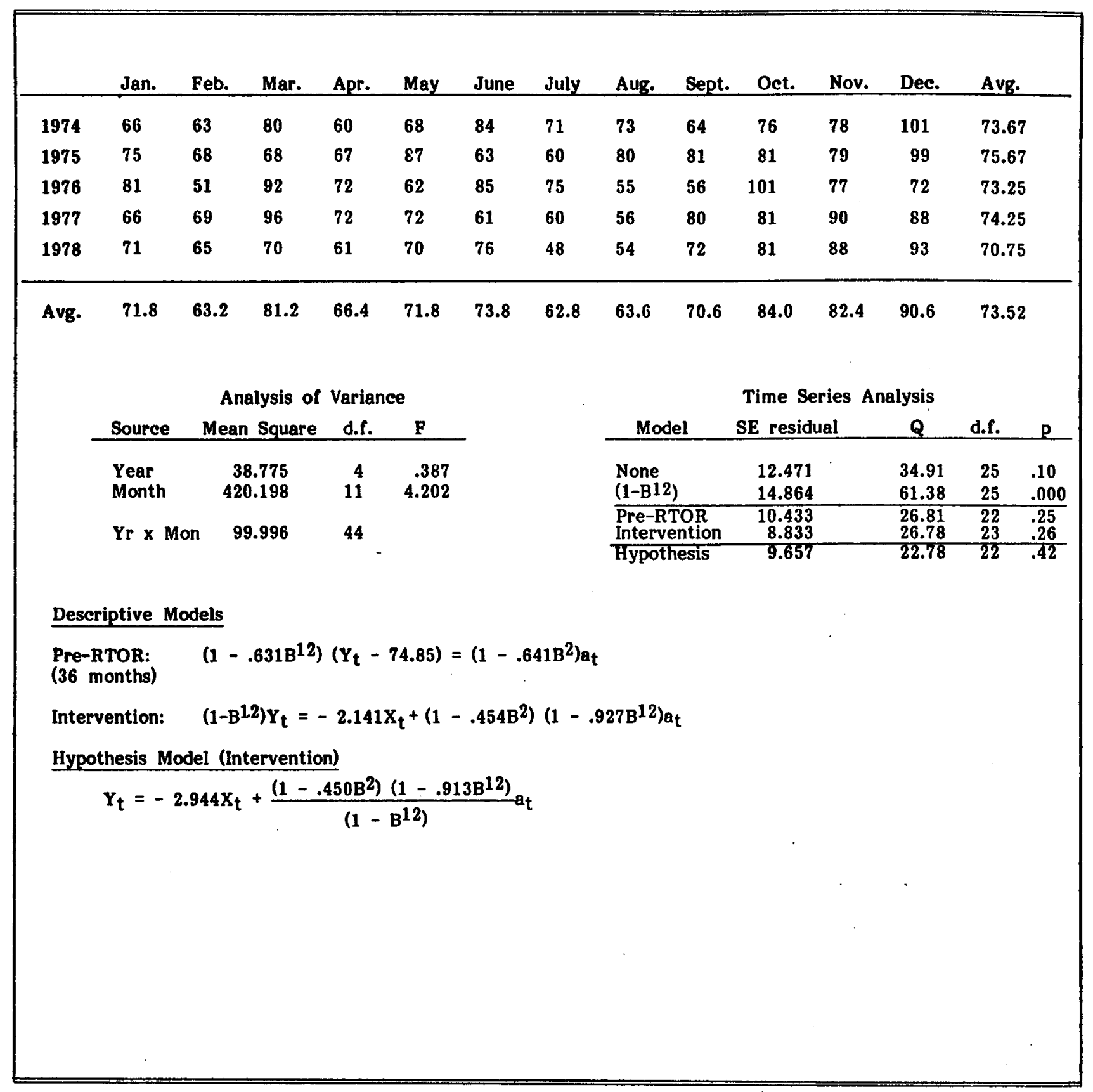




\section{Pedestrians in New York State (not New York City), Unsignalized Locations.}

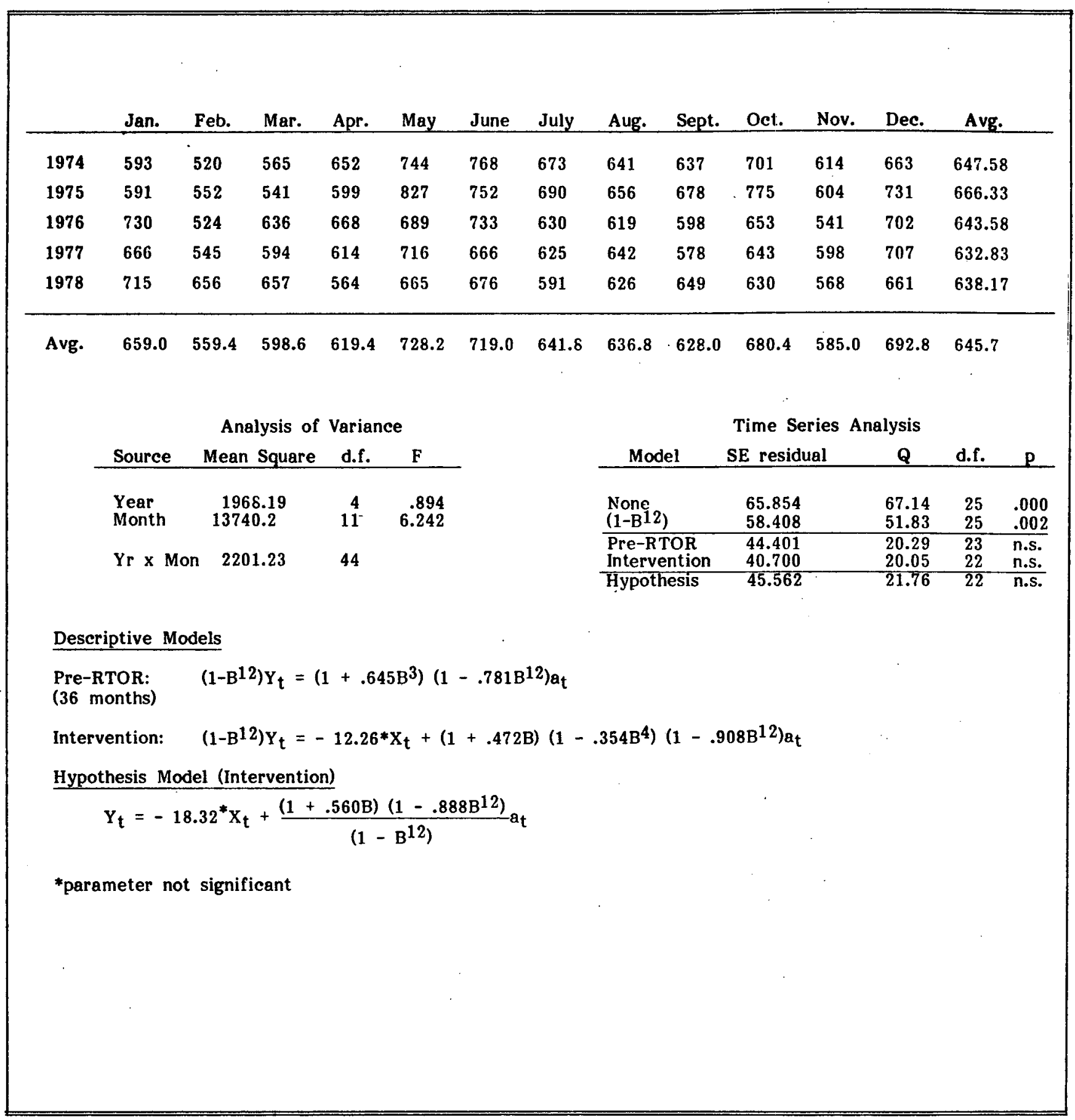


Pedestrians in New York City,

Signalized Location with Vehicle Turning Right.

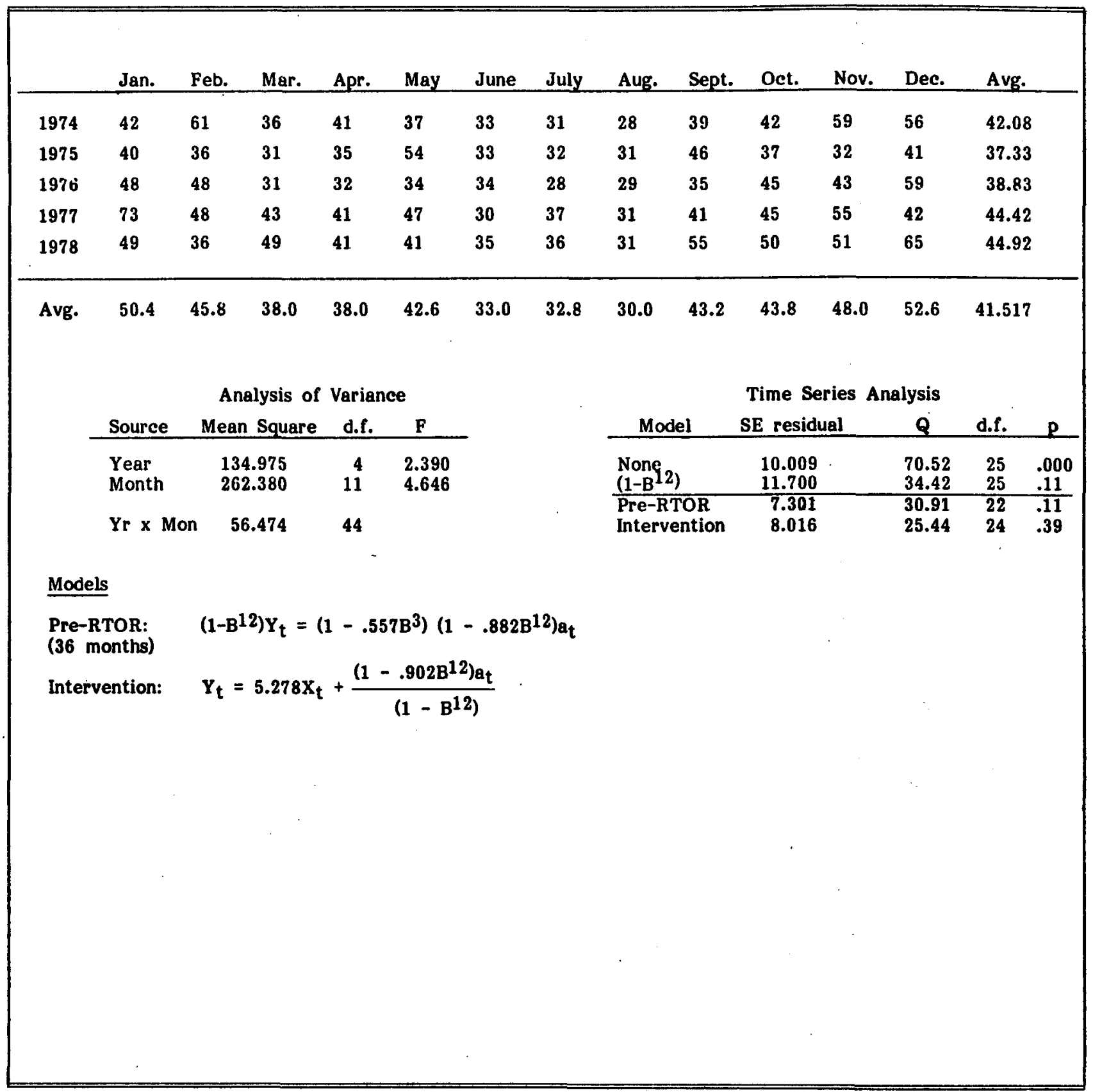




\section{Bikes in New York State (not New York City),}

\section{Signalized Location with Vehicle Turning Right.}

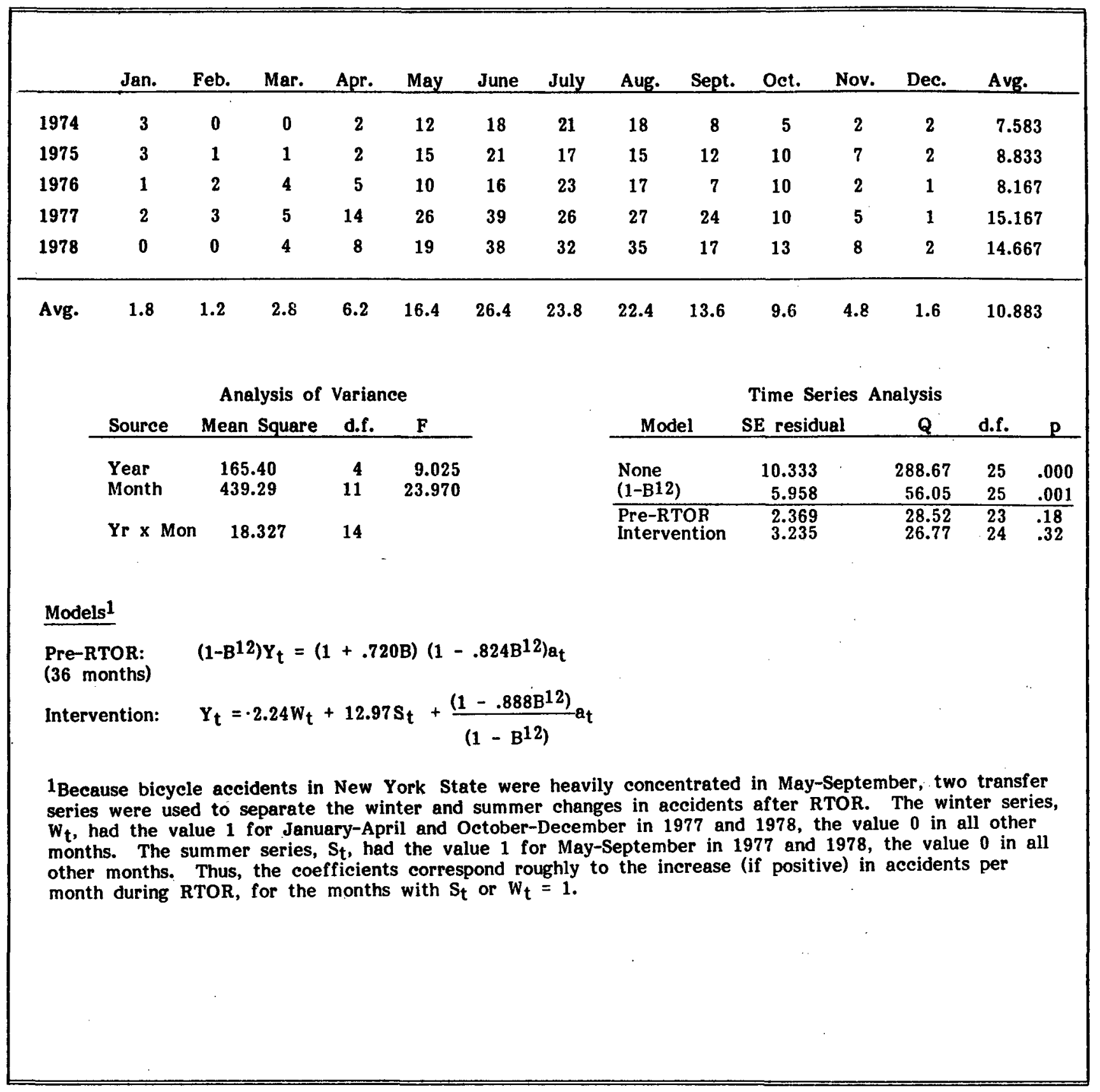


Bikes in Suburbs of New York City,

Signalized Location with Vehicle Turning Right.

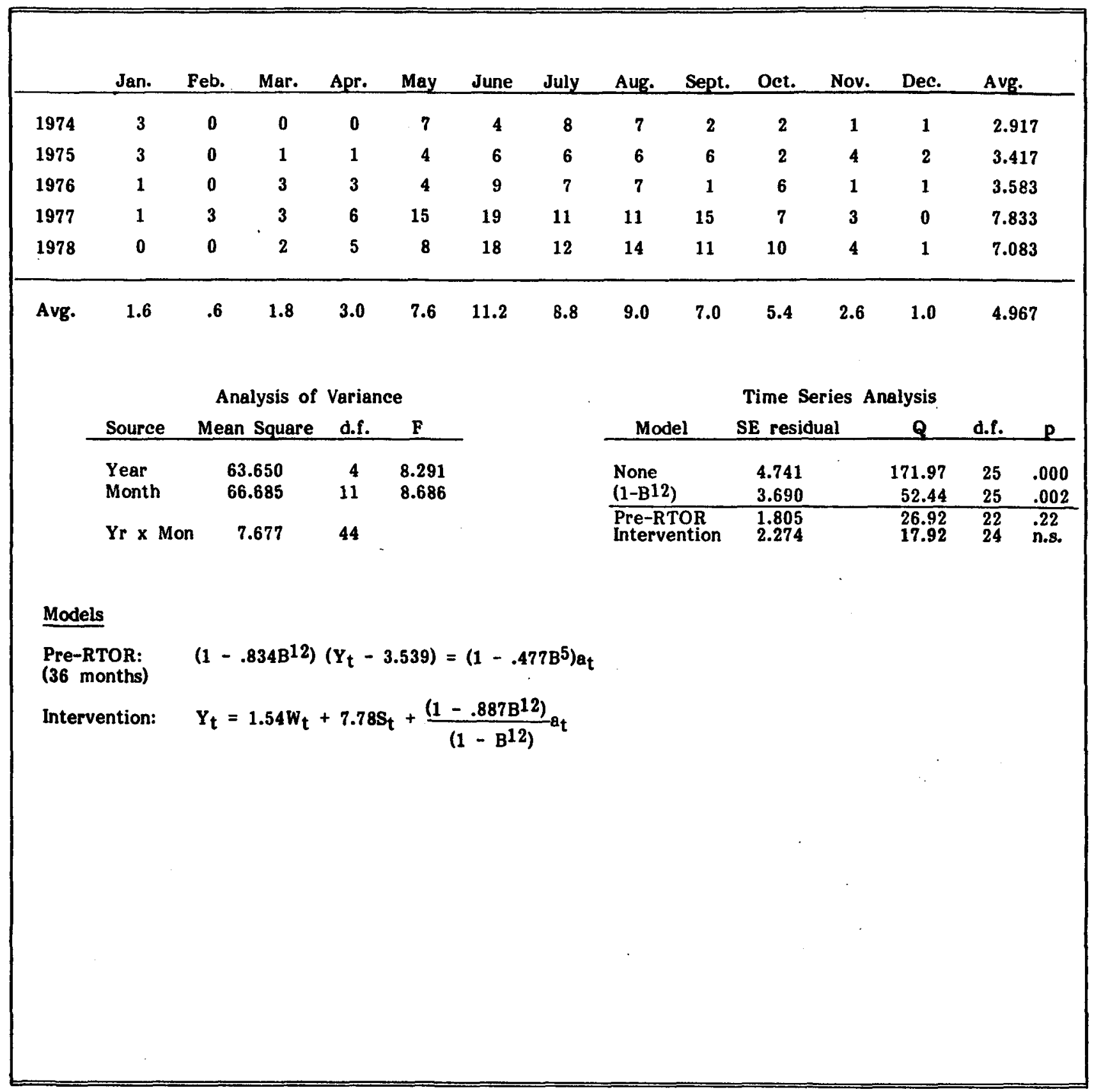


Bikes in New York Upstate Urban, Signalized Location with Vehicle Turning Right.

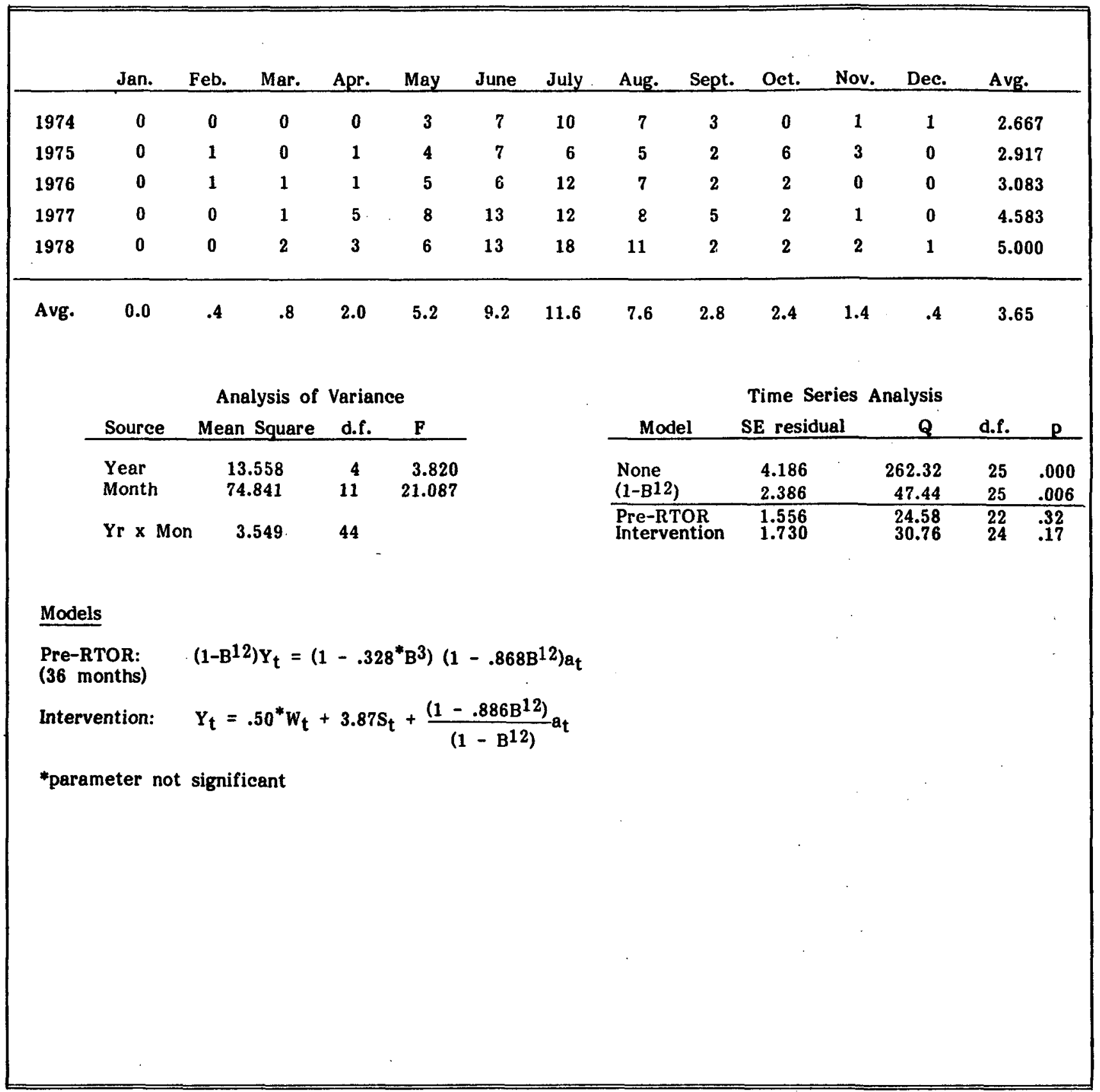


Bikes in New York Upstate Other,

Signalized Location with Vehicle Turning Right.

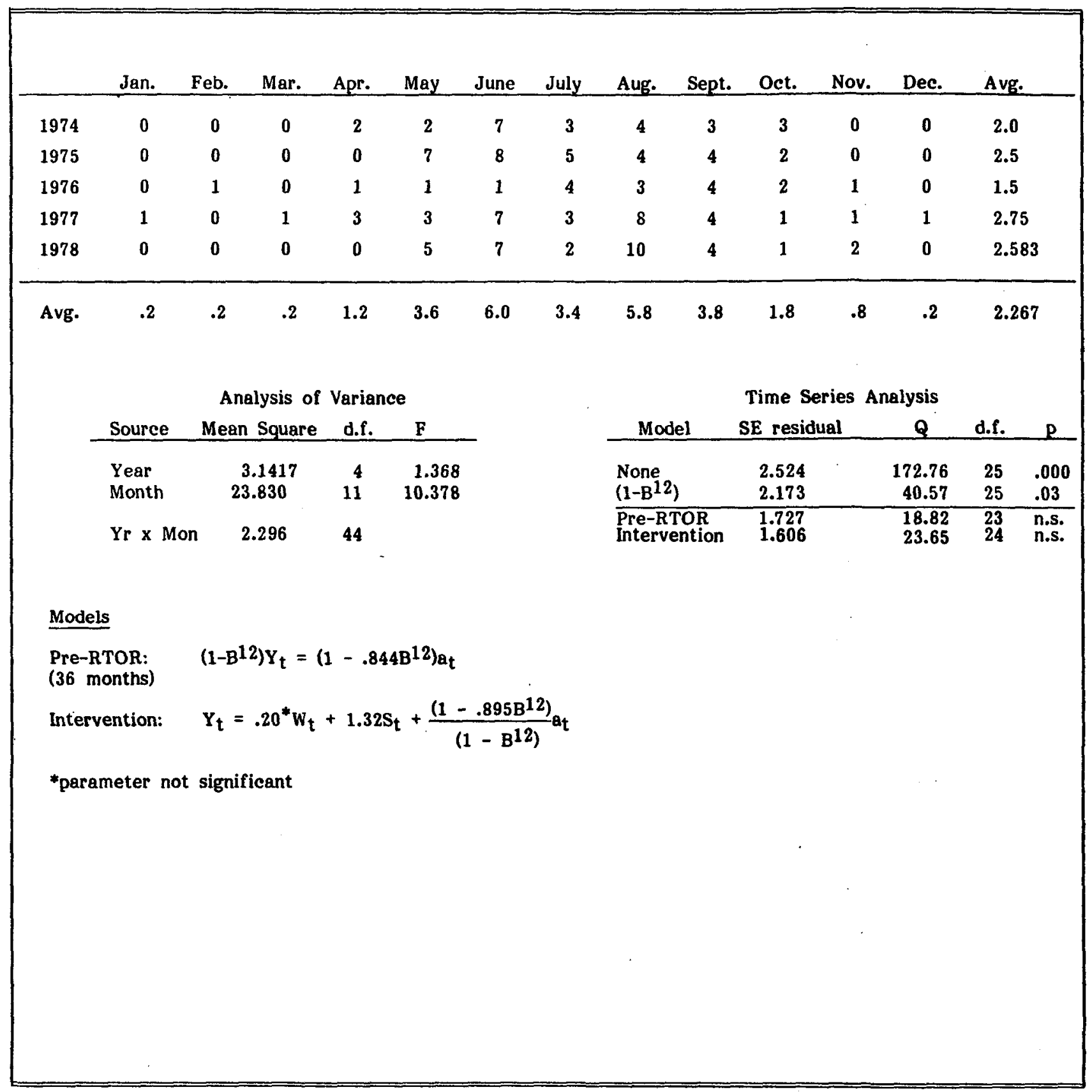


Bikes in New York State (not New York City),

Signalized Location with Vehicle Turning Left.

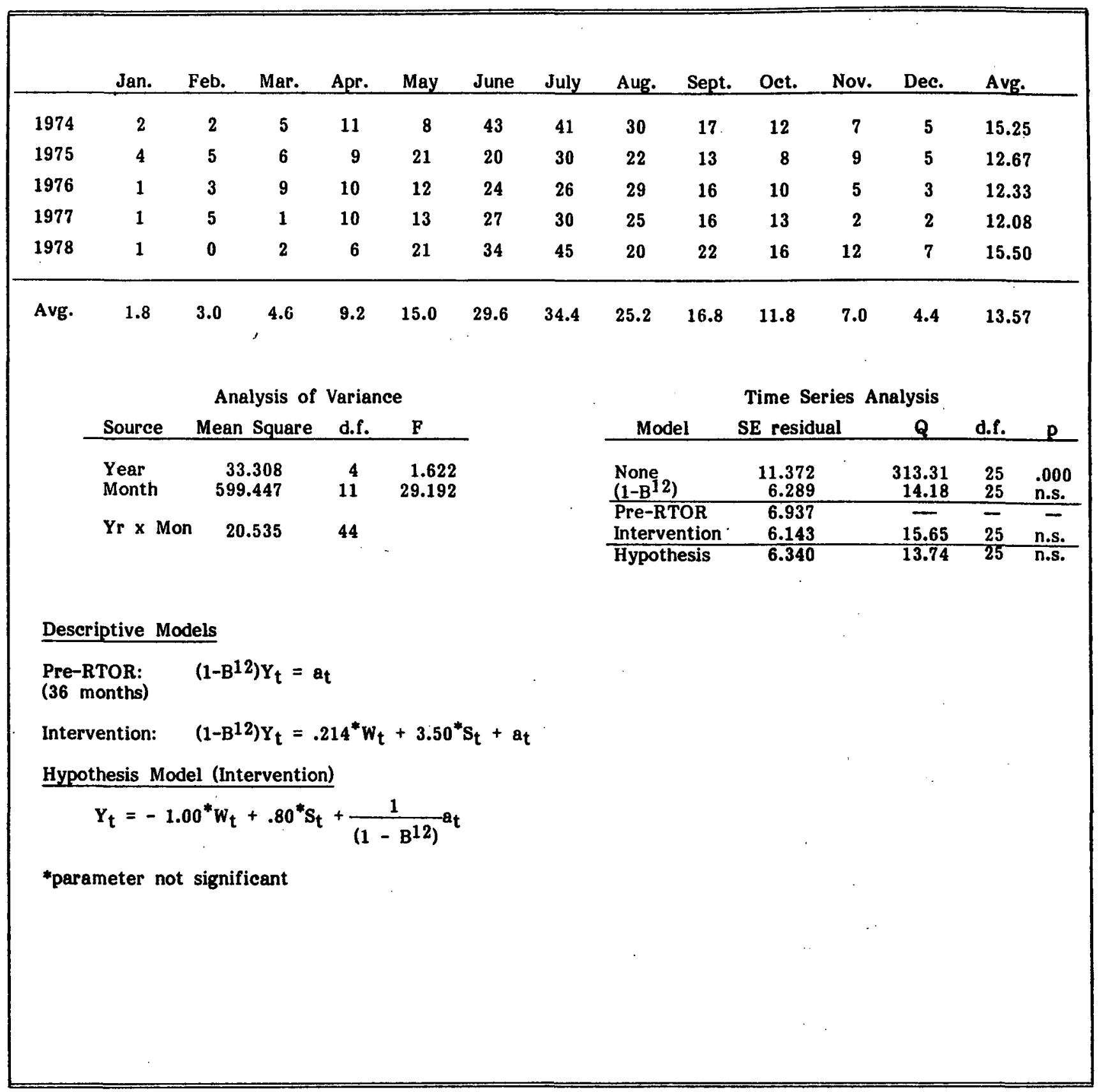


Bikes in New York State (not New York City),

Signalized Location with Other Vehicle Actions.

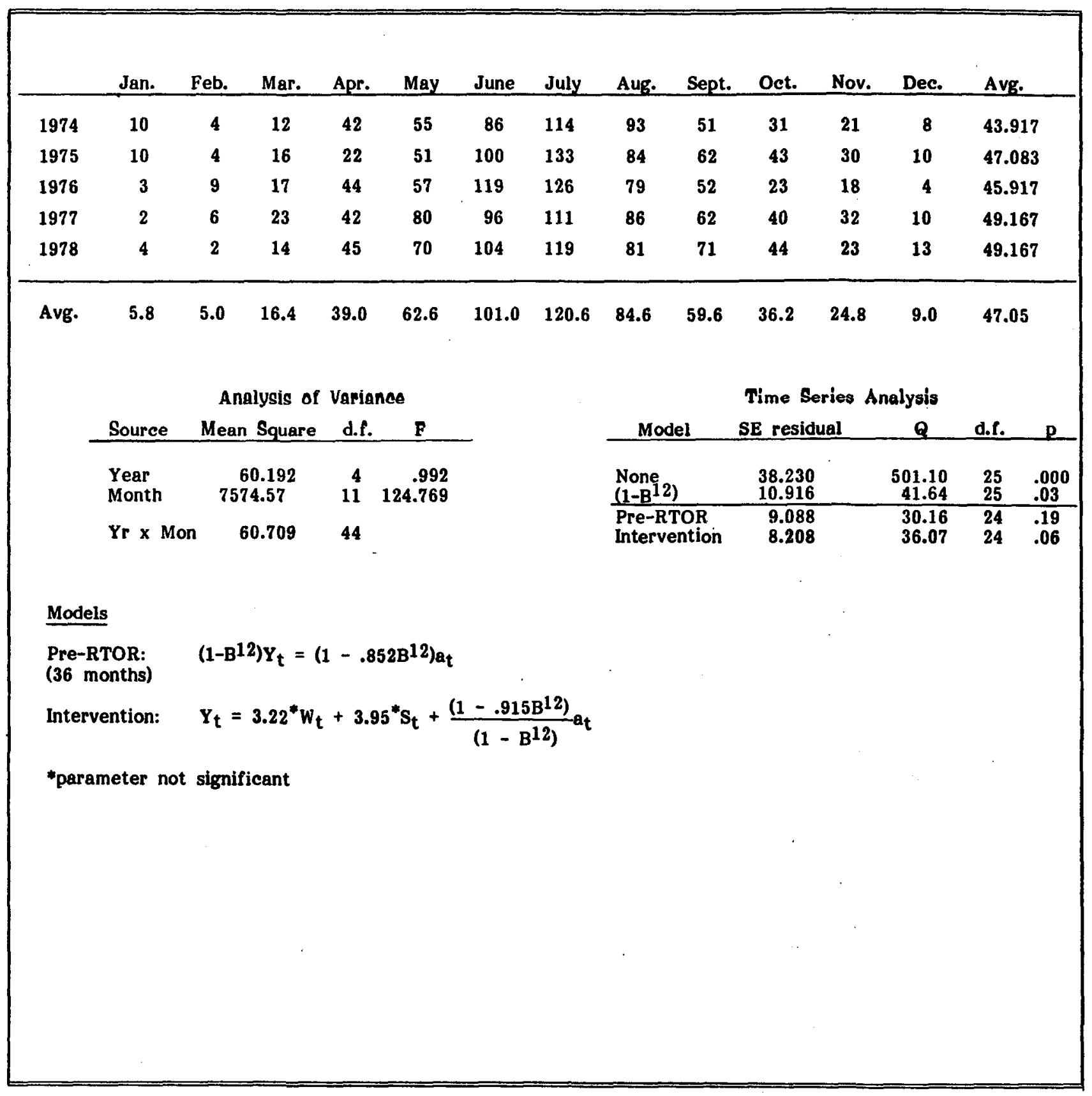


Bikes in New York State (not New York City),

Unsignalized Location.

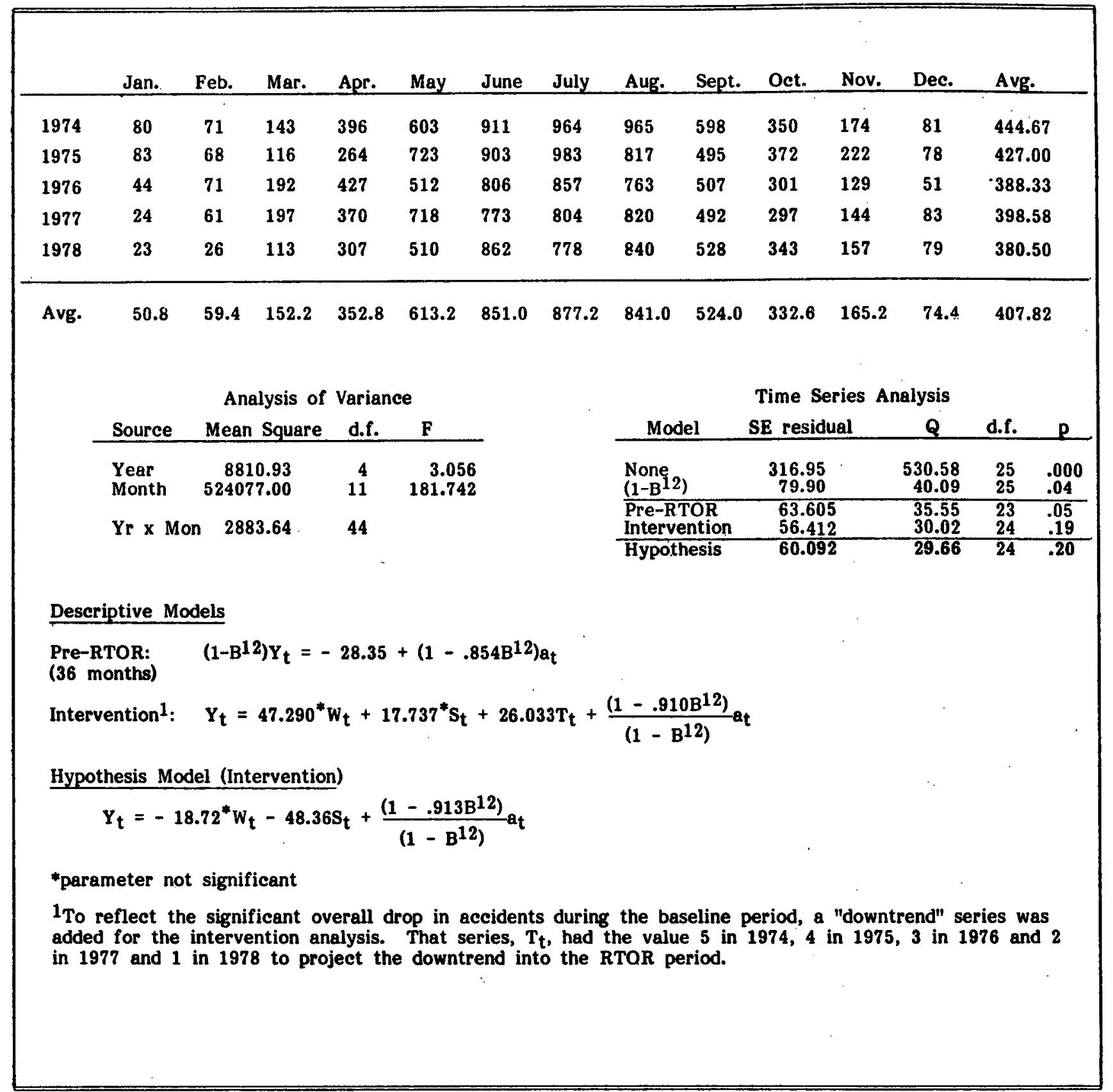


Bikes in New York City,

Signalized Location with Vehicle Turning Right.

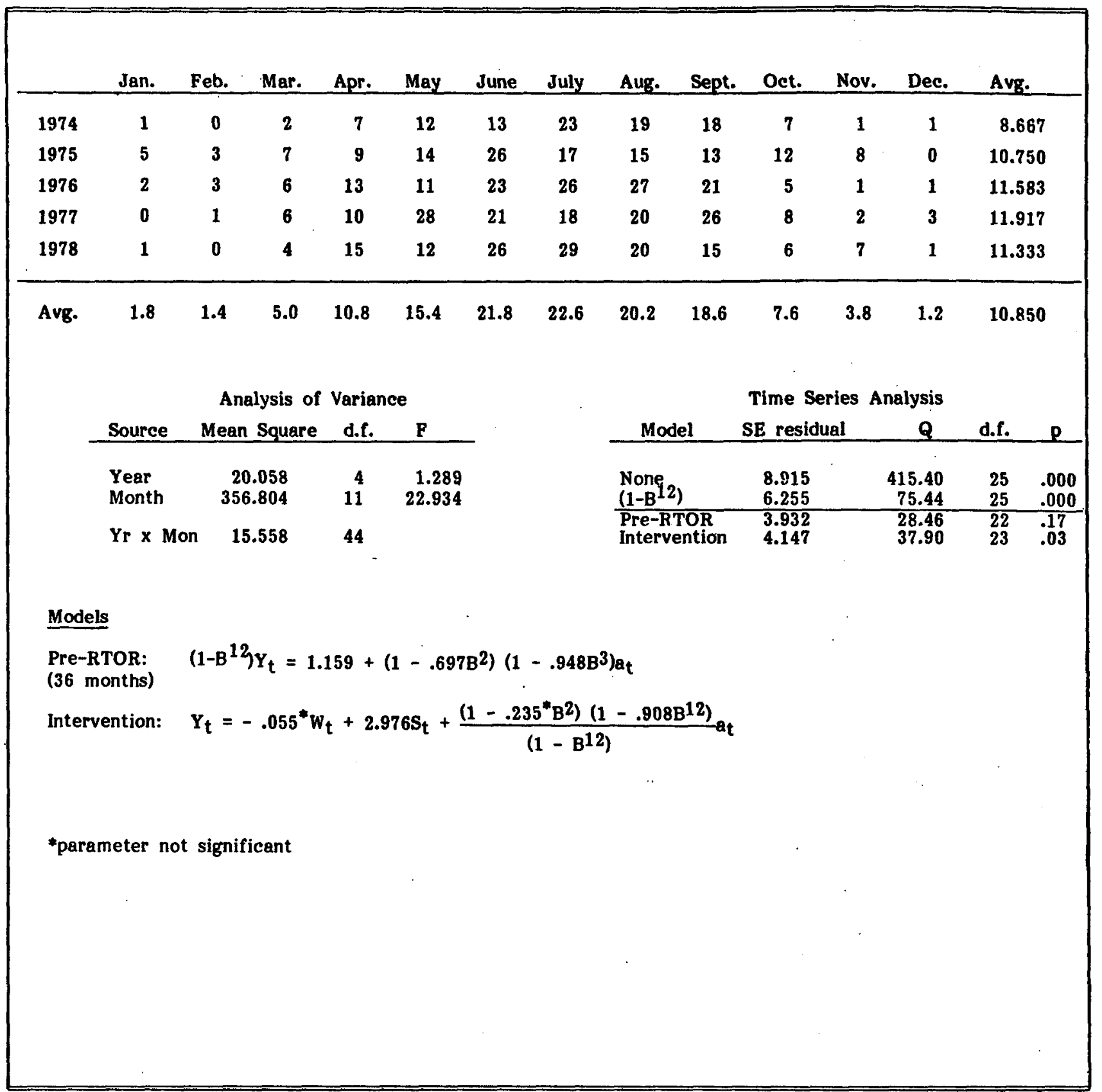


Ohio Pedestrian Accidents,

Signalized Location with Vehicle Turning Right.

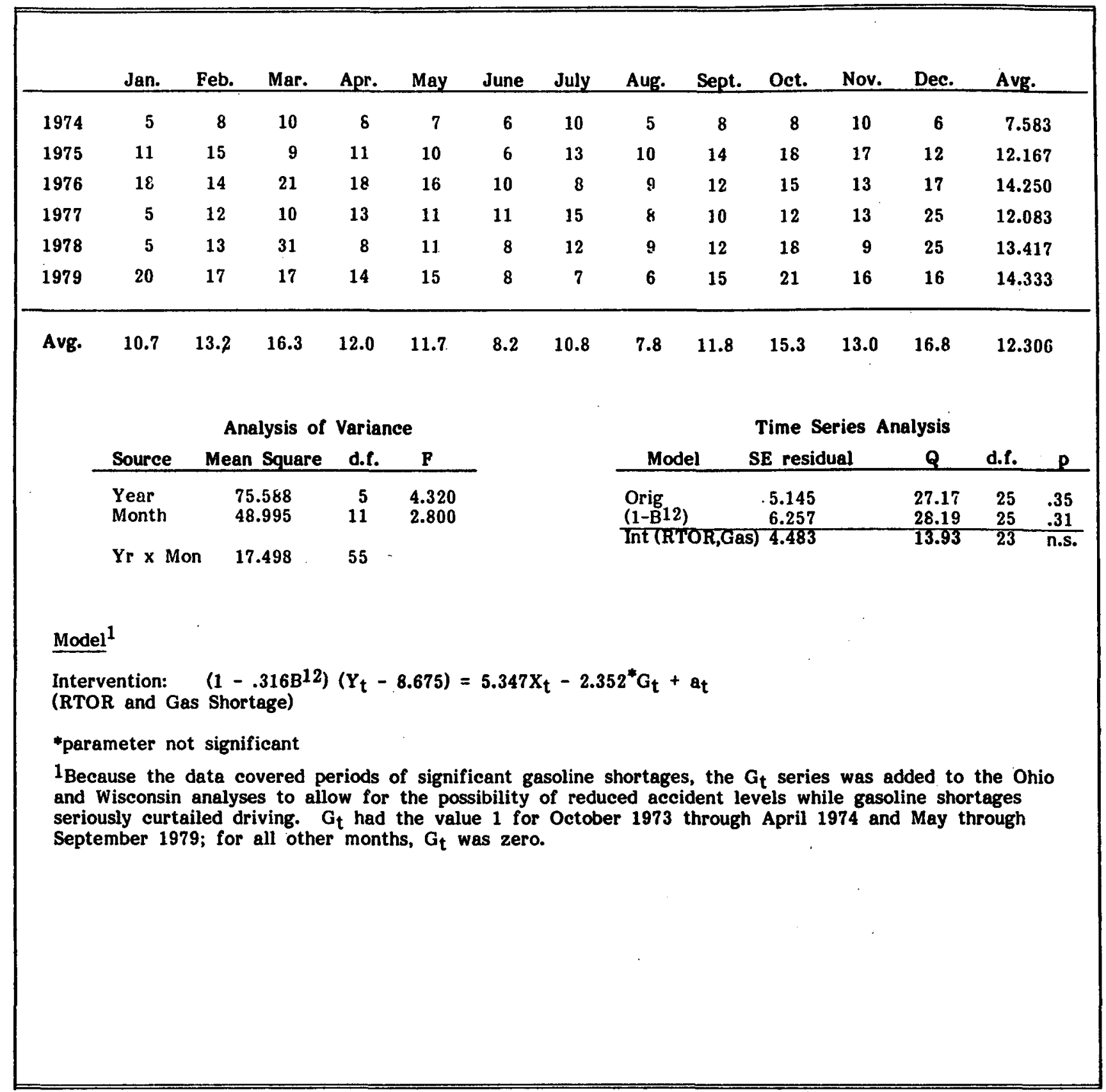


Ohio Bike Accidents,

Signalized Location with Vehicle Turning Right.

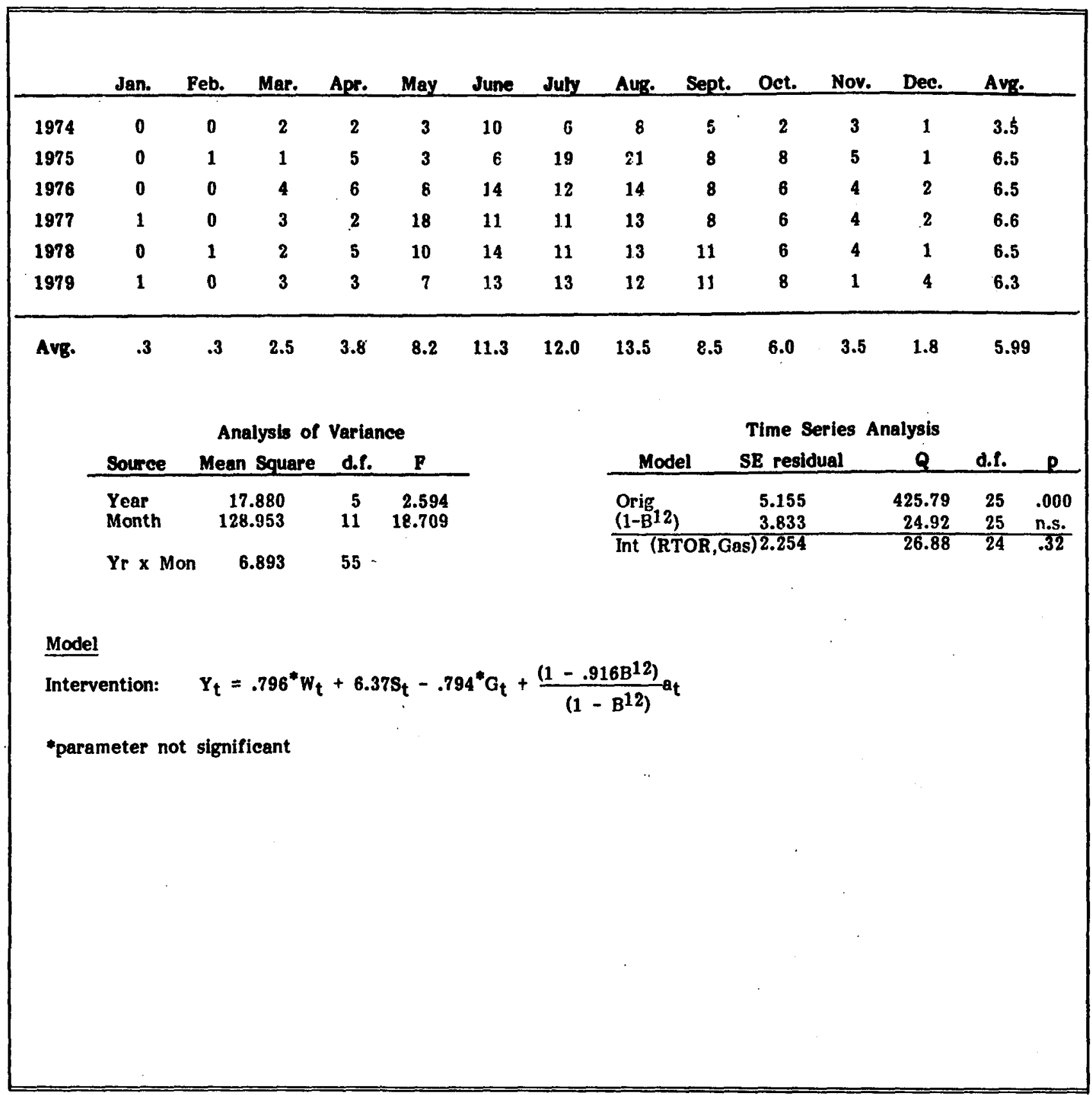


Wisconsin Pedestrian Accidents,

Signalized Location with Vehicle Turning Right.

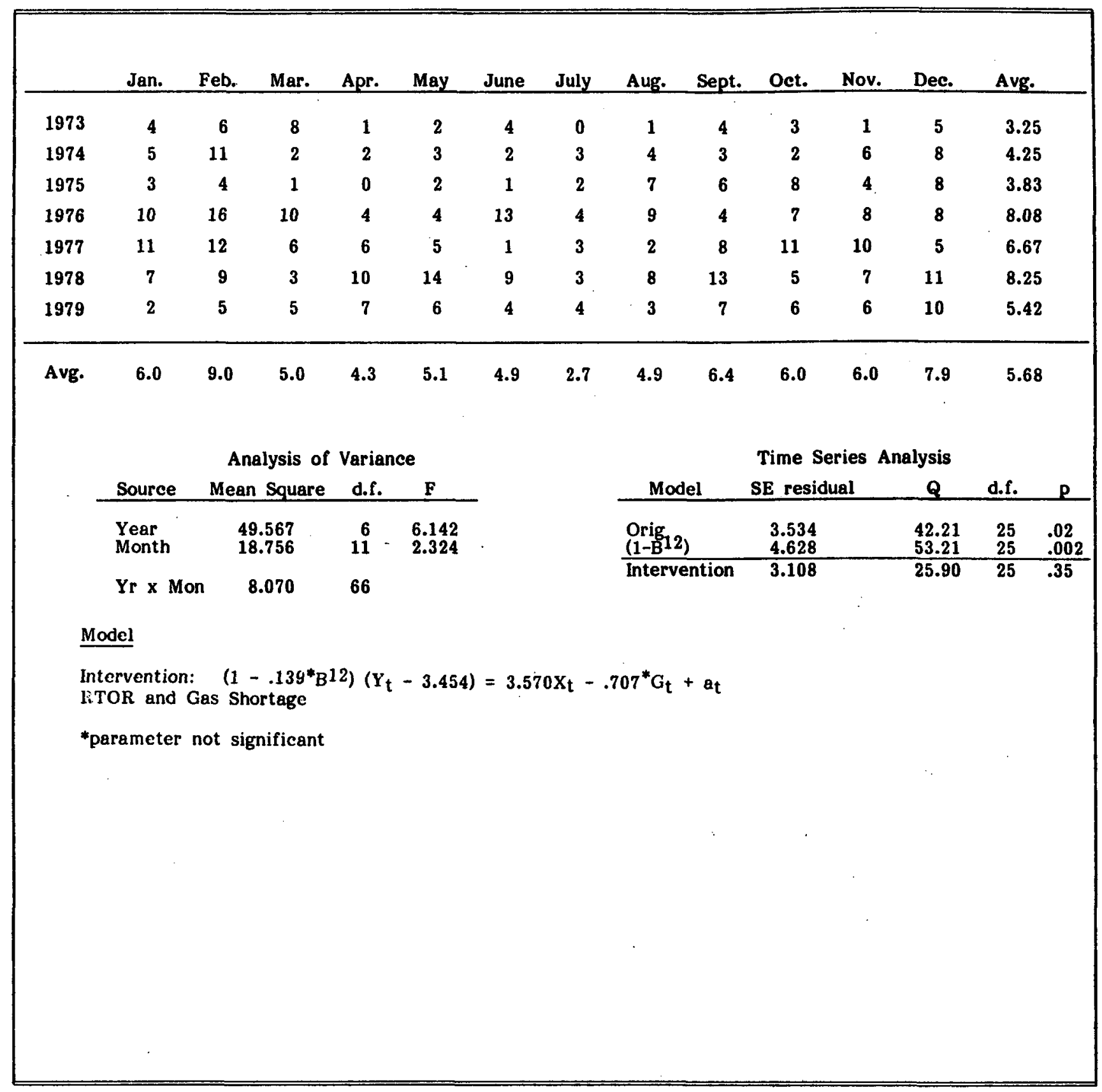


Wisconsin Bike Accidents,

Signalized with Vehicle Turning Right.

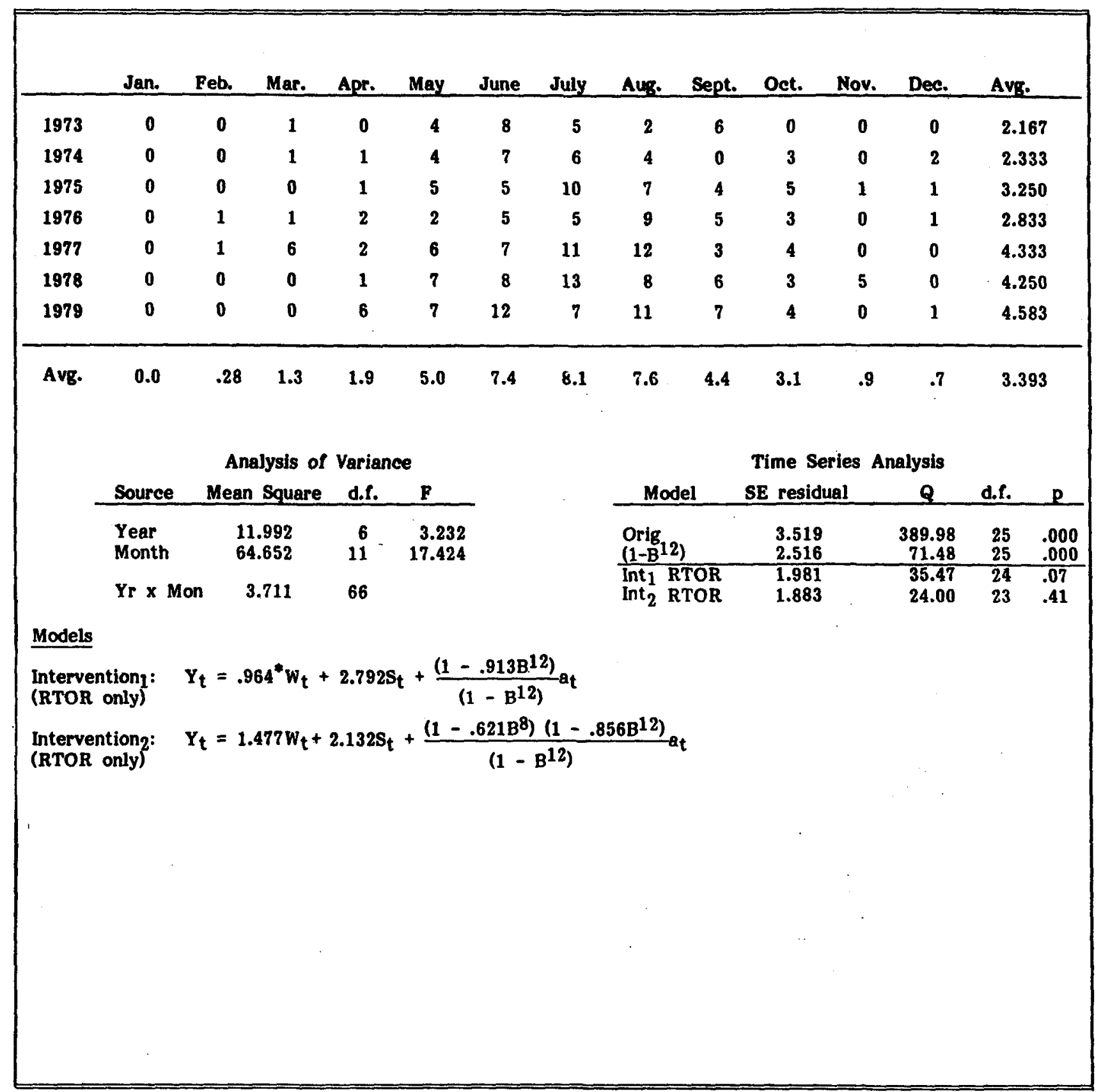


New Orleans Pedestrian Accidents,

Signalized Location with Vehicle Turning Right.

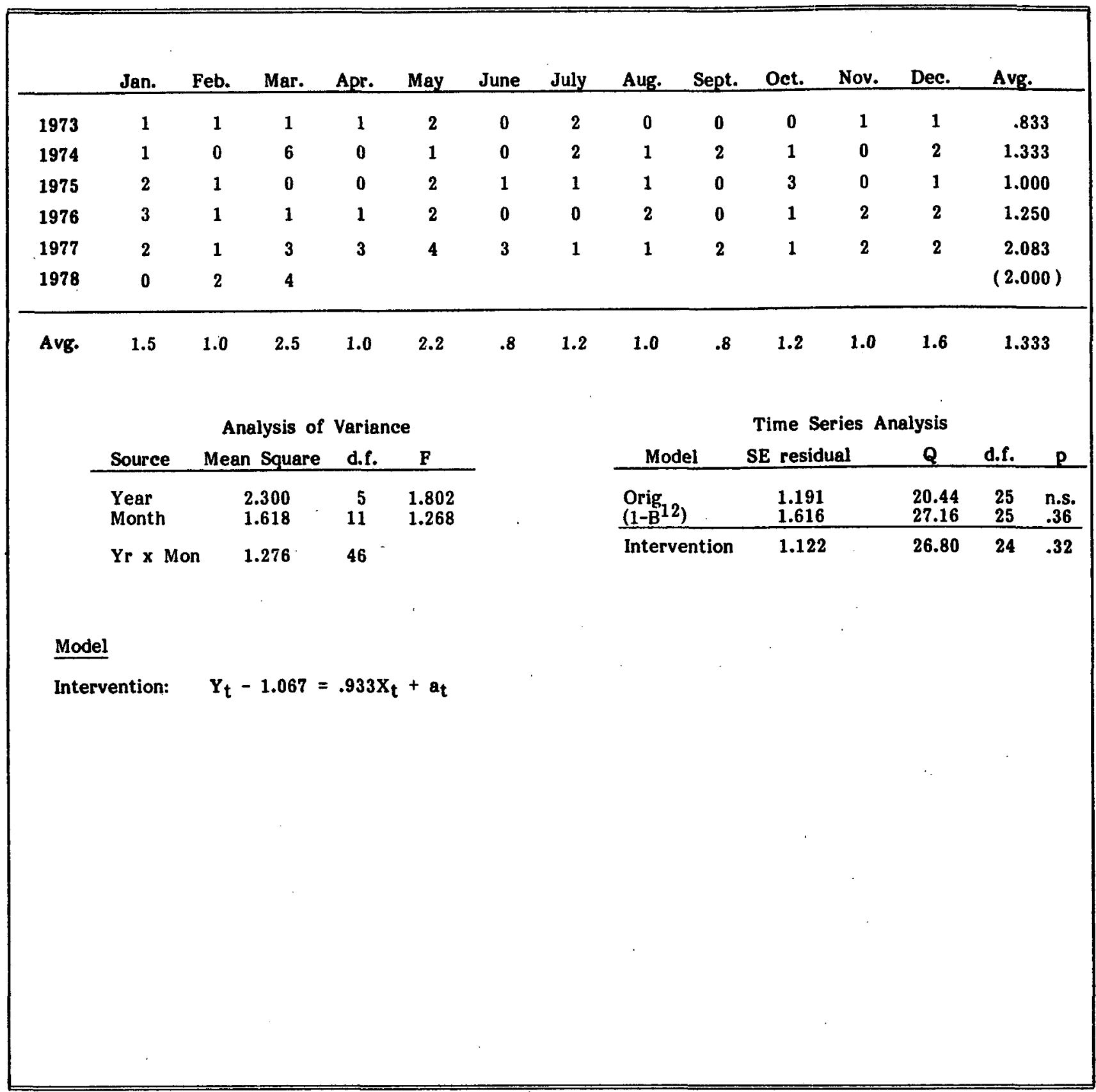




\section{REFERENCES}

Blomberg, R.D., Preusser, D.F., Hale, A. and Leaf, W.A. Experimental Field Test of Proposed Pedestrian Safety Messages. Final Report, Contract No. DOT-HS-4-00952, Dunlap and Associates, Inc., Darien, CT: 3 Vols. (in process).

Blomberg, R.D., Leaf, W.A., Hale, A., Farrell, M.L. and Cross, K.D. Identification and Development of Countermeasures for Bicyclist/Motor Vehicle Problem Types. Final Report, Contract No. DOT-HS-7-01726, Dunlap and Associates, Inc., Darien, CT: 3 Vols. (in process).

Box, George E.P. and Jenkins, G.M. Time Series Analysis: Forecasting and Control. San Francisco, CA: Holden-Day, Inc., 1976.

Cross, Kenneth D. and Fisher, Gary. A Study of Bicycle/Motor-Vehicle Accidents: Identification of Problem Types and Countermeasure Approaches. Vol. I, Final Report, Contract No. DOT-HS-4-00982, September 1977.

Hochstein, S. Now is the time for all good traffic engineers to come to the aid of their profession and save the country from RTOR. ITE Journal, May 1981, 61-63.

McCleary, Richard and Hay, Richard A. Jr. Applied Time Series Analysis for the Social Sciences. Beverly Hills, CA: Sage Publications, Inc., 1980 .

McGee, H.W., Stimpson, W.A., Cohen, J., King, G.F. and Morris, R.F. Right-Turn-On-Red. Final Technical Report, Contract No. DOT-FH-11-8251, Alan M. Voorhees and Associates, Inc., May 1976.

McLaughlin, J.F. and Michael, H.L. Right Turn on Red: Utilization and Impact. Purdue University, June 1976.

Roy, J.C. The Effect of Right Turn on Red on Traffic Performance and Accidents at Signalized Intersections. Berkeley, CA: The Institute of Transportation and Traffic Engineering, University of California, 1956.

Safety and Delay Impacts of Right Turn on Red. American Association of State Highway and Transportation Officials, Washington, DC, June 1979.

Snyder, M.B. and Knoblauch, R. Pedestrian Safety: The Identification of Precipitating Factors and Possible Countermeasures. Vols. I \& II. Contract No. DOT-FH-11-7312, January 1971. PB 197749.

Uniform Vehicle Code and Model Traffic Ordinance. National Committee on Uniform Traffic Laws and Ordinances, Charlottesville, VA: The Michie Company, 1968 (1980 Annual Supplement).

Zador, P., Moshman, J. and Marcus, L. Adoption of Right Turn On Red: Effects on Crashes at Signalized Intersections. Insurance Institute for Highway Safety, August 1980 . 